\title{
II. Kiesinger und die Frankreichpolitik
}

\section{Grundlagen der Außenpolitik: Kiesinger muß sich gegen Adenauer behaupten}

Die Erneuerung der Frankreichpolitik war die zentrale Aufgabe zu Beginn der Großen Koalition. So sahen es Altbundeskanzler Adenauer und der neue Kanzler Kiesinger. Doch je mehr Kiesinger in sein neues Amt hineinwuchs, desto deutlicher zeichnete sich ein Konflikt zwischen beiden um die außenpolitischen Grundlagen der Koalition ab, in deren Verlauf Kiesinger unter starken Druck geriet, sich aber am Ende behaupten konnte. Um den Ausgangspunkt, die Kritik an der Frankreichpolitik Schröders, zu verstehen, muß die Bedeutung der Frankreichpolitik in der Ära Adenauer kurz beschrieben werden.

\section{Die Bedeutung Frankreichs für die Außenpolitik der Bundesrepublik}

Am Anfang der Außenpolitik der Großen Koalition stand der Wunsch nach Versöhnung mit dem französischen Staatspräsidenten. Es waren kaum vier Jahre vergangen, seitdem Frankreich und die Bundesrepublik den deutsch-französischen Vertrag unterzeichnet hatten. Für de Gaulle wie für den damaligen Bundeskanzler Adenauer verbanden sich mit dem Vertrag vom 22. Januar 1963 große, aber unterschiedliche Hoffnungen. De Gaulle sah in dem Werk eine Form der politischen Zusammenarbeit zwischen den beiden alten Völkern, den Germanen und Galliern, die auf der Souveränität beider Staaten aufbaute. Eine gemeinsame Politik sollte von den Regierungen abgesprochen werden. Auch Adenauer sah im Vertrag die Grundlage von politischer Kooperation, die allerdings später alle westeuropäischen Staaten umfassen sollte. Er erstrebte eine europäische Politik, die am Ende durch supranationale Institutionen gelenkt werden sollte. Mit dem Vertrag sollte zudem die Aussöhnung zweier Völker besiegelt werden, die sich in den vergangenen zwei Jahrhunderten fünfmal auf dem Schlachtfeld begegnet waren. Adenauer, der seinen Landsleuten zutiefst mißtraute, hatte schon im März 1950 für eine Zusammenlegung von Deutschland und Frankreich - ihrer Wirtschaft, ihrer Parlamente, ihrer Nationalitäten - geworben. Durch die totale Integration hoffte er zu verhindern, daß die Deutschen noch einmal nationalen Führern in den Krieg folgen würden. Und er hatte Erfolg. Zwar war das Echo in Frankreich auf seinen Vorschlag gering; doch die Initiative Schumans für eine gemeinsame Montanunion im Mai 1950 bot Anlaß für den Aufbau einer Institution, die erstmals auf dem Prinzip der gegenseitigen Kontrolle basierte. Die Behörde war mit souveränen Rechten ausgestattet und arbeitete erfolgreich ${ }^{1}$. Um sie herum entstand 1957 die Europäische Wirtschaftsgemeinschaft. Die EWG war als erster Teil einer noch zu bildenden politischen Union verstanden worden. Allerdings war der Versuch, eine integrierte europäische Armee mit deutschen Truppen, die Europäische Verteidigungsgemeinschaft (EVG), zu gründen, bereits 1954 an der französischen Nationalversammlung gescheitert.

\footnotetext{
I Vgl. Herbst, Option, S. 74 ff.; Loth (Europa, S. 81 f.) ist der Meinung, daß der Schuman-Plan im wesentlichen aus der Befürchtung Frankreichs heraus vorgeschlagen wurde, Engländer und Amerikaner könnten eine Initiative für einen deutschen Wehrbeitrag und die Erhöhung der deutschen Stahlproduktion starten und könnte Frankreich jeglichen Einfluß verlieren.
} 
Als de Gaulle 1958 erneut an die Macht kam, schien das Ziel einer Europäischen Union in weite Ferne zu rücken. In der Vierten Republik hatten die Gaullisten die Montanunion, die EVG und die Römischen Verträge bekämpft. De Gaulle war ein scharfer Gegner supranationaler Institutionen. Er warb dagegen für ein „Europa der Vaterländer“. Es ging ihm um die Annäherung und Abstimmung souveräner Staaten mit den Mitteln der Diplomatie. Er strebte ein Konzert der europäischen Mächte an. Als die sechs Mitgliedstaaten 1961 und 1962 über eine Union verhandelten, wurden daher schnell die Gegensätze offenbar. Die Union diente de Gaulle vor allem dazu, ein europäisches Gegengewicht zu den übermächtigen USA zu bilden. Der Staatspräsident schloß daher aus, daß die Briten daran teilnehmen konnten. Er betrachtete England als "trojanisches Pferd“, durch das die Amerikaner heimlich Eingang zu den europäischen Mächten finden würden. An dieser Haltung scheiterten 1962 die Verhandlungen².

Als es auf der europäischen Ebene zum Stillstand kam, zielte de Gaulle auf ein enges deutsch-französisches Verhältnis, dessen Wurzeln auf das legendäre erste Treffen mit Adenauer auf seinem Landsitz in Colombey-les-deux-Églises zurückgingen. Die Tatsache, daß de Gaulle danach nie mehr einen Staatsmann in seinem Haus in Lothringen empfing, läßt auf die Bedeutung schließen, die er dem Treffen zuwies. Über das Gespräch haben beide Staatsmänner unterschiedliche Beschreibungen in ihren Memoiren gegeben ${ }^{3}$, aber heraus kam ein Gentlemen's Agreement: De Gaulle sicherte den Deutschen die französische Unterstützung für den bestehenden Status Berlins und für die Forderung der Bundesrepublik nach der Wiedervereinigung zu. Im Gegenzug verpflichtete sich Adenauer, in der Wiedervereinigungsfrage Langmut zu bewahren und die Frage nach der Ostgrenze zurückzustellen, um die Anerkennung der Oder-Neiße-Grenze in der $\mathrm{Zu}$ kunft vorzubereiten. Außerdem sollte Bonn auf Atomwaffen verzichten ${ }^{4}$. Erstmals wurde während des Treffens angeregt, zwischen den beiden Staaten ständig Konsultationen auf Botschafterebene einzuführen ${ }^{5}$. Der Gedanke an regelmäßige Kontakte war auch in den folgenden Gesprächen immer wieder Thema. Als de Gaulle im September 1962 eine triumphale Deutschlandreise unternahm, ging er auf das Drängen Adenauers ein, die Kontakte zwischen Paris und Bonn in einem Konsultativvertrag zu regeln.

Es war ein günstiger Zeitpunkt für den General. Die wichtigsten Ziele, die er sich bei seinem Regierungsantritt gesetzt hatte, waren inzwischen erreicht worden 6 . Für das Algerienproblem hatte er eine Lösung gefunden, indem der ehemaligen Kolonie 1962 die Unabhängigkeit zugestanden wurde. Die notorischen wirtschaftlichen Probleme der Vierten Republik hatte er beseitigt, der Franc war stabil, Frankreich profitierte vom Markt der Europäischen Gemeinschaft. Schließlich hatte de Gaulle auch außenpolitisch an Bedeutung hinzugewinnen können. Seitdem Frankreich ab 1960 eine eigene Atomstreitmacht aufbaute, war es zum wichtigsten und stärksten Staat in Westeuropa aufgestiegen, hatte darin die Bundesrepublik trotz deren wirtschaftlicher Potenz überholt. De Gaulle hatte Frankreich somit einen außenpolitischen Spielraum geschaffen, den die Bundesre-

${ }^{2}$ Vgl. Grosser, Außenpolitik, S. 234.

${ }^{3}$ Vgl. de Gaulle, Memoiren der Hoffnung, S. 218 ff., und Adenauer, Erinnerungen 1955-1959, S. $417 \mathrm{ff}$. Ziebura (Beziehungen, S. 109) urteilt, daß sich das Verhältnis Adenauers zu de Gaulle letztlich einer rationalen Analyse entzogen habe. Der Bundeskanzler habe geglaubt, trotz der unterschiedlichen Beurteilung der meisten Probleme, den Staatspräsidenten auf seine Linie in der Europa- und Natopolitik verpflichtet zu haben.

${ }^{4}$ Vgl. Herbst, Option, S. 197.

${ }^{5}$ Vgl. Jansen, Die Entstehung, Protokoll der Unterredung, S. 250.

${ }^{6}$ Vgl. Herbst, S. 204 f. 
gierung niemals besitzen würde und nach seinem Willen auch nicht bekommen sollte. Diese Überlegung sprach aber nicht gegen den geplanten deutsch-französischen Vertrag. Im Gegenteil: Der Staatspräsident rechnete sich aus, daß Frankreich mit Hilfe der ökonomischen Produktivität Deutschlands noch an Macht gewinnen konnte, falls die Bundesrepublik von ihren engen Beziehungen zu den USA abrückte und sich fest an Frankreich anlehnte.

Aber es kam anders. Adenauer mußte sich dem starken Druck aus Washington?, aber auch der Überzeugung vieler Unionspolitiker beugen, die die atlantischen Bindungen nicht zugunsten eines deutsch-französischen Sonderverhältnisses opfern wollten. De Gaulle zog sich den Ärger des Bundestages vor allem dadurch zu, daß er eine Woche vor Unterzeichnung des Vertrages ein Veto gegen den Beitritt Englands zu den Europäischen Gemeinschaften einlegte. Der Bundestag ratifizierte daher den Vertrag im Mai 1963 mit einer Präambel, die sich auf jene Ziele verpflichtete, welche den Vorstellungen de Gaulles diametral entgegenstanden. Dort bestätigte die deutsche Seite, daß sie von dem Willen erfüllt sei, „durch die Anwendung dieses Vertrages die großen Ziele zu fördern, die die Bundesrepublik Deutschland in Gemeinschaft mit den anderen ihr verbündeten Staaten seit Jahren anstrebt und die ihre Politik bestimmen; nämlich die Erhaltung und Festigung des Zusammenschlusses der freien Völker, insbesondere einer engen Partnerschaft zwischen Europa und den Vereinigten Staaten von Amerika, [...] die gemeinsame Verteidigung im Rahmen des nordatlantischen Bündnisses und die Integrierung der Streitkräfte der in diesem Bündnis zusammengeschlossenen Staaten, die Einigung Europas auf dem durch die Schaffung der Europäischen Gemeinschaften begonnenen Wege unter Einbeziehung Großbritanniens"8.

Die Auseinandersetzung in der Union nahm an Schärfe zu, als Adenauer im Herbst 1963 abtrat und Erhard seinen Platz einnahm. Von einem deutsch-französischen Sonderverhältnis wollte Schröder, der jetzt mächtiger gewordene Außenminister, nichts wissen. Frankreich verdiene das weltweite Gehör nicht, daß man de Gaulle schenke, erklärte er dem französischen Botschafter. Frankreich leide vielmehr an Schwächen, die der letzte Weltkrieg an den Tag gebracht habe und die auch durch den politischen Schwung de Gaulles nicht ausgeglichen werden könnten?.

Der General war bald verärgert und enttäuscht über die neue Bonner Regierung, die ihn mit Gleichgültigkeit behandelte. In seiner Neujahrsbotschaft am 31. Dezember 1963 nannte er den Vertrag lediglich einen „Versuch“, den Beziehungen zur Bundesrepublik eine neue Basis zu geben ${ }^{10}$. Zu Ostern 1964 wurde Strauß durch französische Mittelsmänner beauftragt, Erhard darauf vorzubereiten, daß de Gaulle im Juli zum letzten Mal die Frage stellen werde, ob Deutschland bereit sei, eine enge Kooperation einzugehen. Sie sollte - das war der Köder - auch eine Zusammenarbeit auf nuklearem Gebiet ein-

\footnotetext{
7 Vgl. Schwarz, Ära Adenauer, 1957-1963, S. 293. Der frühere Außenminister Acheson ließ Adenauer mitteilen, die Unterzeichnung des deutsch-französischen Vertrages sei einer der schwärzesten Tage für ihn in der Nachkriegszeit gewesen. Schwarz weist allerdings darauf hin, daß sich Adenauer zur gleichen Zeit für eine Nuklearpolitik im Rahmen der atlantischen Partnerschaft entschieden hatte. Amerikanischen Diplomaten war es damit gelungen, das militärpolitische Kernelement aus dem gaullistischen Konzept einer deutsch-französischen Partnerschaft herauszuoperieren. ${ }^{8}$ EA 18 (1963), Folge 14, Gesetz vom 15.6.1963, S. D 347.

${ }^{9}$ Vgl. Seydoux, Botschafter, S. 52.

10 Vgl. Grosser (Außenpolitik, S. 230), der erklärt: „Das Verhältnis Gerhard Schröders zu seinem französischen Amtskollegen sowie zu de Gaulle war von Anfang bis Ende ihrer Mandatszeit [...] vollends getrübt. Und der Kanzler selbst [...] war in den Augen des französischen Präsidenten kein ebenbürtiger Gesprächspartner.“
} 
schließen. Falls Erhard zustimme, werde man unverzüglich die Einzelheiten festlegen; falls der Kanzler ablehne, werde Frankreich eine Kursänderung vornehmen. Dann werde sich de Gaulle verstärkt auf den Osten konzentrieren und besonders das Verhältnis zu den Polen vertiefen. Als de Gaulle im Juli 1964 nach Bonn kam, erteilten ihm der Kanzler und sein Außenminister eine Absage. In der Abschlußsitzung unternahm der Franzose einen letzten Versuch. Als glänzender Redner hielt er ein emphatisches Plädoyer für eine deutsch-französische Zusammenarbeit, das viele Zuhörer ergriff. Doch Schröder reagierte nüchtern: „Ich danke dem Herrn Präsidenten, wir fahren fort in der Tagesordnung.“ Als de Gaulle später sein Flugzeug bestieg, sagte er: „Je suis décu, découragé, mais furieux. " 11 Dabei blieb es. Das Verhältnis verharrte in diesem Schwebezustand. De Gaulle erhielt nach wie vor sein Angebot aufrecht, aber sein Mißtrauen verstärkte sich. Im Dezember 1965 erklärte er in einem Fernsehinterview: ,Wir wissen absolut nicht, wohin Deutschlands Ehrgeiz geht. Wir hoffen natürlich, daß es im Sinne der Vernunft verläuft, und wir haben Gründe, es zu hoffen. Man kann jedoch nicht sagen, daß man dessen absolut sicher ist. " ${ }^{12}$

Das war die Lage, als im Herbst 1966 die Regierung Erhard auseinanderbrach. Kiesinger hielt die Entwicklung im deutsch-französischen Verhältnis wie Adenauer für katastrophal. Auch er beteiligte sich an der Diskussion um die Außenpolitik Schröders in der eigenen Partei.

\section{Kiesingers Kritik an Schröder}

Drei Tage nach dem Austritt der FDP aus dem Bündnis, am 30. Oktober 1966, beendete der Ministerpräsident mit einer Rede den Parteitag der südbadischen CDU in Bad Krozingen, in der er auch auf die Außenpolitik einging. Er wolle keine neuen Auseinandersetzungen in die Öffentlichkeit tragen, sagte Kiesinger dort, sondern aufrütteln und darauf hinweisen, daß es "tödlich“ sein könne, in der Außenpolitik eine "geschichtliche Chance durch Untätigkeit, Ratlosigkeit oder Phantasielosigkeit zu versäumen“. Und er fügte hinzu: „Ich hoffe, daß ich verstanden worden bin!“13

Er war verstanden worden. Die Südbadener klatschten begeistert Beifall. Zwei Wochen später, Kiesinger war gerade zum Kanzlerkandidaten der Union gewählt worden, forderte er auf dem Deutschlandtag der Jungen Union in den Würzburger Huttensälen dazu auf, den großen Augenblick der Geschichte zur Aussöhnung und Zusammenarbeit mit Frankreich nicht tatenlos vorübergehen zu lassen ${ }^{14}$. Mit diesen Äußerungen stellte er sich in eine Reihe mit Adenauer und Strauß, den Führern der „Gaullisten“ in der Union. Aber der Kanzlerkandidat machte ebenfalls deutlich, daß er nicht einseitig auf Frankreich setzen wolle. Er lasse sich nicht die Alternative zwischen Gaullisten und Atlantikern aufzwingen, sondern wolle einen „Weg der Mitte“ gehen. Und tatsächlich bewies er durch die Aufnahme Schröders in die Regierung, daß er den innerparteilichen Mehrheitsverhältnissen mehr Bedeutung beimaß als den außenpolitischen Folgen, die dieser Schritt im Verhältnis zu Frankreich haben konnte.

\footnotetext{
${ }^{11}$ Strauß, Erinnerungen, S. 433; siehe auch Osterheld, Gespräch mit dem Verfasser, 6.10.1988.

12 Stercken (Hrsg.), Vive la France, S. 91.

${ }^{13}$ Frankfurter Allgemeine Zeitung, 31.10.1966; vgl. CDU-Landesverband, Von der CDU in BadenWürttemberg, 1986, S. 33.

${ }^{14}$ Vgl. Frankfurter Allgemeine Zeitung, 14.11.1966.
} 
Adenauer freilich sah das anders. Nachdem es gelungen war, Erhard endlich aus dem Kanzleramt zu vertreiben, setzte der CDU-Ehrenvorsitzende seine ganzen Hoffnungen auf Kiesinger. Vom ersten Tag der Regierungsbildung an warb er beharrlich beim Kanzler für die Vollendung des politischen Bündnisses mit de Gaulle. Dabei schreckte er auch nicht vor Drohungen zurück.

\section{„Das Kabinett des Dr. K. “- Mißtrauen Adenauers}

„Na, die Zusammensetzung, wenn ich dat so sehe - ein bißchen jespenstisch muß ich schon sagen", kommentierte Adenauer das Kabinett der Großen Koalition nach seiner Vereidigung am 1. Dezember 1966 im Bundestag ${ }^{15}$. Gespenstisch wirkte es auf den Altbundeskanzler, Brandt, Heinemann, Strauß und Wehner in der Regierung vereint zu sehen. Brandt war nur fünf Jahre zuvor, im Wahlkampf 1961, sein Konkurrent um das Kanzleramt gewesen. Heinemann, der neue Justizminister, hatte im ersten Bundeskabinett aus Protest gegen Adenauers Angebot einer deutschen Wiederbewaffnung an die Westmächte sein Amt als Innenminister aufgegeben und war $1957 \mathrm{zu}$ den Sozialdemokraten übergetreten. Strauß galt bei der SPD und der FDP seit seinem erzwungenen Rücktritt als Verteidigungsminister 1962 im Zusammenhang mit der Spiegel-Affäre als unzumutbare Belastung für die Bundespolitik ${ }^{16}$. Schließlich war da noch Wehner, den Adenauer schon 1959 als „führende[ $n$ ] Mann in der Sozialdemokratie“ bezeichnet hatte ${ }^{17}$. Während Adenauer allerdings 1957 verhindern wollte, daß Wehner den Vorsitz im Gesamtdeutschen Ausschuß des Bundestages erhielt, weil er den Zielen des ehemaligen Kommunisten mißtraute, schien er jetzt davon überzeugt, der Sozialdemokrat müsse unbedingt an der Regierung teilnehmen. Wehner solle die Koalition zusammenhalten. „Hoffentlich wird uns der Wehner nicht krank“, erklärte er Anfang Januar 1967 dem stellvertretenden Pressesprecher Ahlers, aber wenige Wochen später warnte er erneut, Wehner sei der „stärkste Mann im Kabinett", auch Kiesinger suche es ihm in erster Linie „recht zu machen" 18 .

Für einen schweren Fehler hielt es Adenauer dagegen, daß jener Mann ins Kabinett aufgenommen worden war, den er für die außenpolitische Fehlentwicklung der Regierung von Erhard verantwortlich machte. In persönlichen Gesprächen hatte er Kiesinger in den Tagen der Koalitionsverhandlungen nachdrücklich davor gewarnt, seinem früheren Innen- und dann Außenminister das Verteidigungsressort zu überlassen. Die Aufnahme Schröders in die Regierung, besonders aber in den sensiblen Bereich der Verteidigung, setze ein falsches Signal für Frankreich. Staatspräsident de Gaulle werfe den Deutschen vor, in der Verteidigung sich völlig in die Abhängigkeit der Vereinigten Staaten begeben zu haben. Den deutschen Willen zu einem engeren Verhältnis mit Frankreich,

\footnotetext{
15 Spiegel, 5.12.1966, S. 37 .

16 Vgl. Schwarz, Ära Adenauer, 1957-1963, S. 271. Der CSU-Vorsitzende hatte vor dem Bundestag im November 1962 seine Rolle bei der Verhaftung Ahlers' zunächst verschwiegen und erst später Stück für Stück zugegeben. Das kostete ihn sein Ministeramt. Nachdem die Koalitionsverhandlungen zwischen CDU/CSU und SPD im November 1966 bereits abgeschlossen waren, forderten die Sozialdemokraten von Strauß eine öffentliche Entschuldigung für sein damaliges Verhalten. Aber Strauß weigerte sich, und die SPD mußte dies akzeptieren, wenn sie nicht die gerade getroffenen Absprachen wieder gefährden wollte. Dafür berief sie den Spiegel-Redakteur Ahlers zum stellvertretenden Regierungssprecher.

17 Morsey/Schwarz (Hrsg.), Adenauer, Teegespräche 1959-1961, S. 113.

${ }^{18}$ Krone, Aufzeichnungen, S. 190, und Schwarz, Adenauer. Der Staatsmann, Adenauer im Gespräch mit Otto A. Friedrich im März 1967, S. 977.
} 
meinte Adenauer, werde der General nach dem Stand der Kooperation zwischen Paris und Bonn auf diesem Gebiet beurteilen. Daher dürfe Kiesinger nicht ausgerechnet einen Mann in das Verteidigungsministerium berufen, der in den drei Jahren der Regierung Erhard de Gaulles Werben um die Bundesrepublik enttäuscht und dadurch die Annäherung Frankreichs an die Sowjetunion mitverursacht habe. Adenauer sprach mit bissiger Kälte über Schröder. Bei Kiesinger setzte sich der Eindruck fest, daß der „alte Herr“ Schröder „bis aufs Blut" hasse ${ }^{19}$.

Der Druck auf Kiesinger, Schröder nicht in das Kabinett aufzunehmen, verstärkte sich bis zur Vereidigung der Regierung. Nicht nur Adenauer bedrängte den Kanzlerkandidaten. Aus der Umgebung des Altbundeskanzlers meldeten sich warnende Stimmen. Globke, der ehemalige Staatssekretär im Kanzleramt und Vertraute Adenauers, telefonierte am 29. November 1966 mit dem baden-württembergischen Staatsminister Seifriz. Seifriz operierte in der ersten Zeit als Kiesingers Sekretär und Verbindungsmann in Bonn. In einer Aktennotiz teilte Seifriz Kiesinger mit, Globke habe „schwerste Bedenken“ gegen die Berufung von Bundesminister Schröder zum Verteidigungsminister. Wenn Brandt Außenminister werde und Schröder Verteidigungsminister, werde dies die Stellung von Schröder im künftigen Kabinett wesentlich stärken. Er sehe in dieser gestärkten Position Schröders „den Keim für den künftigen Zerfall des neuen Kabinetts“. Frankreich werde durch verstärkte Annäherung an Moskau reagieren. „Er bittet deshalb dringend, von einer Berufung von Herrn Schröder als Verteidigungsminister abzusehen. Gegebenenfalls bringe er Herrn Stoltenberg in Vorschlag." ${ }^{20}$

Kiesinger teilte die Ansicht, daß die vordringlichste Aufgabe der deutschen Außenpolitik darin bestand, die Beziehungen zu Paris zu stärken. „Als ich die Regierung übernahm, war [...] das Verhältnis zu Frankreich gestört", stellte er fest. Das sollte sich ändern, denn „ohne ein erträgliches Verhältnis zu Frankreich war unsere ganze Politik gefährdet “"21. Trotzdem ordnete er den möglichen Rückschlag, den die Berufung Schröders auf einen Ministerposten im Verhältnis zu Paris auslösen konnte, bei der Entscheidung um die Besetzung des Kabinetts innenpolitischen Interessen unter. Kiesinger sah in Schröder in erster Linie seinen stärksten Konkurrenten. Bei der Abstimmung in der Fraktion hatte eine Gruppe von rund achtzig Fraktionsmitgliedern den norddeutschen Protestanten beharrlich in drei Wahlgängen unterstützt. Schröder war zwar unterlegen, aber die protestantische Hausmacht blieb ihm erhalten. Sie bildete auch weiterhin einen Machtfaktor, und Kiesinger mußte dies in seine Bemühungen um die Bildung der Großen Koalition mit einkalkulieren. Er glaubte, daß ihm Schröder als Fraktionsvorsitzender mehr Schwierigkeiten bereiten konnte, als wenn dieser der Kabinettsdisziplin unterläge. Daher erläuterte Kiesinger Wehner, man müsse Schröder einbinden, um zu verhindern, daß er den Fraktionsvorsitz übernähme ${ }^{22}$. Nach außen tarnte der Kanzler dieses Motiv. Er habe versucht, beiden Mitbewerbern um die Kandidatur gegenüber eine loyale Haltung zu zeigen, ,indem ich dem einen ein wichtiges Ressort anbot“, sagte er in einem Interview. Dem anderen, dem Fraktionsvorsitzenden Barzel, habe er bescheinigt, daß er ihn bei den schwierigen Koalitionsverhandlungen loyal und geschickt unterstützt habe ${ }^{23}$.

\footnotetext{
19 AdKASt, Kiesinger I - 226, F/3., A 322, Gespräch mit Löwe, 31.1.1978, S. 11.

${ }^{20}$ AdKASt, Kiesinger I - 226, D/IV.6, A 007, Seifriz an Kiesinger, Vermerk vom 29.11.1966.

${ }^{21}$ AdKASt, Kiesinger I - 226, F/3., A 322, Gespräch mit Löwe, 31.1.1978, S. 19.

22 Vgl. Wehner, Gespräch mit Baring, 25.1.1977. Wehner schien diese Überlegung übrigens nicht überzeugend zu sein, ihm habe das nicht eingeleuchtet.

${ }^{23}$ Stuttgarter Zeitung, 5.12.1966. Barzel war für Kiesinger nach dessen blamabler Abstimmungsniederlage kein ernsthafter Konkurrent mehr.
} 
Trotz deutlicher Mahnungen gehörte Schröder also dem neuen Kabinett an. Diese Tatsache beunruhigte Adenauer. Für ihn stand Kiesingers Entscheidung im Gegensatz zu dessen persönlichen und öffentlichen Erklärungen, die Beziehungen zu Paris in Ordnung zu bringen. Er vermutete, daß sich der neue Regierungschef übernommen hatte und den oftmals nur geringen Einfluß des Kanzlers auf die einzelnen Ressorts möglicherweise aus seiner Stuttgarter Perspektive unterschätzte. Schon am Tag nach der Vereidigung, am 2. Dezember 1966, schrieb Adenauer unter dem Vermerk „persönlich!“ an Kiesinger:

„Wir waren uns in den Gesprächen, die der Regierungsneubildung vorausgingen, darüber einig, daß neben den außerordentlich schweren innenpolitischen Problemen, deren Lösung entschlossenes und auch unpopuläres Handeln erfordert, vor allem die Außenpolitik ein Prüfstein für Erfolg oder Mißerfolg der neuen Bundesregierung sein werde. Ich habe mich gefreut, Übereinstimmung mit Ihnen vor allem in der Überzeugung feststellen zu können, daß eine Verbesserung unserer außenpolitischen Position die Neuordnung und Intensivierung unseres Verhältnisses zu Frankreich und den USA voraussetze. Beides, unser Verhältnis zu den USA und zu Frankreich, wird durch die Arbeit von zwei Ressorts, des Auswärtigen Amtes und des Bundesministeriums der Verteidigung, maßgeblich beeinflußt.

$\mathrm{Zu}$ Ihnen und Ihrer Entschlossenheit, Ihre Richtlinienkompetenz wahrzunehmen, habe ich volles Vertrauen. Aber ich kann nicht verhehlen, daß ich wegen der personellen Besetzung dieser beiden Ressorts in großer Sorge bin. Ich weiß genau, wie wirksam ein Ressortminister an den Richtlinien des Bundeskanzlers, vorbeiregieren' kann, wenn es an der vollen Übereinstimmung fehlt. Vor allem aber frage ich mich, wie wird und muß es auf Frankreich wirken, wenn ein Minister, der es als Außenminister nicht vermocht, ja nicht einmal versucht hat, den deutsch-französischen Freundschaftsvertrag mit wirklichem Leben zu erfüllen, jetzt die Leitung eines Ressorts innehat, dessen Bereich entscheidende Elemente zur Wiederanknüpfung eines engeren und vertrauensvolleren Verhältnisses dieser beiden Nachbarländer umfaßt. Ich glaube nicht, daß das Ihre Aufgabe und die Verwirklichung Ihrer Absichten im Blick auf Frankreich erleichtert. Dabei scheint mir die Lösung dieser zentralen Frage unserer Außenpolitik auch aus folgendem Grunde so brennend wichtig zu sein:

Unsere Ostpolitik, vor allem unser Verhältnis zu der UdSSR, muß immer stärker im Zusammenhang mit unserem Verhältnis zu Frankreich gesehen werden. Ich brauche nur auf den Besuch des sowjetischen Ministerpräsidenten Kossygin in Frankreich hinzuweisen, um zu verdeutlichen, was ich meine, die bedrohliche Vision unserer Umklammerung, aber auch die Chance, über ein enges Zusammengehen mit Frankreich, dessen Staatspräsident bei seinem Besuch in Moskau und wiederum in den vergangenen Tagen zu der Wiedervereinigungsfrage loyal und mit unbeirrbarer Entschiedenheit Stellung genommen hat, schließlich zu einer Verringerung der Spannungen in Europa zu kommen, ohne die unser großes deutsches Anliegen nicht gelöst werden kann.

Sie werden es verstehen, wenn ich diesen Sorgen Ihnen gegenüber Ausdruck verleihe. Ich fühle mich verpflichtet dazu, sowohl als ehemaliger Bundeskanzler, der die Versöhnung mit Frankreich und die Herbeiführung einer freundschaftlichen Zusammenarbeit auf möglichst vielen Gebieten als eine seiner wesentlichsten Aufgaben und Leistungen ansah, wie auch als Freund und als Ehrenvorsitzender der Partei, der wir gemeinsam zu einem Wahlsieg im Jahre 1969 verhelfen wollen. ${ }^{24}$

Interessant an dem Brief war der für Adenauer wichtige und typische Hinweis am Schluß auf seine Legitimität als Freund und Ehrenvorsitzender der CDU. Dieser Satz mußte trotz des freundlich säuselnden Tones auf Kiesinger wie ein Schlag wirken: Adenauer wies Kiesinger darauf hin, daß er gar keinen anderen Weg sehe, als den von ihm vorgezeichneten, um die nächsten Wahlen für die Union zu gewinnen. Darin steckte auch eine unverhohlene Drohung: Falls Kiesinger sich nicht entschiedener um das Verhältnis zu Frankreich kümmerte, könnte er, Adenauer, sich gegen den Kanzler stellen. Der Ehrenvorsitzende mahnte, seine Sorgen nicht einfach abzutun, sondern ernst zu nehmen. Bis zum letzten Absatz konnte das Schreiben tatsächlich von Kiesinger „nur“ als Ausdruck gewisser Sorgen eines älteren, erfahrenen Politikers aufgefaßt werden, dem man

${ }^{24}$ AdKASt, Kiesinger I - 226, D/IV.6, A 001, Adenauer an Kiesinger vom 2.12.1966. 
gerne zuhört, dessen Rat aber, gerade weil er ungebeten erteilt wurde, beiseite geschoben werden durfte. Die Drohung am Schluß dagegen sollte Kiesinger von dem Ernst Adenauers überzeugen. Das war der Sinn des Schreibens.

\section{Kiesingers Verhältnis zu Adenauer}

Eine Antwort Kiesingers auf den Versuch Adenauers, sich in die Politik der Koalition einzuschalten, ist nicht vorhanden. Aber eine persönliche Aussprache muß stattgefunden haben, denn am 5. Dezember, drei Tage nach seinem ersten Schreiben, folgte ein weiterer Brief des Altbundeskanzlers. Darin nahm dieser auf ein Gespräch „vor ein paar Tagen" Bezug und schlug den CSU-Politiker Guttenberg als Parlamentarischen Staatssekretär im Bundeskanzleramt vor. „Meines Erachtens brauchen Sie für diese Stelle einen Mann von überlegenem Urteil, klaren politischen Vorstellungen und der Fähigkeit, sich durchzusetzen und andere zu überzeugen. Alle diese Eigenschaften hat der Abgeordnete von Guttenberg in hohem Maße." Wichtig war auch in diesem Schreiben der Schlußsatz, der ganz wie im Brief vom 2. Dezember in scheinbar harmlosen Formulierungen die Erwartung Adenauers ausdrückte, daß er von Kiesinger die Befolgung seines Rates erwarte: „Ich glaube, daß ich in manchen Sorgen, die ich mit Ihnen teile, beruhigter sein könnte, wenn Ihnen dieser Mann zur Seite stehen würde.“25

Es ist raffiniert, wie der Altbundeskanzler in diesem Satz scheinbar die gemeinsam geteilten Sorgen ansprach und den Eindruck vermittelte, als ob beide dieselben Probleme nicht in Ruhe schlafen ließen. Kiesinger hatte ihm bei seinem Besuch ein paar Tage zuvor vermutlich erklärt, er sehe die gleichen Probleme im Verhältnis zu Frankreich, wie sie Adenauer beschrieben habe. Tatsächlich zeigte aber der Schlußsatz, daß Adenauer es für notwendig hielt, Kiesinger noch einmal mit „sanftem“ Nachdruck die Bedeutung der Lösung in seinem Sinne nahezulegen. Adenauer erwartete, daß der seit fünf Tagen amtierende Bundeskanzler den CSU-Abgeordneten zum Parlamentarischen Staatssekretär bestellen werde. Guttenberg war zusammen mit Strauß außenpolitischer Experte der CSU und ein strenger Verfechter eines engen Bündnisses mit de Gaulle. Mit ihm hoffte Adenauer einen Mann im Kanzleramt zu plazieren, der Kiesinger auf den richtigen politischen Weg führen sollte.

Adenauer hat, wie zu den meisten Politikern, mit denen er zusammenarbeiten mußte, auch zu Kiesinger Distanz gewahrt. Er schätzte die rhetorischen Fähigkeiten des schwäbischen Abgeordneten, aber besaß kein Verständnis für die innere Unabhängigkeit, die sich Kiesinger leisten zu können glaubte. Auf dem ersten Bundesparteitag in Goslar 1950 sollte der junge Abgeordnete nach dem Willen des damaligen Kanzlers zum geschäftsführenden Vorstandsmitglied gewählt werden. Tatsächlich erhielt Kiesinger im Parteiausschuß die Mehrheit, doch er nahm die Wahl nicht an. „Und Sie wollen 'ne Politiker sein", soll ihn Adenauer daraufhin kopfschüttelnd gefragt haben. Kiesinger rechtfertigte sich damit, daß die Berliner CDU und eine starke norddeutsche Truppe gegen in gestimmt hätten. „Gegenüber den sich deutlich abzeichnenden Widerständen wäre ich daher in eine zu starke Abhängigkeit vom Bundeskanzler geraten. Bei allem Respekt vor Konrad Adenauer: Dazu fühlte ich mich doch auch wieder nicht schwach genug. ${ }^{26}$

Tatsächlich liebte es Kiesinger nicht, sich in Situationen zu begeben, die einen ständigen kämpferischen Einsatz verlangten. Er brauchte das Gefühl, von einer deutlichen Mehr-

\footnotetext{
${ }^{25}$ AdKASt, Kiesinger I - 226, D/IV.6, A 001, Adenauer an Kiesinger vom 5.12.1966.

${ }^{26}$ Kiesinger, Erlebnisse mit Konrad Adenauer, S. 64.
} 
heit getragen zu werden. Einer Auseinandersetzung suchte er grundsätzlich aus dem Wege zu gehen, wenn es sich vermeiden ließ. Das galt insbesondere für sein Verhältnis zu Adenauer. Er sah deutlich, daß ein Streit mit dem „alten Herrn“, wie Adenauer respektvoll genannt wurde, seine Position frühzeitig schwächen konnte. Es traf sich daher gut, daß Adenauer Guttenberg zu einem Zeitpunkt vorschlug, als Kiesinger dem CSU-Politiker schon den Posten angeboten hatte ${ }^{27}$.

Adenauer bekam somit, was er wollte. Er wußte eben mit dem neuen Kanzler umzugehen. Seine Briefe waren dabei bewußt eingesetzte Instrumente zur freundlichen Disziplinierung. Sie erlaubten ihm auch, die Distanz aufrechtzuerhalten. Seine Anreden lauteten durchgängig "Sehr geehrter Herr Bundeskanzler", während Kiesinger zwischen Verehrung und Distanz schwankte und sich bisweilen abzugrenzen suchte. Am 12. Dezember schrieb er beispielsweise "Sehr verehrter Herr Altbundeskanzler" ${ }^{28}$, aber eine Woche später benutzte Kiesinger die kühlere Anrede „Sehr geehrter Herr Altbundeskanzler"29. Damit reagierte er sehr deutlich auf den Charakter der Briefe, die er von Adenauer bekam: Wenn dieser freundlich schrieb, schickte Kiesinger freundliche, sogar verehrungsvolle Worte zurück. Drohte Adenauer gar, dann zeigte sich Kiesinger abweisend, trotzig, stritt alles ab, wies Vorwürfe von sich. Trotzdem suchte und fand Adenauer Wege, seinen Forderungen Nachdruck zu verleihen. Adenauer wußte genau, wie empfindlich Kiesinger reagierte, wenn er auf die Vergangenheit als NSDAP-Mitglied angesprochen wurde. Und Adenauer machte sich diese Empfindsamkeit zunutze.

\section{Das NSDAP-Mitglied und die Juden - Adenauer nutzt Kiesingers Schwäche}

Denn während der Unterhaltung, die Kiesinger nach dem 2. Dezember 1966 mit Adenauer geführt hatte, legte ihm der Altbundeskanzler ein Schreiben des bekannten Autors und Wahrers der Interessen jüdischer Verfolgter, Simon Wiesenthal, vor. Wiesenthal behauptete, er habe Informationen, wonach Kiesinger auf der Jahrestagung der Donauschwaben am 3. und 4. September 1966 in Sindelfingen angeblich eine „Festansprache zum Lobe“ einer NS-Gruppe gehalten haben solle. Kiesinger reagierte heftig auf diese Unterstellung. In einem Brief, den er einen Tag vor der Regierungserklärung verfaßte, bestritt er die Vorwürfe energisch und schrieb: „Weder wußte ich etwas von angeblichen Streitigkeiten zwischen ehemaligen NS-Funktionären und Katholiken unter den Donauschwaben, obwohl ich diese seit Jahren als Ministerpräsident des Patenlandes kenne, noch habe ich eine Festansprache zum Lobe dieser NS-Gruppe gehalten, noch haben auf meine Ansprache hin Wahlen stattgefunden. An dem nachfolgenden Festessen habe ich überhaupt nicht teilgenommen und besonders empört bin ich, über das angebliche Gespräch über das internationale Judentum. Hier sind üble Subjekte am Werk!"30

Den Kanzler ärgerten die Vorwürfe. War nicht gerade durch das Denunziantenpapier bewiesen, daß ihn keine Schuld traf? Dort stand es schwarz auf weiß: Er hatte sich lautstark gegen die Ziele der Nazis ausgesprochen und war bei der SS dafür denunziert worden. Und die Verbrechen der Nazis an den Juden? Gerade weil er mit ihnen nichts zu tun,

\footnotetext{
${ }^{27}$ Vgl. Guttenberg (Fußnoten, S. 82), der schreibt, Kiesinger habe ihn kurz vor seiner Wahl zum Bundeskanzler, also vor dem 1.12.1966, gefragt, ob er sein Parlamentarischer Staatssekretär werden wolle.

${ }^{28}$ AdKASt, Kiesinger I - 226, D/IV.6, A 001, Kiesinger an Adenauer vom 12.12.1966.

${ }^{29}$ AdKASt, Kiesinger I - 226, D/IV.6, A 001, Kiesinger an Adenauer vom 22.12.1966.

${ }^{30}$ AdKASt, Kiesinger I - 226, D/IV.6, A 001, Kiesinger an Adenauer vom 12.12.1966, S. 1.
} 
sie weder gewollt noch von ihnen gewußt hatte, war er Kanzler geworden ${ }^{31}$. Er fühlte sich als Repräsentant all derer, die im Land geblieben waren, sich mit den Nazis arrangiert hatten, aber für die Verbrechen nicht die Verantwortung trugen und mit ihnen nichts zu tun haben wollten. Um ihrer Versöhnung mit der neuen Republik willen übernahm er das Amt des Bundeskanzlers. In diesem Sinne war Kiesinger durch den Rat einiger führender Persönlichkeiten ermutigt worden, darunter der Herausgeber einer jüdischen Wochenzeitung in Deutschland, Karl Marx, und der Propst Heinrich Grüber ${ }^{32}$. Das Wort des Kirchenmannes zählte viel. Denn der Überlebende der KZs von Sachsenhausen und Dachau galt als eine über die Grenzen hinaus geachtete moralische Autorität. Im November 1966 wagte er es beispielsweise, die Kritik amerikanischer Juden an Kiesinger zurückzuweisen ${ }^{33}$. An die amerikanischen Juden gewandt, die „jetzt eine antideutsche Stimmungsmache betreiben“, erklärte er, wer als Jude außerhalb des Machtbereiches von Hitler sein Leben nicht gewagt und sein Vermögen nicht geopfert habe, solle sich als "Mitschuldiger“ fühlen und sich nicht über „Mitläufer" ein Urteil erlauben ${ }^{34}$. Später dankte ihm Kiesinger und erklärte wörtlich: „Ich glaube, daß ich ohne seinen [Karl Marx] und Ihren Rat den Mut nicht gehabt hätte, die Bürde meines jetzigen Amtes auf mich zu nehmen. “35

Trotz dieses Einsatzes, der Ermutigung und des Zuspruchs von moralisch integren Männern muß der von Wiesenthal an Adenauer übermittelte Brief bei Kiesinger Unbehagen ausgelöst haben. Beschuldigungen, die mit seiner Vergangenheit als Mitglied der NSDAP in Zusammenhang standen, auch wenn sie aus der Luft gegriffen waren, brachten ihn besonders gegenüber Adenauer in eine unangenehme Lage. Und es schien kein Zufall zu sein, daß der Altbundeskanzler, mit Hilfe dieser Vorwürfe, Kiesinger genau in dem Augenblick in die Defensive zu drängen suchte, in dem er politische Forderungen erhob.

Das war übrigens kein Novum. Schon einmal hatte sich Adenauer der "Schwäche“ Kiesingers für seine Ziele bedient. Kiesinger erinnerte sich an die Situation im Jahre 1954. Damals ging es um die Nachfolge des Bundestagspräsidenten Hermann Ehlers. Die Parteivorsitzenden von FDP und SPD, Thomas Dehler und Ollenhauer, wollten Adenauer dazu überreden, Kiesinger zum Bundestagspräsidenten zu wählen. Der Kanzler wischte aber mit einer Bemerkung diesen Vorschlag zur Seite: „Dat jeht doch nich, dat alte Nazi!“ 36 Wie anfällig Kiesinger aus diesem Grund gerade auch während seiner Kanzlerschaft war, ist Adenauer immer bewußt geblieben. Kiesinger könnten bei internationalen Schwierigkeiten - die er als Kanzler zu bestehen habe - Vorgänge aus seiner politischen Vergangenheit entgegengehalten werden, meinte er noch Mitte März $1967^{37}$.

Kurz vor seiner Regierungserklärung am 13. Dezember 1966 befand sich Bundeskanzler Kiesinger politisch also unter starkem Druck. Adenauer nutzte alle ihm zu Gebote stehenden Mittel, um seinen außenpolitischen Forderungen Gewicht zu verleihen. Trotz-

\footnotetext{
${ }^{31} \mathrm{Vgl}$. Kiesinger, Jahre, S. 19. Kiesinger korrigiert die zuvor oft gemachte Äußerung, er habe von den Verbrechen der Nazis nichts gewußt. Während des Zweiten Weltkrieges habe er seinem Vater „erschüttert“ von den Gerüchten über die Vernichtung der Juden berichtet und gesagt: „Unser Land wird von Verbrechern regiert."

${ }^{32}$ Vgl. AdKASt, Kiesinger I - 226, D/IV.6, A 003, Grüber an Kiesinger vom 6.12.1966, S. 1.

${ }^{33}$ Zur Kritik aus den USA an Kiesinger siehe etwa HIoWRP, Acc. 741058 M. 47/48, Box 83, Kissinger an Emmet vom 14.12.1966: „I am still not happy about making an apologia for someone joining the Nazi Party. " Kissinger hatte die Johnson-Administration wegen deren Deutschlandpolitik attackiert und die Bundesregierung verteidigt, seine Haltung zu Kiesinger war aber ambivalent.

${ }^{34}$ Der Tagesspiegel, 25.11.1966.

${ }^{35}$ AdKASt, Kiesinger I - 226, D/IV.6, A 003, Kiesinger an Grüber vom 29.12.1966.

${ }^{36}$ Majer, Gespräch mit dem Verfasser, 12.12.1988. Das Zitat ist Majer von Kiesinger berichtet worden.

${ }^{37}$ Vgl. Schwarz, Der Staatsmann, Adenauer, Gespräch mit Friedrich, S. 934.
} 
dem ließ sich Kiesinger bei der Abfassung der Erklärung davon nicht beirren. Sie war keineswegs ganz auf Frankreich ausgerichtet. Die Passage über das Verhältnis zu Frankreich kam fast am Schluß, und der Kanzler betonte dort, das Verhältnis zu Frankreich und den Vereinigten Staaten besitze für die Bundesrepublik die gleiche Bedeutung!

\section{Die Regierungserklärung: Mit dem Scheitern der Regierung Erbard wird die Große Koalition geboren}

Am 12. Dezember behandelte und billigte das Kabinett die Regierungserklärung. Obwohl sie wesentlich von Kiesinger formuliert worden war, hatte sie wenig Kritik des Koalitionspartners ausgelöst. Der Regierungschef las den Text seiner versammelten Ministerrunde vor. Es habe nur kleinere Textkorrekturen gegeben, sprachliche, stilistische Änderungen seien vorgenommen worden, berichtete Kiesinger danach ${ }^{38}$. Einen Tag später trug er sie im Bundestag vor. Die Rede eröffnete mit einer Rechtfertigung der neuen Regierungsbildung: „Der Bildung der Bundesregierung [...] ist eine lange, schwelende Krise vorausgegangen, deren Ursachen sich auf Jahre zurückverfolgen lassen“, hieß es. „Ihr offener Ausbruch erfolgte kaum ein Jahr nach den Wahlen zum 5. Deutschen Bundestag, die einen eindrucksvollen Vertrauensbeweis für meinen Vorgänger, Professor Ludwig Erhard, erbracht und den Parteien der bisherigen Regierungskoalition deren Fortsetzung ermöglicht hatten. In der Folge belasteten innenpolitische Schwierigkeiten, innerparteiliche Auseinandersetzungen und außenpolitische Sorgen die Arbeit der Regierung. " ${ }^{39}$

Das harte Wort von der „schwelenden Krise“, das einige Unionsmitglieder Kiesinger übelnahmen, fiel aus mehreren Gründen. Kiesinger hat später darauf hingewiesen, daß er mit diesem Begriff die zunehmende Bedeutung der FDP im Parteiensystem seit 1961 als „Zünglein an der Waage“ und ihre gleichzeitig wachsende Labilität angesprochen habe. In der Koalition mit der Union hätten die Liberalen ständig an Stimmen verloren. Bei der Bundestagswahl des Jahres 1965 büßten sie 18 Bundestagsmandate ein. Die Partei habe daraufhin eine Profilneurose entwickelt. In der Koalition entfernte sie sich bei innen- und außenpolitischen Themen immer weiter von der Union. Ein Regieren wurde fortan schwerer und schwerer, der Bruch der Koalition Erhard/Mende schien unausweichlich. Die Große Koalition sei notwendig geworden, erläuterte Kiesinger im Rückblick, um die Handlungsfähigkeit und die Stabilität der Bundesregierung wiederherzustellen ${ }^{40}$.

Hinzu kam, daß Kiesinger gerade auch in außenpolitischer Hinsicht die Große Koalition als Gegenregierung zum christlich-liberalen Bündnis sah. Das galt nicht nur für die Wiederbelebung des deutsch-französischen Verhältnisses, sondern auch für neue, ernsthafte Bemühungen um die Sowjetunion. Schon im ersten Satz sollte diese neue Ausrichtung seiner Regierung zum Ausdruck kommen. Die SPD besaß ein starkes Interesse an dieser Formulierung, um sich vor den Kritikern der Koalition in der eigenen Partei zu rechtfertigen. Die Entscheidung der sozialdemokratischen Führung würde ihren Mitgliedern nur dann plausibel erscheinen, wenn man behaupten konnte, die „Krise“ habe es notwendig gemacht, aus Pflichtgefühl gegenüber dem Staat Regierungsverantwortung zu übernehmen. So dachte man zumindest das Bündnis mit dem jahrelang bekämpften Rivalen zu erklären.

\footnotetext{
${ }^{38}$ Vgl. AdKASt, Kiesinger I - 226, F/, A 322, Zeugen der Zeit, ARD-Sendung, aufgezeichnet am 8.6.1972, S. 100.

${ }^{39}$ VdDB, 5. Wahlperiode, 80. Sitzung vom 13.12.1966, S. 3656.

${ }^{40} \mathrm{Vgl}$. Kiesinger, So war es, I, 17.11.1974.
} 
Ein persönlicher Groll Kiesingers auf Erhard mochte auch noch eine Rolle gespielt haben. Der noch amtierende Kanzler hatte wenige Stunden vor der endgültigen Besiegelung der Großen Koalition am 25. November 1966 versucht, die Verhandlungen mit der SPD zu torpedieren. Pressesprecher Karl-Günter von Hase bestritt da öffentlich den sozialdemokratischen Vorwurf, die Regierung habe Mißwirtschaft zu verantworten. Diese Behauptung entbehre jeglicher Grundlage, erklärte er. Die Öffentlichkeit sei von der tatsächlichen Lage auf innen- und außenpolitischem Gebiet mangelhaft unterrichtet. „Zu einem Offenbarungseid ist keinerlei Anlaß." Wer ihn fordere, zersetze die allen Parteien gemeinsame Grundlage der demokratischen Politik ${ }^{41}$.

Diese letzte Handlung des scheidenden Kanzlers wirkte daher so provozierend, weil sie nicht mit der CDU/CSU-Fraktion abgesprochen war ${ }^{42}$, die einer solchen Erklärung auch nicht zugestimmt hätte. Kiesinger mußte das als grobe Einmischung in seine Bemühungen um die Regierungsbildung auffassen. Er reagierte prompt und scharf. Der Spiegel kolportierte das böse Wort vom „mumifizierten Kanzler“, der ihn endlich in Ruhe lassen solle ${ }^{43}$. Der noch amtierende Kanzler war dem Kandidaten lästig geworden. Es schien schicksalhaft zu sein, daß beide Politiker sich in wichtigen Abschnitten ihrer persönlichen Karriere begegneten. 1957 hatte Adenauer Erhard als Hiobsboten auserkoren. Er sollte Kiesinger darüber informieren, daß es mit dem schon versprochenen Justizministerium nichts werden würde. „Der Kanzler winde sich in Qualen“, hatte der sanftmütige Erhard damals zu Kiesinger gesagt. Jetzt, acht Jahre später, war es Kiesinger, der von einem erbitterten Erhard das Kanzleramt übernahm.

\section{Die Friedensformel und Kiesingers Zurückbaltung beim Thema Frankreich}

Der erste und größte Teil der Regierungserklärung befaßte sich mit der konjunkturellen und haushaltspolitischen Lage der Bundesrepublik. Er stammte in den wesentlichen Zügen aus der Feder des neuen Wirtschaftsministers Schiller. Das hat Kiesinger später allerdings bedauert. „Der schwächste Teil ist der wirtschaftspolitische, da war ich am entgegenkommendsten gegenüber den Formulierungen, die Herr Schiller vorgeschlagen hat", erklärte er im Rückblick ${ }^{44}$. Des Kanzlers nachträgliche Kritik läßt sich aus der Tatsache erklären, daß er darauf angewiesen war, die Sanierung der Wirtschaft dem brillanten Fachmann zu überlassen. An Schiller, seinen Gedanken und Wortschöpfungen kam man damals nicht vorbei, als man den Kandidaten für das Amt des Wirtschaftsministers auswählte, betonte Kiesinger immer wieder. So wurde die wirtschaftspolitische Passage zwangsläufig von den Vorstellungen des Ministers bestimmt.

Die übrigen Teile waren im Sonderzug von Bonn nach Tübingen von Kiesinger redigiert und formuliert worden. Die einzelnen Ressorts der Bundesregierung hatten Papiere vorbereitet und an das Bundeskanzleramt geleitet. Auf der Zugfahrt wurden die Exposés gelesen, diskutiert und schließlich gekürzt. Es habe sich im Grunde um ein „Streichorchester" gehandelt, beschrieb der Verbindungsmann zum Verteidigungsminister im Kanzleramt, Oberst Gerd Stamp, den Vorgang. Manche Ministerien gestalteten ihren Entwurf weitschweifig. Über Stunden mußte der Kanzler all „das Zeug“ lesen ${ }^{45}$. Dann wurde ge-

\footnotetext{
${ }^{41}$ Frankfurter Allgemeine Zeitung, 26.11.1966.

${ }^{42}$ Vgl. Knorr, Entscheidungsprozeß, S. 283, Fn 166. Nicht einmal alle Minister sollen den Text der Erklärung gekannt haben.

${ }^{43}$ Der Spiegel, 5.12.1966, S. 37.

${ }_{44}$ AdKASt, Kiesinger I - 226, F/3., A 322, Gespräch mit Löwe, 31.1.1978, S. 99.

${ }^{45}$ Stamp, Gespräch mit dem Verfasser, 30.11.1987: „Tausendmal gesagt und immer wieder neu aufgewärmt.“
} 
strichen, das Wesentliche neu formuliert und der Sekretärin Helga Franke diktiert. Satz für Satz habe er die Texte durchgesprochen und sie dann neu formuliert, erklärte Kiesinger später ${ }^{46}$.

Auch die Idee, den außenpolitischen Teil mit dem Gedanken des „Friedens“ zu beginnen, stammte vom Kanzler. Kiesinger wollte in dieser Regierungserklärung andere Akzente setzen als seine Vorgänger. Zuviel Gewicht sollte den Nato- und Verteidigungsfragen nicht zukommen. Er wolle den Eindruck vermeiden, als drehe sich in Deutschland immer „alles ums Militär“, erläuterte er dem Kabinett ${ }^{47}$. So begann dieser Part mit den Worten: „Alle unsere Bemühungen um die innere Ordnung, um wirtschaftliches Wachstum und soziale Gerechtigkeit [...] haben freilich nur Sinn und Bestand, wenn es gelingt, den Frieden und eine freiheitliche Lebensordnung zu bewahren. Daß der Friede bewahrt werde, ist die Hoffnung aller Völker, und das deutsche Volk wünscht dies nicht weniger als die anderen. Darum ist der Wille zum Frieden und zur Verständigung der Völker das erste Wort und das erste Grundanliegen der Außenpolitik dieser Regierung." ${ }^{48}$

Die Betonung des Begriffs Frieden kam nicht von ungefähr. Schon als Ministerpräsident Baden-Württembergs sah Kiesinger es als seine Aufgabe an, die Bedürfnisse des Bürgers nach Kultur und Erziehung zu befriedigen und zu fördern. Das Ziel des Staates sollte die Vervollkommnung seiner Bürger sein. Der Staat mußte den äußeren Rahmen sichern und den Frieden bewahren, damit der Bürger seiner kulturellen Erziehung nachgehen und seine Sitten verfeinern konnte. Besonders stolz war der Ministerpräsident daher auf die beiden Universitäten Konstanz und Ulm, deren Gründungen in seine Regierungszeit fielen. Jetzt oblag ihm als Kanzler die Pflicht, den inneren und äußeren Frieden zu bewahren und zu sichern. Daher galt - auch dies war ein neuer Akzent - das erste Wort dem potentiellen Feind, der Sowjetunion. Das deutsche Volk hege weder Feindschaft noch $\mathrm{Haß}$ gegen die Völker der Sowjetunion, sagte er, es wolle im Gegenteil in guter friedlicher Nachbarschaft leben ${ }^{49}$. Der Kanzler stellte bewußt die Sowjetunion an die erste Stelle des außenpolitischen Teils. Er zeigte damit, daß er sich verstärkt um das Verhältnis mit Moskau bemühen wollte. Das Angebot eines Gewaltverzichts an die Adresse Moskaus wurde wiederholt. Die Regierung Erhard hatte es erstmals in ihrer Friedensnote vom März 1966 eingebracht, und Kiesinger fügte jetzt hinzu, in einen Gewaltverzicht solle das ungelöste Problem der deutschen Teilung mit einbezogen werden. Mit anderen Worten: Er war zur Garantie der innerdeutschen Grenze bereit.

Neu und überraschend war auch die Bemerkung zur polnisch-deutschen Grenze. Die Grenzen eines wiedervereinigten Deutschlands könnten zwar nur in einer frei vereinbarten Regelung mit einer gesamtdeutschen Regierung festgelegt werden, versicherte Kiesinger. Aber den Polen bot er die Bereitschaft zu einer Regelung an, „einer Regelung, die die Voraussetzung für ein von beiden Völkern gebilligtes, dauerhaftes und friedliches Verhältnis guter Nachbarschaft schaffen soll“" Kein Kanzler hatte sich bis dahin zu diesem heiklen Punkt so offen geäußert und war so weit gegangen. Kiesinger versprach zwar nichts, was einer friedensvertraglichen Regelung vorbehalten bleiben mußte, also etwa die Anerkennung der Oder-Neiße-Linie. Aber er ging doch auf die polnischen Sorgen

${ }^{46}$ Vgl. AdKASt, Kiesinger I - 226, F/3., A 322, Gespräch mit Löwe, 31.1.1978, S. 45.

${ }^{47}$ Der Spiegel, 5.12.1966, S. 29.

${ }^{48}$ VdDB, 5. Wahlperiode, 80. Sitzung vom 13.12.1966, S. $3661 \mathrm{f}$.

${ }^{49}$ Vgl. ebenda, S. 3662. 
ein, indem er immerhin für den Fall eines Friedensschlusses und einer Wiedervereinigung eine Anerkennung der gegenwärtigen Grenze in Aussicht stellte.

Es handelte sich in dieser Frage um keinen Gedanken, den Kiesinger für seine Kanzlerschaft neu ersonnen hatte. Viele seiner Vorschläge stammten - wie dieser auch - bereits aus seiner Zeit als Abgeordneter. Im April 1957 erklärte er anläßlich einer Diskussion zwischen englischen und deutschen Parlamentariern in Königswinter, die Grenzen von 1937 könnten eines Tages zur Diskussion gestellt werden, nämlich dann, wenn diese Diskussion mit einem „freien“ Polen geführt werde. Mit diesem freien Polen müsse „im Geiste freundlichster Nachbarschaft " verhandelt werden. Er gehe mit der Forderung bewußt über das Angebot des bloßen Gewaltverzichts hinaus ${ }^{50}$. Damit hatte Kiesinger schon zehn Jahre vor seiner Kanzlerschaft die Bereitwilligkeit angedeutet, das Problem der OderNeiße-Grenze im Sinne der polnischen Erwartungen zu lösen.

Als drittes beschäftigte sich der Bundeskanzler mit den USA. Er bekannte sich zur Fortsetzung und Vertiefung der Beziehung zum atlantischen Partner, eine Erklärung, wie sie General de Gaulle sicherlich enttäuschen mußte. Kiesinger sagte wörtlich: „Mit den Vereinigten Staaten von Amerika sind wir durch vielfache freundschaftliche Beziehungen und im Nordatlantischen Pakt eng verbunden, dessen Festigung und zeitgerechte Fortentwicklung uns ein wichtiges Anliegen ist. Diese Regierung wird keine der großen Hilfen vergessen, die uns die Vereinigten Staaten in den vergangenen beiden Jahrzehnten geleistet haben. Sie weiß, daß das Bündnis mit den Vereinigten Staaten und den übrigen Partnern des nordatlantischen Paktes auch heute und in der Zukunft, die wir zu überblicken vermögen, für uns lebenswichtig ist." ${ }^{1}$

De Gaulle wird diese Passage stirnrunzelnd gelesen haben. Noch mißtrauischer sollte ihn aber die anschließende Erklärung zu den bestehenden Europäischen Gemeinschaften gemacht haben. Vehement hatte sich de Gaulle gegen den Beitritt Englands gewandt, ihn im Januar 1963 durch sein Veto verhindert. Mit England, so einer seiner Gründe gegen den britischen Beitritt, werde auch der Einfluß der Vereinigten Staaten - durch die "Hintertür" - in die Europäische Gemeinschaft hineingebracht werden. Daher muß ihn enttäuscht haben, daß der Kanzler zu diesem Thema vorbrachte, besonders würde die Bundesregierung eine Teilnahme Großbritanniens und anderer EFTA-Länder ${ }^{52}$ an den Europäischen Gemeinschaften begrüßen.

Erst jetzt, an fünfter Stelle, befaßte sich der Bundeskanzler mit Frankreich, nachdem er das Verhältnis zu den USA bekräftigt und nachdem er sich zur Aufnahme Englands in die Europäische Gemeinschaft bekannt hatte. Schon diese Erklärungen dämpften etwaige Hoffnungen de Gaulles auf die neue Regierung. In sechs Unterpunkten erläuterte Kiesinger die Lage und die Möglichkeiten. Erstaunlich ist, wie offen er hier das Interesse Bonns formulierte. Das war kein überzeugendes Plädoyer für einen einseitigen Gaullismus, wie man es von ihm erwartet hatte. Im ersten Absatz betonte er das „besonders hohe Maß an Übereinstimmung der Interessen " beider Völker aufgrund der Geographie und aus der „Bilanz der Geschichte“ - ein insgesamt noch sehr allgemein gehaltenes Bekenntnis. Aber der folgende Absatz enthielt die entscheidende Aussage. Kiesinger erklärte, gemeinsam mit Frankreich, dem ältesten Verbündeten Amerikas in Europa, halte die neue Regierung ein solides Bündnis zwischen den freien, sich einigenden Nationen

${ }^{50} \mathrm{DzD}$ (1957), Band 3, S. $586 \mathrm{f}$.

${ }^{51} \mathrm{VdDB}, 13.12 .1966$, S. $3662 \mathrm{f}$.

52 Der Europäischen Freihandelsgemeinschaft (EFTA) gehörten zu dieser Zeit an: England, Schweden, Norwegen, Dänemark, Österreich, Schweiz, Portugal, Irland. 
Europas und den Vereinigten Staaten von Amerika für unerläßlich. Dies sei unabhängig davon, wie immer auch „die Struktur dieses Bündnisses angesichts einer gewandelten Welt künftig gestaltet“ werde. „Wir weigern uns, uns eine falsche und gefährliche Alternative der Wahl aufreden zu lassen. “53

Das Protokoll verzeichnet an dieser Stelle Beifall bei den Regierungsparteien. Die SPD, aber offensichtlich auch Teile von CDU/CSU begrüßten, daß Kiesinger eine einseitige Orientierung auf Frankreich oder die Vereinigten Staaten ablehnte. Aber die Äußerung war auch als ein Angebot an den Staatspräsidenten de Gaulle gedacht. Kiesinger formulierte geschickt, indem er so tat, als ob die Bündnisse der europäischen Staaten sich wandeln könnten. Damit nahm er scheinbar den Standpunkt de Gaulles ein, der in seiner Ostpolitik seit 1964 versuchte, für die Auflösung der Blöcke in Europa zu werben, und dabei besonders bei den Polen und den Rumänen ein positives Echo fand ${ }^{54}$. Kiesinger bezog die sich wandelnde Struktur der Nato in diese "französische Perspektive“ mit ein. Er spielte damit auf den Auszug Frankreichs aus der militärischen Organisation des Bündnisses wenige Monate zuvor an. Auch wenn die französischen Truppen der Befehlsgewalt der Nato entzogen worden waren, so plädierte Kiesinger jetzt für die Beibehaltung des Nordatlantischen Vertrages. Auf diese Weise verband er das deutsche Interesse an den atlantischen Beziehungen mit dem französischen Wunsch nach Unabhängigkeit und zeigte einen Weg auf, der beiden Aspekten so gerecht wie möglich wurde.

Auch in den folgenden Punkten betonte Kiesinger den "gaullistischen“ Charakter seiner Frankreichpolitik. Kernsatz der vierten Aussage war: Die deutsch-französische Zusammenarbeit richte sich gegen kein anderes Volk und Land. „Europa kann nur mit Frankreich und Deutschland, nicht ohne oder gar gegen eines der beiden Länder, gebaut werden“, verkündete er. Damit sollte vermutlich einerseits die Sowjetunion gemeint sein. Der Kanzler drückte seinen Wunsch aus, das Zusammengehen von Bonn und $\mathrm{Pa}$ ris solle von Moskau nicht als Bedrohung aufgefaßt werden. Andererseits dürfte Kiesinger allerdings auch an England gedacht haben. Es bestand die Gefahr, daß die Briten die Bundesregierung eines Tages dazu drängen konnten, eine europäische Einigung ohne Frankreich anzustreben. Solche Pläne hielt Kiesinger allerdings für utopisch und für gefährlich. Deutschland hätte sich in diesem Fall der Gefahr einer Umklammerung durch die Sowjetunion und durch Frankreich ausgesetzt, die der Alptraum Adenauers war.

Die Punkte fünf und sechs skizzierten den Rahmen, in dem künftig eine verstärkte deutsch-französische Kooperation stattfinden sollte. Das galt für die Verbesserung des Verhältnisses zu den osteuropäischen Nachbarn sowie für eine konkret koordinierte Politik beider Länder. Am Schluß appellierte der Kanzler an Frankreich, die existierenden Probleme nicht allzu hoch einzuschätzen. „Die besonderen Gegebenheiten unserer beiden Nationen werden auch in Zukunft in manchen Fragen Unterschiede von Interessen und Meinungen aufweisen. Die Bundesregierung ist jedoch überzeugt, daß solche Probleme geringer wiegen als die für das Schicksal unserer beiden Völker und Europas gebieterische Notwendigkeit zu einer immer weitere Bereiche umfassenden wirtschaftlichen, technologischen, kulturellen, militärischen und politischen Zusammenarbeit." 55

\footnotetext{
${ }^{53} \mathrm{VdDB}, 13.12 .1966$, S. 3663

${ }^{54}$ Vgl. Schütze, Die Ostpolitik Frankreichs, S. 166-174; Grosser, Außenpolitik, S. 254 ff.; siehe dazu auch Görner, Vom Atlantik.

55 VdDB, 13.12.1966, S. 3664.
} 
Die Regierungserklärung enthielt bezüglich der Vorstellungen de Gaulles also widersprüchliche Botschaften ${ }^{56}$. Zwar zeugte der Abschnitt über die Frankreichpolitik von gaullistischem Geist. Aber die zuvor genannten, eindeutigen Bekenntnisse des neuen Bundeskanzlers zur Bindung der Bundesrepublik an die Vereinigten Staaten sowie zur Aufnahme Englands in die EG widersprachen dieser Tendenz. Beide Punkte erachtete de Gaulle im Verhältnis zur Bundesregierung als entscheidend. Sein Angebot galt nur unter der Vorbedingung, daß Bonn seine Abhängigkeit von Washington verringerte und den Beitritt Londons in die Gemeinschaft nicht länger unterstützte.

\section{Kiesingers Distanz zur gaullistischen Konzeption im Juni 1966}

Die Widersprüchlichkeit ergab sich aus der Verbindung von zwei Elementen: Einerseits sollte das Regierungsprogramm - besonders nach den mit Adenauer geführten Gesprächen - gaullistische Züge tragen, andererseits wollte Kiesinger der außenpolitischen Konzeption de Gaulles nicht uneingeschränkt folgen ${ }^{57}$. Schon seit langer Zeit stand er dem Angebot des Generals eher skeptisch gegenüber. Als einfacher Abgeordneter hatte sich Kiesinger, der selbst ein wenig Französisch sprach, für die Reden und Schriften der wichtigen französischen Politiker interessiert. Dazu zählten auch die Texte des im selbstgewählten Exil in Colombey-les-deux-Églises verweilenden de Gaulle.

De Gaulle besaß damals in Deutschland einen schlechten Ruf. Er stand für die harte Deutschlandpolitik der Franzosen in der unmittelbaren Nachkriegszeit: der Forderung nach Abtrennung des Saarlandes, nach der Internationalisierung der Ruhr und der Dezentralisierung Deutschlands. Die Oder-Neiße-Grenze hatte er bereits 1944 Stalin gegenüber anerkannt. Bei dieser Haltung blieb er auch später in der Zeit der deutsch-französischen Aussöhnung, am Anfang der sechziger Jahre. Aber in den anderen Punkten hatte er sich der europäischen Entwicklung angepaßt. Nachdem der General 1958 an die Regierungsspitze zurückgekehrt war, setzte er sich für ein neues Europa vom Atlantik bis zum Ural ein, in dem Deutschland - die Bundesrepublik mit Sachsen und Preußen, wie er die DDR nannte - wiedervereinigt sein würde.

Kiesinger behauptet, dieser Sinneswandel des großen Franzosen habe sich schon 1950 angekündigt. De Gaulle hätte im März 1950 auf die Anregung Adenauers enthusiastisch reagiert, eine deutsch-französische Union mit einem gemeinsamen Wirtschaftsparlament zu gründen ${ }^{58}$. „Was wiegt gegenüber solchen Perspektiven der Streit um die Saar! “ hatte de Gaulle damals ausgerufen. Man stehe geradezu geblendet von dem Gedanken, was deutsche Tüchtigkeit und französische Valeurs vereinigt zu schaffen vermöchten, meinte er damals ${ }^{59}$. Er zeigte sich tief beeindruckt von der Perspektive einer gemeinsamen Union der beiden Nachbarvölker. Wie sah aber das Angebot des französischen Staatspräsiden-

${ }^{56}$ Vgl. Ziebura, Beziehungen, S. 135; Ziebura spricht vom "Janusgesicht" der Regierungserklärung: „Neben Verhandlungsangeboten an die Sowjetunion und die osteuropäischen Staaten tritt ein langer Passus, in dem fast überschwenglich festgestellt wird, daß sich die Interessen der Bundesrepublik und Frankreichs durch, ein besonders hohes $\mathrm{Maß}$ an Übereinstimmung' auszeichnen, was im Klartext bedeutete, daß man bereit war auf die gaullistische Linie stärker als in der Vergangenheit einzuschwenken." Besson (Außenpolitik, S. 383) behauptet, daß die Bundesregierung weniger daran dachte, Frankreich einen „Vorrang" einzuräumen, als vielmehr daran, wieder ein „ausgewogenes Verhältnis zu den beiden wichtigsten Bündnispartnern herzustellen“.

57 Vgl. Hildebrand, Erhard, S. 317.

58 Vgl. Kiesinger, Jahre, S. 388.

59 Vgl. Kiesinger, Stationen, S. 189. Im Juni 1966 hatte Kiesinger als Ministerpräsident in einer Rede auf diesen Satz des Generals hingewiesen. 
ten an die Bundesregierung im Herbst 1966 aus? Kiesinger suchte die Zielsetzung de Gaulles so zu erklären: Es gäbe theoretisch drei Möglichkeiten, die deutsche Wiedervereinigung zu erlangen. Die erste führe am Ende zu einem Deutschland, das die Nato verlassen und neutral sein würde. Aber gegen diese Lösung sprächen viele Argumente, meinte der Ministerpräsident in einer Rede in Hohenheim am 7. Juni 1966. Abgesehen davon, $\mathrm{da}$ auch die Sowjetunion sich nicht bereit erklärt hätte, die Wiedervereinigung in Freiheit zuzugestehen, sei das eine für Europa nicht akzeptable Lösung. Denn ein solches Deutschland werde in den Sog des Einflusses der Sowjetunion geraten.

Die zweite theoretisch mögliche Lösung bestehe darin, fuhr Kiesinger fort, daß man „eine weltgeschichtliche Stunde abwarte, in der die Sowjetunion in irgendeine schwere Krise - sei es im Gebiet ihres europäischen Herrschaftsbereichs, sei es gegenüber China - gerate“. Aber auch auf eine solche Möglichkeit wollte der deutsche Politiker nicht zu große Hoffnungen setzen. Eine Politik, die dieses Ziel verfolge, werde von den Franzosen als lebensgefährlich bezeichnet und - er glaube mit Recht - abgelehnt. Es bleibe also nur ein dritter Weg, und hier versuche de Gaulle die Deutschen zu überzeugen, daß Frankreich die einzige Macht sei, der es „wirklich um die Wiedervereinigung nach dem Prinzip des Selbstbestimmungsrechts “, wenn auch in realistisch entworfenen Etappen, gehe. Wenn aber diese Politik verfolgt werden solle, dann setze sie selbstverständlich eine Regelung der deutschen Grenzen, damit meine de Gaulle die Oder-Neiße-Grenze, und eine Vereinbarung über die deutsche Bewaffnung voraus. Und der französische Staatspräsident erwarte, die Deutschen sollten sich von einer direkten oder indirekten Mitbeteiligung an einer atomaren Bewaffnung distanzieren. „Das ist die Offerte, die de Gaulle uns macht und die er bei seiner Reise in Moskau den Russen machen möchte. “60

Kiesinger hielt es also schon 1966 für möglich, daß eine innere Krise die Sowjetunion dazu zwingen könne, die Wiedervereinigung Deutschlands zuzugestehen. Es handelte sich aber um keine politische Option, die zu verfolgen gar einer deutschen Regierung offenstand. Diese Krise konnte nur von selbst im Innern des Imperiums ausbrechen, ohne Einwirkung von außen. Daher ließ sich diese Möglichkeit in keinen Fahrplan zur Erlangung der deutschen Einheit einbeziehen.

Dagegen bot Frankreich eine interessante Perspektive, die Kiesinger schon vor seiner Kanzlerzeit deutlich gesehen hat. Es lief auf ein Arrangement mit den Sowjets hinaus. Als Voraussetzung für eine europäische Ordnung sollten die Deutschen zwei Bedingungen erfüllen: einmal die Anerkennung der Oder-Neiße-Grenze sowie den Verzicht auf eine atomare Bewaffnung. Im Gegenzug würde Deutschland seine Einheit wiedererlangen. Das war eine einfache Rechnung, die aber für Kiesinger nicht glatt aufging. Auch er war von der Möglichkeit eines Arrangements mit Moskau überzeugt. Daher lehnte der Ministerpräsident den Vorschlag de Gaulles nicht von vornherein ab. Aber er wies in der zitierten Rede auch auf das Wort Maurice Schumanns, des Vorsitzenden des Auswärtigen Ausschusses im französischen Parlament, hin, keine deutsche Regierung werde sich bereitfinden, leichtfertige Vorleistungen zu erbringen. Keine deutsche Regierung, ergänzte Kiesinger, könne einer solchen Politik zustimmen, ohne dafür Garantien von Moskau zu erhalten.

Kiesinger erteilte de Gaulle also schon zu diesem Zeitpunkt eine Absage. Zwar schloß er nicht aus, daß sich eines Tages de Gaulle mit seiner europäischen Vision durchsetzen

${ }^{60}$ Kiesinger, Stationen, Rede vom 7.6.1966 in Hohenheim, S. 196 f. Die Aussagen zu de Gaulle gehen auf dessen Äußerungen am 4.2.1965 zurück. In der Rede bezieht sich Kiesinger fälschlicherweise auf den 4.1.1965; vgl. EA 20 (1965), Folge 4, S. 94 ff. 
werde ${ }^{61}$. Doch dafür fehlten jetzt die Voraussetzungen - Bedingungen, die nicht Frankreich, sondern die sowjetische Führung schaffen mußte. Mit anderen Worten: Erst wenn Moskau erklärte, es werde der Vereinigung zustimmen, unter Bedingungen, die Bonn zu erfüllen habe, konnte sich die Bundesregierung auf die Vision de Gaulles einlassen. Alles andere kam zu früh.

\section{Adenauers positive Reaktion auf die Erklärung}

Trotz der zwiespältigen Aussagen der Regierungserklärung zeigte sich Adenauer befriedigt. Kiesinger vermerkt im Rückblick, daß der Altbundeskanzler seine Regierungserklärung und die darauf folgenden Entscheidungen ausdrücklich begrüßt habe ${ }^{62}$. Noch am 13. Dezember schickte Adenauer an den Bundeskanzler den zweiten Band seiner gerade erschienenen Erinnerungen. Im Begleitschreiben hieß es mit freundlichen, fast warmen Worten: „Der zweite Band meiner, Erinnerungen', der jetzt der Öffentlichkeit übergeben wurde, behandelt eine Zeitspanne, in welcher Sie als eines der maßgebenden Mitglieder unserer Bundestagsfraktion mitgewirkt haben, den Beginn einer eigenständigen Außenpolitik neu zu gestalten. Ich würde mich freuen, wenn Sie das beigefügte Exemplar als Zeichen meines Dankes für Ihre damalige Hilfe und in Erinnerung an unsere gemeinsame Arbeit betrachten würden." ${ }^{63}$

Aber Adenauer wird die Leistung Kiesingers nicht zu hoch eingeschätzt haben. Denn der damalige Abgeordnete ist nur ein einziges Mal im Text namentlich erwähnt worden $^{64}$. Kiesinger fühlte sich dennoch geschmeichelt. In seinem Dankesschreiben zeigte er sich demutsvoll. Es werde für ihn immer eine große Freude bleiben, schrieb er, daß „ich zu meinem bescheidenen Teil im Bundestag an der Entwicklung einer eigenständigen deutschen Außenpolitik, die Ihren Namen trägt, teilnehmen konnte". Er unterschrieb mit „Ihr ergebener Kiesinger"65. Über Weihnachten 1966 hatte sich das Verhältnis der beiden christdemokratischen Führer entspannt. Jetzt bereitete sich der Kanzler auf den ersten Gipfel im Rahmen der im deutsch-französischen Vertrag geregelten Konsultationen vor. Er fand Anfang Januar 1967 in Paris statt.

\section{Kiesinger und de Gaulle: zwei Staatsmänner - zwei Zielsetzungen}

De Gaulle erkannte die Reserviertheit Kiesingers gegenüber seinem Angebot sofort, als er die Regierungserklärung studierte. Dem neuen Außenminister Brandt, der sich auf seiner ersten Auslandsreise nach Paris begeben hatte, erklärte der Staatspräsident am 15. Dezember 1966, die Regierungserklärung habe er mit Interesse gelesen. Er halte die Aussagen bezüglich einer Entspannung des sowjetisch-deutschen Verhältnisses sowie zur Politik gegenüber der Tschechoslowakei für gut. „Was Polen anbelangt, ist die Bundesregierung allerdings nicht sehr bestimmt“", mäkelte er, „,sondern sagt nur, daß man später über diese Dinge zu

\footnotetext{
${ }^{61}$ Vgl. Hildebrand, Erhard, S. 317.

${ }^{62}$ Vgl. Kiesinger, So war es, Teil I, 17.11.1974.

${ }^{63}$ AdKASt, Kiesinger I - 226, D/IV.6, A 001, Adenauer an Kiesinger vom 13.12.1966.

${ }^{64} \mathrm{Vgl}$. Adenauer, Erinnerungen, S. 490. Kiesinger wird hier lediglich als Begleiter der Moskaureise 1955 erwähnt.

${ }^{65}$ AdKASt, Kiesinger I - 226, D/IV.6, A 001, Kiesinger an Adenauer vom 22.12.1966.
} 
sprechen haben werde." Er sei nicht sicher, daß dies die Situation verändern werde ${ }^{66}$. Der General brauchte das Bonner Zugeständnis hinsichtlich der Oder-Neiße-Linie für seine Politik gegenüber den Sowjets. Ihnen versprach er die Anerkennung der Grenze durch die Deutschen; den Deutschen versprach er die sowjetische Zustimmung zur Wiedervereinigung. Solange die Bundesrepublik ihre Einwilligung verweigerte, konnte de Gaulle nicht als Vermittler auftreten. Daher lag ihm soviel an diesem Thema.

Brandt war trotzdem mit guten Nachrichten aus Paris zurückgekehrt. De Gaulle sei ganz auf die Linie der Regierungserklärung eingeschwenkt. Vor allem wolle er sich in Moskau für Bonn verwenden. Wörtlich habe der Staatspräsident erklärt: „Wenn Deutschland es will, wird Frankreich - es hat damit sogar schon begonnen - ihm auf diesem Weg gern helfen, vor allem in Moskau. “ Darüber hinaus versicherte das französische Staatsoberhaupt der neuen Bundesregierung, daß er in der Politik der Entspannung nichts tun werde, was Deutschland schaden könnte ${ }^{67}$. Das waren gute Voraussetzungen für das erste Treffen in Paris am 13. Januar 1967. Der Staatspräsident plante allerdings, sich bei dem bevorstehenden Gipfeltreffen zurückzuhalten. Er werde zu seinen Gesprächspartnern sehr nett, aber unverbindlich sein, erklärte de Gaulle bei der Vorbereitung des Treffens seinen Beratern. Er habe genug getan, jetzt seien die Partner dran, ihre Karten offenzulegen ${ }^{68}$. Sein Angebot an die Bundesregierung sei bekannt, taktische Scheingefechte könne er anderen überlassen. Mochten die Deutschen jetzt endlich entscheiden, welchen Standpunkt sie einnehmen wollten.

Doch man täuscht sich, wenn man annimmt, de Gaulle habe dem Besuch gelassen entgegengesehen. Er hatte mit großem Interesse die Regierungsbildung verfolgt und die Regierungserklärung studiert. Besonders die Tatsache hatte er begrüßt, daß die Sozialdemokraten in die Regierung aufgenommen worden waren und daß Brandt das Außenministerium übernommen hatte. Beeindruckt von der Persönlichkeit des Regierenden Bürgermeisters von Berlin, hatte er nach der ersten Begegnung 1958 richtig vorausgesehen: „Monsieur, wir werden uns wiedersehen." 69 Und, wie Adenauer vorausgesagt hatte, nahm es der General auch keineswegs gleichgültig hin, daß der frühere Außenminister Schröder als Bundesminister der Verteidigung mit in der neuen Regierung saß. „Mais Gerhard Schröder reste une force politique “, lautete die Überzeugung der französischen Regierung, wie es in einem Hintergrundbericht des Intendanten des Saarländischen Rundfunks, Franz Mai, an den Kanzler hieß $\beta^{70}$.

Über seine Haltung zu diesem Minister ließ de Gaulle auch während dieses ersten Staatsbesuches von Anfang an keine Zweifel aufkommen. Kanzler und Verteidigungsminister flogen in getrennten Maschinen nach Paris. Als der Jet des Ministers auf dem Flughafen Orly landete, lotste ihn das Protokoll an die falsche Ecke des Flugplatzes, so daß der Empfang der deutschen Delegation ohne Schröder stattfand ${ }^{71}$.

\section{Kiesinger und de Gaulle}

Trotz der Reserviertheit, die Kiesinger der ostpolitischen Konzeption de Gaulles entgegenbrachte, sah der Kanzler keine andere Chance für die Bundesrepublik, als zusammen

\footnotetext{
${ }^{66}$ Brandt, Begegnungen, S. 157.

67 Ebenda, S. 153.

${ }^{68} \mathrm{Vgl}$. Seydoux, Botschafter in Deutschland, S. 97.

${ }^{69}$ Der Spiegel, 19.12.1966, S. 53.

70 AdKASt, Kiesinger I - 226, D/IV.6, A 006, Mai an Kiesinger vom 15.2.1967, S. 1.

71 Vgl. Stamp, Gespräch mit dem Verfasser, 30.11.1987.
} 
mit Frankreich nach einer Verständigung mit dem Osten zu suchen. Frankreich war und blieb für die Bundesrepublik der Schlüssel zur Außenpolitik. Eine Einigung zwischen West- und Osteuropa - die einzige Chance für die Wiedervereinigung - schien ohne de Gaulle nicht möglich zu sein. Davon war zumindest Kiesinger überzeugt. Mit Frankreichs Fürsprache konnten erste Barrieren des Mißtrauens im Osten abgebaut werden. Und ein weiterer Gedanke kam hinzu: Ohne das Wohlwollen von Paris konnte die Lage für Bonn sogar gefährlich werden. Es habe einmal eine Zeit gegeben, erklärte Kiesinger 1978, in der die Engländer eine Ersatzkonstruktion für das vereinigte Europa forderten, in der sie gesagt hätten, Frankreich solle ausgeschlossen bleiben; das lasse man jetzt einfach auf der Seite liegen. Er habe aber davor gewarnt und erklärt: „Seid ihr noch bei Trost?" Wenn de Gaulle von seiner Konzeption nicht abgehe, dann könne er als Kanzler nur dafür sorgen, daß Frankreich sich nicht Rußland zuwende. Dies hätte für Deutschland und für Europa katastrophale Folgen. Man müsse eben in Gottes Namen warten, bis einmal ein anderer Regierungschef Frankreich regiere ${ }^{72}$. Kiesinger sah deutlich eine Gefahr, die im Herbst 1966 in der neu erwärmten Beziehung zwischen Elysee-Palast und dem Kreml lag. Es bestand die Möglichkeit, daß Frankreich sich wie vor dem Ersten Weltkrieg mit Rußland gegen Deutschland verbündete und es damit in die Zange nahm. Ein im Westen isolierter de Gaulle konnte die Bundesrepublik noch stärker schädigen: Er hatte die Oder-Neiße-Grenze anerkannt, warum nicht auch die DDR? Man konnte de Gaulle alles Mögliche zutrauen, erklärte Kiesinger später ${ }^{73}$.

Der Kanzler sorgte sich auch um das persönliche Verhältnis zwischen ihm und dem General. Es war immerhin sein erster Auftritt im Ausland. Von der Übereinstimmung mit dem Franzosen hing auch die Einschätzung der Großen Koalition in der deutschen Öffentlichkeit ab. Wie würde aber de Gaulle, der Führer der französischen Exilregierung in London während der deutschen Besatzung Frankreichs, ihm als ehemaligem Mitglied der NSDAP gegenübertreten? Kiesinger war sich nicht sicher, ob das Treffen gut ausgehen werde. Doch davon, daß er sich um das Verhältnis gesorgt hatte, wollte er hinterher nichts wissen. Beide Staatsmänner hätten sich immer gut verstanden, erklärte Kiesinger. Und zwar seit der Zeit, als sie sich kennengelernt hatten - also seit dem triumphalen Deutschlandbesuch des Franzosen im September 196274. Damals sprach de Gaulle in Ludwigsburg vor deutschen Jugendlichen und hinterließ einen tiefen Eindruck, da er seine Rede in deutscher Sprache hielt. Auch Kiesinger hatte im Anschluß an die Ansprache des Franzosen, der die Deutschen ein "großes Volk“ genannt hatte, gesprochen, und zwar so, daß ihm hinterher de Gaulle das Kompliment machte, Kiesinger sei ein „richtiger Volksredner“. Den Franzosen hatte vor allem beeindruckt, daß der Ministerpräsident frei redete ${ }^{75}$.

Von dieser ersten Begegnung rührt Kiesingers Urteil über de Gaulle her. Der Franzose übte auf ihn eine nachhaltige Wirkung aus. De Gaulle sei eine Mischung aus einerseits weit vorausschauend, andererseits "tief verstrickt“ in alte Vorstellungen, meinte er.

\footnotetext{
72 AdKASt, Kiesinger I - 226, F/3., A 322, Gespräch mit Löwe, 31.1.1978, S. 37.

${ }^{3}$ Vgl. ebenda, S. $19 \mathrm{f}$.

${ }^{74}$ Vgl. Herwarth, Gespräch mit dem Verfasser, 23.10.1986. Beide hatten sich später wiedergetroffen, als Kiesinger an den Verhandlungen der Regierung seines Vorgängers, Erhard, als Beauftragter der Länder teilgenommen hatte. Im Außenministerium erinnerte man sich noch des zähen Ringens um das Bundesbanner am Auto des baden-württembergischen Ministerpräsidenten, ohne das der rangbewußte Kiesinger nicht an den Verhandlungen teilnehmen wollte.

${ }_{75}$ Rundel, Gespräch mit dem Verfasser, 6.8.1989. Kiesinger hatte die Rede noch bis kurz vor dem Eintreffen des Generals auf dem Flughafen immer wieder eingeübt.
} 
Kiesinger bemerkte aber auch eine Schwäche des Franzosen. Er lasse sich von Emotionen fortreißen. Das könne man an seinen Reden sehen und durch seine unbedachten Äußerungen belegen. De Gaulle sei ein ungewöhnlich kluger Mann, der aber, insbesondere wenn er vor Massen stehe, sich zu ungewollten Äußerungen hinreißen lasse. Er, Kiesinger, habe ja gesehen, wie de Gaulle ständig „mit der Masse gemurmelt“ habe, als er in Ludwigsburg zum ersten Mal vor einem ausländischen Publikum aufgetreten sei. De Gaulle vor einer Masse - das sei ein ganz besonderes Phänomen: Es spräche dann aus ihm heraus - de Gaulle verliere die Kontrolle, wollte Kiesinger damit sagen ${ }^{76}$. Kiesinger glaubte, die rhetorischen Ausbrüche des Franzosen in Quebec wie in Hindenburg seien solche Improvisationen gewesen. Am 25. Juli 1967 hatte der Staatspräsident in einer Rede den französischen Charakter einer kanadischen Provinz beschworen, am Ende Hochrufe auf dieses französische Kanada, das „freie Quebec“ ausgerufen, worauf die kanadische Regierung verärgert reagierte, de Gaulle seine Reise abbrach und nach Paris zurückkehrte. Im Ton vergriffen hatte sich der Präsident auch in Zabrze, dem früheren Hindenburg. Dort behauptete er Anfang September 1967, die Stadt sei die „schlesischste aller schlesischen und daher polnischste aller polnischen Städte“, womit er die Deutschen erzürnte. Die Bundesregierung wies de Gaulle zurecht: Seit Jahrhunderten sei dieses Gebiet deutsch gewesen! Der französische Staatspräsident habe sich wegen des rhetorischen Ausbruches in Hindenburg zweimal entschuldigt, hieß es später, nachdem Kiesinger ihn brieflich auf den Fehler hingewiesen habe. Die Tatsache der Entschuldigung wertete der Kanzler als Indiz dafür, daß die Masse de Gaulle zu seiner Aussage verführt habe.

Auch de Gaulle beobachtete seinen Gast, insbesondere das Verhältnis des Kanzlers zu seinem Außenminister. Am Abend des 13. Januar tauschte man beim ersten Zusammentreffen im Elysee-Palast zunächst Komplimente aus. Kiesinger sagte schmeichelnd, verglichen mit de Gaulles souveräner Art, politische Probleme zu behandeln, sei er selbst ein Anfänger. Der Franzose antwortete galant: „Wenn Sie so gut anfangen, wo werden Sie in vierzehn Jahren sein!“ Er spielte auf die Dauer der Regierungszeit Adenauers an. Intern fiel sein Urteil zurückhaltender aus, wie der französische Botschafter François Seydoux berichtet: „Seiner Umgebung sagte allerdings der General, er habe den Eindruck, daß sich Kanzler und Außenminister zwar gut verständen, doch die Entspannung oder vielmehr deren Tempo nicht im selben Lichte sähen: Kiesinger wünsche sie sich langsamer, Brandt schneller. Hierin läge wahrscheinlich eine Quelle zukünftiger Konflikte. Dieser schlummernde Gegensatz rate zur Vorsicht." 7

\section{Zweideutige Bilanz}

Trotz des freundlichen, herzlichen Empfangs, den Kiesinger durch de Gaulle erhielt, war die Bilanz der drei persönlichen Gespräche zwischen dem Staatspräsidenten und dem Kanzler im Elysee-Palast eher mager. Kiesinger betonte im Anschluß zwar, daß vor allem Geist und Inhalt des deutsch-französischen Vertrages und die Kooperation auf außenpolitischem Gebiet „wirklich einen guten Schritt nach vorn gemacht“ hätten. Der Vertrag sei wiederbelebt worden ${ }^{78}$. Aber wer genau hinschaute, konnte erkennen, daß in den allermeisten Fragen Differenzen vorherrschten. Das galt gerade auch für den Bereich der Außenpolitik, den die neue deutsche Regierung als gemeinsame Basis herauszustellen

\footnotetext{
${ }^{76}$ AdKASt, Kiesinger I - 226, D/II.1, A 008, Gespräch mit Wirsing, 5.10.1967, S. 9.

7 Seydoux, Botschafter, S. 97.

${ }^{78}$ BPA, Kiesinger im SWF, 15.1.1967, Anhang II, S. 1.
} 
versucht hatte: die Ostpolitik. Schon nach dem ersten Tag formulierte Kiesinger vorsichtig die unterschiedlichen Standpunkte: „Für Frankreich sieht die europäische détente, entente et coopération - um eine Formel General de Gaulles zu gebrauchen - natürlich leichter aus als für uns; denn für uns muß ja diese Entente schon einschließen jenen Prozeß der Wiedervereinigung, der in irgendeiner Weise synchronisiert sein muß mit dieser Détente, die wir zusammen mit Frankreich durchführen wollen." Einen Fahrplan dafür gebe es nicht. Man sei nüchtern und realistisch, aber man sehe auch keinen anderen Weg, um beides zu bewahren und zu erreichen: „Den Frieden, auf den wir nicht verzichten können, und die Lösung der deutschen Frage, auf die wir nicht verzichten wollen. “79

Kiesinger sorgte sich um die Frage, wie die Wiedervereinigung als Ziel einer Entspannung erreicht werden könne. Für ihn hatte das entscheidende Problem der Ostpolitik bisher in der Tatsache bestanden, daß die Sowjetunion eine Wiedervereinigung selbst für den Fall nicht in Aussicht stellte, daß sich die deutsche Politik ihr gegenüber radikal änderte. Für Moskau zählte nur die Anerkennung der polnischen Westgrenze und des Status quo in Europa. Darüber hinaus wollten die Sowjets die Deutschen vom Besitz der Atomwaffen ausschließen. Eine Ostpolitik, wie sie sich de Gaulle vorstellte, schien für die Bundesregierung vor diesem Hintergrund unrealistisch.

Aus vielen Gründen befand sich die französische Regierung aber in einer besseren Lage als die Bundesregierung. Man sei im Ziel einig, erklärte Kiesinger in Paris. Aber für Frankreich sei das natürlich alles viel leichter. Frankreich habe keine unmittelbaren Probleme mit den osteuropäischen Ländern. Deutschland dagegen habe „diese Probleme, all die ungelösten Probleme, die wir als Erbe einer vergangenen Zeit haben übernehmen müs-

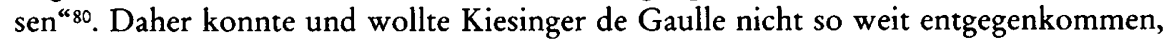
wie es der Franzose erwartete, erhoffte. Der Kanzler war nicht bereit, die Anerkennung der Oder-Neiße-Linie zu versprechen oder vor einem Friedensvertrag in Aussicht zu stellen. Das war aber nicht der einzige Bereich in der Außenpolitik, in dem die Kooperationsmöglichkeiten beschränkt blieben. So fand sich beispielsweise im Rüstungssektor kein Ansatzpunkt für die angestrebte Zusammenarbeit - auf Grund anderweitiger deutscher Verpflichtungen. Die Neue Zürcher Zeitung kommentierte: Bonn sei auf diesem Gebiet, das einmal als Kernstück gemeinsamen Handelns gedacht war, zu stark auf Washington ausgerichtet und durch Waffenbestellungen in den USA festgelegt. Es bleibe kein großer Spielraum für neue Abmachungen mit Frankreich ${ }^{81}$. Besonders diese Tatsache mußte auf de Gaulle ernüchternd wirken. Er hatte die enge Verbindung der Deutschen zu den Amerikanern durch ein noch engeres Verhältnis zwischen der Bundesrepublik und Frankreich ersetzen wollen.

Der amerikanische Einfluß auf die Bundesrepublik stand auch bei den anderen umstrittenen Problemen zwischen Deutschen und Franzosen im Mittelpunkt. Neben den Rüstungsgütern, die die Bundesregierung in großem Umfang als Ausgleich für die amerikanischen Truppenstationierungskosten in den USA bestellen mußte, konnte auch in der Frage des Währungssystems und der von Frankreich propagierten Einführung des Goldstandards zwischen den beiden Ländern keine Einigung erzielt werden. De Gaulle verfolgte das Ziel, die amerikanische Reservewährung, den Dollar, durch Gold zu ersetzen. Als zweitgrößter Goldbesitzer - Frankreich hatte 1967 5,2 Milliarden Dollar in

\footnotetext{
${ }^{79} \mathrm{BPA}$, Kiesinger für die DW, 14.1.1967, Anhang II a, S. $1 \mathrm{f}$.

${ }^{80}$ Ebenda.

${ }^{81}$ Vgl. Neue Zürcher Zeitung, 14.1.1967.
} 
Gold gehortet - hätte Frankreich in der Währungspolitik, etwa bei der Vergabe von Krediten, im Kreis der anderen europäischen Staaten die führende Position übernommen. Mit Hilfe des Goldes sollte der Glanz der „Gloire de la France“ wieder zurückkehren ${ }^{82}$. Aber die Deutschen dachten anders und unterstützten das Konzept der Franzosen nicht, das sich gegen die Herrschaft des Sterling-Blocks richtete.

Unterschiedliche Standpunkte blieben auch in der Frage des Beitritts von Großbritannien zur Europäischen Gemeinschaft bestehen. De Gaulle lehnte ihn ab, während Kiesinger ihn begrüßte. Der Kanzler teilte nicht die Ansicht des Staatspräsidenten, England suche in Europa allenfalls eine Freihandelszone, aber keine politische Union. Und es blieb zwischen beiden auch umstritten, wie denn das Ziel einer politischen Union des geeinten Europa zu erreichen sei. De Gaulle erklärte Kiesinger, er sei nicht länger geneigt, den deutschen Präsidenten der Europäischen Kommission, Walter Hallstein, in seinem Amt zu bestätigen. Hallstein war ein Befürworter des supranationalen Charakters der Gemeinschaft - ein Gedanke, den der Präsident strikt abgelehnt und sogar boykottiert hatte. Nicht von einem Europa der Technokraten, wie er gegenüber Kiesinger abschätzig formulierte ${ }^{83}$, sondern von einem europäischen Bund der Staaten und Völker erwarte er die Kraft, gemeinsam die Zukunft zu meistern. Monsieur Hallstein solle in Ruhe seine Weihnachtsgans zu Hause verzehren, erklärte daher der Staatspräsident ${ }^{84}$.

So überwogen die Meinungsunterschiede zwischen beiden Regierungen. Die Deutschen hatten es sich zur Aufgabe gemacht, den deutsch-französischen Vertrag wiederzubeleben. Doch selbst bei allem guten Willen war nicht zu übersehen, daß beide Staatschefs mehr trennte als nur unterschiedliche Ansichten zu einigen Fragen. Es verwundert daher, daß die Bekenntnisse zu einer vertieften Zusammenarbeit in der Entspannungspolitik nur von wenigen Beobachtern skeptisch kommentiert wurden. In einem Heft der angesehenen Zeitschrift Europa-Archiv kam der Generalsekretär des Centre d'Études de Politique Étrangère in Paris, Jacques Vernant, zu dem Schluß, der Besuch Kiesingers habe den Willen bekräftigt, den deutsch-französischen Beziehungen „die Vertraulichkeit und Bedeutung - wenn nicht den Vorrang“ - wieder zurückzugeben. Und der Bonner Völkerrechtler Ulrich Scheuner meinte, es sei in der Bundesrepublik mit Befriedigung aufgenommen worden, daß künftig dem Verhältnis zu Paris in der deutschen Außenpolitik ein besonderer Platz eingeräumt werde ${ }^{85}$. Lediglich die Neue Zürcher Zeitung blieb in ihrer Kommentierung skeptisch: Es herrsche in Paris der Eindruck vor, daß die Politik der neuen deutschen Regierung noch der Formung bedürfe. De Gaulle wolle zwar an diesem Prozeß mitwirken. „Bei der praktischen Anwendung dieser Politik könnten allerdings wieder alte oder auch neue Gegensätze zwischen der Bundesrepublik und Frankreich hervortreten." 86

\section{De Gaulle und Kiesinger: Zwei unterschiedliche Konzeptionen}

Nie ist der Unterschied in den politischen Auffassungen der beiden Regierungschefs so deutlich geworden wie durch Kiesingers Beschreibungen der Vier-Augen-Gespräche bei diesem Besuch. Es existieren zwei Quellen, einmal das Hintergrundgespräch mit Gisel-

\footnotetext{
${ }^{22}$ Schellhaaß, Internationale Währungsprobleme, S. 456.

${ }^{83} \mathrm{Vgl}$. Kiesinger, So war es, IV, 8.12.1974.

${ }^{84}$ Vgl. Stamp, Gespräch mit dem Verfasser, 30.11.1987; siehe auch Der Spiegel, 15.5.1967, S. 28.

${ }^{85}$ EA 22 (1967), Folge 5, S. 157 und 165.

${ }^{86}$ Neue Zürcher Zeitung, 14.1.1967.
} 
her Wirsing vom Oktober $19677^{87}$; zum anderen sind einige Artikel vorhanden, die Kiesinger im Jahre 1974 als Altbundeskanzler für Bild am Sonntag verfaßt hat, wobei offensichtlich Notizen und Protokolle als Grundlage dienten ${ }^{88}$. Beide Beschreibungen ergänzen sich, aber in den Schlußfolgerungen, die hier interessieren, verrät die Rückschau von 1974 genauer, wo sich beide Staatsmänner im Denken unterschieden. Zunächst die Darstellung der Gespräche, wie sich Kiesinger nach fünf Jahren erinnerte:

General de Gaulle begann mit der Werbung für seine Idee einer gemeinsamen Außenpolitik unter Führung Frankreichs. Dabei verwies er auf sein Angebot: Frankreich setze sich für die Wiedervereinigung beider deutscher Staaten ein. „Die Franzosen kennen die Qualitäten des deutschen Volkes und fühlen sich zu ihm hingezogen“, sagte er wörtlich. „Nachdem wir das Stadium der Feindschaft überwunden hätten, gebe es für die beiden Länder ganz besondere Gründe, miteinander auf gutem Fuß zu stehen, ja Bande zu knüpfen, die stärker seien als mit irgendeinem anderen Volk. Frankreich wolle Deutschland freilich nicht wiedersehen in der Gestalt des Hitlerreiches mit übertriebenen Ambitionen in bezug auf Grenzen und Waffen. Aber es wisse, daß es, um des Friedens willen und wenn es mit Deutschland auf lange Sicht in großem Stil zusammenarbeiten wolle, sich der deutschen Einheit nicht widersetzen könne. Frankreich, so sagte er eindringlich, will Deutschland vereinigt sehen."

Zwar wollten die Russen zu diesem Zeitpunkt davon noch nichts wissen. Sie hätten im Gegenteil vor, die Spaltung aufrechtzuerhalten. Aber sie wüßten, daß dies nicht immer so bleiben könne. Wenn Frankreich und Deutschland mit dem Osten auf eine echte politische Entspannung hinarbeiteten, würde der Osten allmählich seinen Widerstand aufgeben, Kontakt suchen und von Deutschland jenen Nutzen zu gewinnen trachten, den er insbesondere im wirtschaftlichen Bereich erwarten könne. „Immer wieder versicherte mir der General später dasselbe“, betont Kiesinger. Er habe es auch den Russen in Moskau gesagt. Der Tag werde kommen, an dem die Bundesregierung die Oder-NeißeLinie als endgültige Grenze Polens anerkennen müsse. Aber bei der friedlichen Rückgewinnung der Einheit des deutschen Volkes hätten die Deutschen „keinen verläßlicheren Verbündeten als Frankreich, vielleicht [...] den einzigen, der sie ehrlich wolle und nicht nur Lippendienste leiste“"

Dann sprach de Gaulle von dem, was die Bundesrepublik für den gemeinsamen Kurs zu tun habe. Er forderte eine „fundamentale Unabhängigkeit“ von den Vereinigten Staaten - wie „eh und je“, merkt Kiesinger gelangweilt an. Frankreich wolle keine amerikanische Hegemonie, also keine atlantische Integration, weder militärisch noch politisch, noch wirtschaftlich. Die Bundesrepublik habe sich zu leicht mit dieser Abhängigkeit abgefunden, kritisierte de Gaulle, selbst unter Adenauer.

Kiesinger sah das anders. Zwar wolle auch die Bundesrepublik kein Satellit Amerikas sein. Aber ohne den Schutz dieses mächtigen Landes und ohne die Anwesenheit seiner Truppen in Europa seien die Deutschen schutzlos gegenüber der Sowjetunion, widersprach der Kanzler. De Gaulle ließ dieses Argument nur teilweise gelten. „Nicht der Wodka, sondern der Whisky erobert die Welt“", erklärte er Kiesinger. Mit ihren Ideen seien die Russen überhaupt nicht mehr im Vormarsch, sondern auf einem Rückzug. Aber er, de Gaulle, gebe zu, daß die russische Armee und ihre Atomrüstung nach wie vor eine erhebliche Drohung für Europa darstellten. Deshalb werde er auch aus der politischen

\footnotetext{
${ }^{87}$ Vgl. AdKASt, Kiesinger I - 226, D/II.1, A 008, Gespräch mit Wirsing, 5.10.1967.

${ }^{88}$ Vgl. Kiesinger, So war es, I-IV, in: Bild am Sonntag, 17.11.-8.12.1974.

${ }^{89}$ Kiesinger, So war es, IV, 8.12.1974.
} 
Organisation der Nato nicht ausscheiden. Der Kanzler deutete dem Staatspräsidenten an, daß „sein übertriebener Antiamerikanismus für uns eine unerträgliche Lage schafft“. De Gaulle gab dies zu, erwiderte aber, das französische Volk sei in einer so miserablen Verfassung gewesen, daß er ein weiteres Ansteigen des Atlantismus und Amerikanismus in Frankreich nicht habe dulden können. Diese Bemerkung sei wobl als deutliche Spitze gegen die europäischen Pläne Jean Monnets gedacht gewesen, meinte Kiesinger gegenüber dem Journalisten Wirsing90.

Der Kanzler zeigte sich vor allem beeindruckt von den skeptischen Worten, die de Gaulle gebrauchte, wenn er auf den Zustand Frankreichs vor seiner Zeit als Staatspräsident zu sprechen kam. Ihm blieb der Begriff „mépris“ in Erinnerung. Frankreich sei sehr schlecht in Form gewesen, es habe sich in einem verachtenswerten Zustand (mépris) befunden ${ }^{91}$. Andererseits hatte de Gaulle Kiesinger deutlich zu verstehen gegeben: Frankreich sei abgesunken, aber es könne wieder emporsteigen, wenn es gelänge, ein einiges Europa zu schaffen, dessen Herz wiederum Frankreich sein würde. „Er sagte dies nicht mit dürren Worten, aber ich weiß, daß er es meinte und erhoffte. Die Franzosen müßten nur groß genug sein, dies zu wollen, und die Deutschen müßten erkennen, daß es keinen anderen Weg für Europa gäbe“, faßt Kiesinger in dem Artikel zusammen.

Dem deutschen Kanzler machte der General damit klar, daß Frankreich in einem gemeinsamen Europa den Mittelpunkt bilden werde. Auch die Deutschen müßten das akzeptieren. Nur über Europa könne Deutschlands Einheit erreicht werden. Nur über Europa könne die Bundesrepublik ihr staatspolitisches Ziel verwirklichen. Dieses Europa gäbe es nur gemeinsam mit Frankreich, unter Frankreichs Führung. Aber der Bundeskanzler zeigte keine Bereitschaft, auf den Vorschlag des Staatspräsidenten einzugehen ${ }^{92}$. Er schien nicht einmal verstanden zu haben, daß sich die Bundesrepublik nach dem Willen de Gaulles Frankreich unterordnen sollte - zumindest weigerte sich Kiesinger, diesen Gedanken ernsthaft in Erwägung zu ziehen. „Ich empfand die Warnungen vor einer möglichen französischen Hegemonie als lächerlich und verstand den General durchaus, wenn er uns, die wir an Bevölkerung und an Wirtschaftskraft Frankreich überlegen waren, vor, übertriebenen Ambitionen in bezug auf Waffen und auf Grenzen 'warnte. " Diese Aussage konnte doch nur bedeuten, daß Kiesinger glaubte, in einem deutsch-französischen Bündnis werde die Bundesrepublik mit ihrer größeren Bevölkerungszahl und stärkeren Wirtschaftskraft ein Übergewicht Frankreichs verhindern. Und der General warnte vor dem Versuch, eine deutsche Vorherrschaft in Europa zu begründen. Eine Rückkehr zur Großmacht Deutschland wollte allerdings auch Kiesinger nicht, denn nichts habe ihm ferner gelegen, als „für Deutschland in einem geeinigten Europa die führende Rolle anzustreben“. Er sah deutlich, daß nichts sicherer die Einigung Europas verhindert hätte, als „wenn wir wegen solcher Pläne hätten verdächtigt werden können“. Zu schwer habe die Last der jüngsten Geschichte gewogen, der Wahnsinn einer nationalistischen Politik, die eine Flut von Elend über die Deutschen und über einen großen Teil der Welt gebracht hätte. Er habe daher während seiner Regierungszeit jede Kraftmeierei, jede Geste des „Wir sind wieder wer!“ sorgfältig vermieden.

${ }_{90} \mathrm{Vgl}$. AdKASt, Kiesinger I - 226, D/II.1, A 008, Gespräch mit Wirsing, 5.10.1967, S. 9.

${ }^{91}$ Kiesinger, So war es, IV, 8.12.1974; dort heißt es allerdings, de Gaulle habe für das Frankreich von 1958 das Wort „abimée “ [zugrunde gerichtet, verdorben] gebraucht.

${ }_{92}$ Vgl. Hildebrand (Erhard, S. 317), der zwar zu Recht darauf hinweist, daß Kiesinger sich dem Angebot de Gaulles "geschickt" entzogen habe. Der Historiker beschreibt allerdings einen vordergründigen Teil der Motivation des Kanzlers und gewichtet dabei den individuellen Hintergrund geringer, vor dem Kiesinger das Konzept des Franzosen betrachtete und ablehnte. 


\section{Kiesingers politische Weltanschaunng}

Ähnlich wie de Gaulle dachte auch Kiesinger in den Kategorien des 19. Jahrhunderts. Auch er glaubte an die Kraft der Nationalstaaten und an ihr Zusammenspiel: das Konzert der Mächte. Ein geeintes Europa war für ihn nur als Zusammenschluß souveräner Nationen vorstellbar. Er sah Deutschland als Teil des zukünftigen Europa, als einen europäischen Staat unter vielen. Zwar würde Deutschland keine Vorherrschaft anstreben, aber es mußte rehabilitiert werden. Es erhob den Anspruch auf eine den anderen Staaten ebenbürtige Position. Im Grunde wollte der neue Kanzler die Fortsetzung von Bismarcks Reich - ohne die östlichen Territorien, aber mit dem Gebiet der DDR. Die Identität der deutschen Nation sollte nicht in einem europäischen Einheitsstaat aufgehen, sondern mußte erhalten bleiben. Diese Distanz zum einheitlichen Europa, in dem alle Nationalstaaten aufgehen sollten, hat er frühzeitig entwickelt. „Als ich als einer der Europabegeisterten gleich von Anfang an mich umsah, da hat mich eines manchmal unheimlich berührt, nämlich die Sucht mancher Deutschen, mancher europabegeisterten Deutschen in dieser Flucht nach Europa in ein anonymes, vages Europa hinein ihre nationale Identität zu verlieren, aufzugeben", bekannte Kiesinger am Beginn seiner Kanzlerschaft ${ }^{9}$. Das sei eine gefährliche Entwicklung gewesen. Nach wie vor habe die Nation den Kern der staatlichen Gemeinschaft gebildet. Daher brauchte die Republik das Bekenntnis zur deutschen Nation. „Wir leben nun einmal in einer Welt der Nationen und müssen in dieser Welt unseren Platz, den uns gebührenden Rang, mit Würde und Entschiedenheit zu finden versuchen ", erklärte er Klaus Harpprecht ${ }^{94}$.

Es ist kein Zufall, daß Kiesinger sich hier eines Wortes de Gaulles bediente. Frankreich mochte mit den Ergebnissen der beiden Weltkriege seinen „Rang“ eingebüßt haben, aber Deutschland hatte alles verloren, und Kiesinger war diese Tatsache nicht gleichgültig. Um das zu verstehen, ist es sinnvoll, sich den familiären und biographischen Hintergrund des Bundeskanzlers zu vergegenwärtigen. Kiesinger war als Junge nicht in der Tradition der Württemberger aufgewachsen, die jahrhundertelang den Habsburgern näherstanden als den Hohenzollern. Die Familie der Mutter, Domenika Grimm, stammte zwar aus dem Dorf Bubsheim, einem der katholischen vorderösterreichischen Gebiete, aber Kurt Georg nahm die in diesem Teil Deutschlands weitverbreiteten Vorbehalte gegen Preußen trotzdem nicht an. Er mochte von den alten Ressentiments gehört haben, beispielsweise von der Distanz der Württemberger gegenüber Friedrich II., dem der freche Beutezug gegen die österreichische Kaiserin Maria Theresia nie verziehen worden war. Ein solches Geschichtsbild machte auf den jungen Kiesinger aber keinen Eindruck. Dagegen lernte er das von Preußen dominierte, kleindeutsche Reich verehren. „Das deutsche Kaiserreich, so hörten wir es in der Schule und lasen es in den Büchern, war ein mächtiges Land, auf das wir stolz sein durften", heißt es in seinen Erinnerungen". Die Kopfzahl seiner Bevölkerung würde nur von China, Rußland und den Vereinigten Staaten übertroffen. Andere Mächte, so war zu lesen, besäßen freilich viel größere Kolonien, die Franzosen und gar die Briten mit ihren gewaltigen Imperien. Aber auch "unsere“ überseeischen Besitzungen regten die Phantasie des Schülers mächtig an: Deutsch-Südwestafrika, Deutsch-Ostafrika, Kamerun, Togo und die pazifischen Gebiete. Während des Ersten Weltkrieges spielte der Elfjährige einen begeisterten Patrioten. Mit einer kleinen Gruppe von Knaben, einer „Kompanie“, die er anführte, zog er durch den Geburtsort

\footnotetext{
${ }^{93}$ BPA, Kiesinger im ZDF, 5.1.1967, Anhang I, S. 11 (Gespräch mit Harpprecht).

${ }^{94}$ Ebenda.

${ }^{95}$ Kiesinger, Jahre, S. 35.
} 
Ebingen mit schwarz-weiß-roter Fahne. „Der Letzte mit vier oder fünf Jahren wackelte hinterher", erinnert er sich später. „Einer hatte eine Trommel, der andere eine Flöte, und wir sangen dann, O Deutschland hoch in Ehren' mit dem Refrain ,Haltet aus, haltet aus im Sturmgebraus' " "96

Als der Erste Weltkrieg verlorenging, stürzte auch für Kiesinger eine Welt zusammen, „denn ich hatte bis zuletzt an die gute Sache und an den Sieg Deutschlands geglaubt“. Die Niederlage konnte die Treue zu Bismarck, dem Reichsgründer, nicht erschüttern. Als Student in Tübingen zog er jedes Jahr zum Bismarckturm hinauf, „um bei loderndem Feuer den Reichsgründer zu feiern "97. Besonders beeindruckend verlief für Kiesinger der Besuch im Berliner Palais des Reichskanzlers im Jahre 1927. Der damalige Reichskanzler Wilhelm Marx hatte einige Mitglieder seiner alten Studentenverbindung Askania in das Palais in der Wilhelmstraße eingeladen. „Da ich damals Senior der Askania war, erhielt ich vom Reichskanzler einen Ehrenplatz angewiesen: den Stuhl, auf dem einst Bismarck gesessen habe. "98

Die Bewunderung für Bismarck hielt an. Seine Nachfolger hätten das Deutsche Reich zugrunde gerichtet, behauptete Kiesinger im Januar 1967. Sie seien einfach mit dem Phänomen dieses Reiches und seiner Eingliederung in ein europäisches Mächtekonzert nicht fertig geworden. Anders als der Gründer: „Er hat es noch gemeistert, und ich bin auch überzeugt, er hätte es auch noch meistern können. " 99 Der Reichsgründer habe gewußt, was selbst die Paulskirche 1848 völlig vergessen hatte, daß die deutsche Verfassung immer eine europäische Angelegenheit gewesen sei. Nur eine außergewöhnliche Gunst der Umstände konnte es den Deutschen erlauben, ihr Schicksal in die eigene Hand zu nehmen, schreibt Kiesinger in seinen Memoiren ${ }^{100}$.

Diese Erkenntnis galt auch für die Bundesrepublik. Ohne die Zustimmung der anderen Staaten Europas und der Welt konnte Deutschland die Einheit nicht erreichen. Man mußte wieder von vorn beginnen, um Vertrauen werben und eine günstige Lage in Europa abwarten. Kiesinger verglich die Bundesrepublik mit Preußen nach der Niederlage von Jena und Auerstedt. In einem Gespräch zu Beginn seiner Kanzlerschaft erklärte er, der außenpolitische Spielraum Bonns sei verhältnismäßig klein geworden - „Ich erinnere an Preußens Fall und Aufstieg zwischen 1806 und 1813." ${ }^{101}$ Der Vergleich klingt bei aller Abschwächung und Vorsicht interessant. Das Territorium Preußens war nach der katastrophalen Niederlage gegen Napoleon, in der schwächsten Phase seit der Erlangung des Großmachtstatus in Europa, auf die Hälfte reduziert worden. Die gesamten westelbischen Territorien gingen verloren, ferner Westpreußen und die ehemalig polnischen Gebiete.

Mit umgekehrtem Vorzeichen muß man sich die Konstellation nach dem Zweiten Weltkrieg denken. Spekulativ könnte man behaupten, daß die Amerikaner 1945 die Rolle Rußlands für Preußen 1807 übernahmen. Rußland bildete das Gegengewicht zu Frankreich. Nur das Zarenreich, in einer Funktion wie die Vereinigten Staaten eineinhalb Jahrhunderte später gegenüber der Sowjetunion, konnte dem Expansionismus des napoleonischen Frankreichs Einhalt gebieten. Wenn man die - zugegeben nur halb treffende Analogisierung - fortsetzen wollte, taucht die Frage auf, ob sich de Gaulles' Frankreich und

\footnotetext{
${ }^{96}$ Kiesinger, Fügung und Verantwortung, S. 12.

${ }^{97}$ Kiesinger, Jahre, S. 88.

${ }_{98}$ Ebenda, S. 102.

${ }^{99}$ BPA, Kiesinger im ZDF, 5.1.1967, Anhang I, S. 11.

${ }_{100}$ Vgl. Kiesinger, Jahre, S. 89.

101 BPA, Kiesinger im ZDF, 5.1.1967, Anhang I, S. 13.
} 
die Rolle Österreichs unter dem Außenminister und späteren Staatskanzler Klemens Fürst von Metternich vergleichen lassen. Tatsächlich lag in de Gaulles' Streben nach einer europäischen Einheit vom Atlantik bis zum Ural etwas von den Gleichgewichtsvorstellungen Metternichs. Der Fürst verfolgte nicht die Vernichtung Napoleons und der Macht Frankreichs, sondern seine Unterordnung in ein europäisches System ausbalancierter Einflußzonen ${ }^{102}$. De Gaulle war wie Metternich an einem Gleichgewicht in Europa interessiert. Während der Österreicher den Kontinent in Einflußzonen von fünf Großmächten aufteilen wollte, dachte der Franzose an ein Gleichgewicht von Nationalstaaten, wobei Frankreich im Westen Europas, die Sowjetunion im Osten jeweils die Führungsposition einnehmen sollte.

Ein Vergleich der innenpolitischen Lage zwischen dem Preußen der napoleonischen Zeit und der Bundesrepublik läßt sich ebenfalls nur oberflächlich durchführen. Die Niederlage hatte die inneren Schwächen des preußischen Systems offenbart und damit den Weg geebnet für den Reformprozeß Steins und Hardenbergs. Die Gefährdung der Bundesrepublik im Innern lag woanders. Preußen hatte damals einen Krieg verloren, aber sein Regierungssystem behalten. Das war bei der Entstehung der Bundesrepublik anders. Kiesinger verglich Bonn mit der Weimarer Republik. Weimar sei an der fehlenden Unterstützung seiner parlamentarischen Demokratie durch die Mehrheit der politischen Kräfte zugrunde gegangen. Kiesinger sah 1967 diese Gefahr auch für die Bundesrepublik heraufziehen. Anlaß war der plötzliche Erfolg einer national-konservativen Partei, der NPD, die in einigen Ländern der Republik große Stimmengewinne für sich verbuchen konnte ${ }^{103}$. In Bayern hatte sie die FDP bereits aus dem Landtag gedrängt. Zur gleichen Zeit begann sich auf der linken Seite die studentisch geprägte Außerparlamentarische Opposition unter sozialistischem Vorzeichen zu formieren. Kiesinger glaubte hier eine Entwicklung zu beobachten, die der von Weimar ähnlich war. „Auch da weht[e] natürlich der Geist, wo er [wollte]. Und damals wäre ja diese gewaltige Entwicklung in den wenigen Jahren nicht möglich gewesen ohne das, was eben in der Zeit selbst an mächtigen Impulsen vorhanden war. “104 Mit den "mächtigen Impulsen“ meinte Kiesinger den Nationalsozialismus, der die schwachen und eingeschüchterten bürgerlichen Kräfte der Weimarer Republik überspielen konnte. Auch in der Bundesrepublik - so fürchtete Kiesinger - könnten beide Entwicklungen an den rechten und linken Rändern des politischen Spektrums der Bundesrepublik eine neue, verhängnisvolle Bewegung vorbereiten. Es gehe darum, sagte der Kanzler im Januar 1967, daß auch von seiten der Politik eine geistige Erneuerung des politischen Bewußtseins betrieben und gefördert werde. Das geistige Fundament der demokratischen Ordnung müsse gestärkt werden, damit der Fanatismus sie nicht wieder mit sich fortreißen könne.

Seiner Furcht, daß die Menschen des modernen Zeitalters durch die Ideologie vereinnahmt werden könnten, setzte Kiesinger eine Hoffnung entgegen: Der Staat müsse dafür

102 Vgl. Kissinger, Das Gleichgewicht.

${ }^{103}$ Bei der Wahl zum 5. Deutschen Bundestag am 19.9.1965 erzielte sie zwar nur $2 \%$ der Stimmen, und im März 1966 waren es bei den Hamburger Bürgerschaftswahlen noch 3,9\%. Aber am 6.11.1966 konnte die NPD in Hessen schon 7,9\% gewinnen und erstmals mit 8 Mandaten in einen Landtag einziehen. Bei den folgenden Landtagswahlen erreichte sie in Bayern 7,4 \%, in Berlin $7,1 \%$, in Schleswig-Holstein 5,8 \%, in Rheinland-Pfalz 6,9\%, in Niedersachsen 7,0\%, am 1.10.1967 in Bremen 8,8 \% und schließlich am 28.4.1968 in Baden-Württemberg 9,8 \%. Bei den Bundestagswahlen am 28.9.1969 scheiterte sie knapp mit 4,3 \%. Dieses Ergebnis leitete den Niedergang ein.

${ }^{104} \mathrm{BPA}$, Kiesinger im ZDF, 5.1.1967, Anhang I, S. 13. 
sorgen, daß die individuellen Fähigkeiten jedes Menschen ausgebildet würden. Das Individuum brauche die Freiheit, sich selbst kulturell zu vollenden. Die höchste Stufe der Entwicklung habe übrigens Frankreich erreicht. Frankreich war ihm daher ein Vorbild in der Ausbildung von höfischen und höflichen Formen ${ }^{105}$. Nur in der Schaffung des Individuums und seiner Verankerung in der Demokratie könnten die Nachteile und Gefahren der Massengesellschaft ausgeglichen und vermindert werden. Kiesinger selbst versuchte, nach diesem Ideal zu leben. Von seinen Mitarbeitern forderte er Verständnis für das Lyrische und Kenntnisse der Lyrik. Die politischen Berater in Stuttgart waren gehalten, Gedichte auswendig zu kennen und gelegentlich aufzusagen. Wer gar Hölderlin zitierte, konnte des Beifalls des Ministerpräsidenten sicher sein. Und die Poesie war nur ein Teil der umfassenden Bildung, die in der Nähe Kiesingers erwünscht, wenn nicht verlangt wurde. Kiesinger fragte die Mitarbeiter nach Daten und Fakten der Literatur und Geschichte sowie der Geologie ab. „Hölderlin oder Mörike-Gedichte mußte man kennen“, berichtet ein enger Mitarbeiter, „sogar Erdformationen, den Trias, Keuper, Buntsandstein - wie eine solche Landschaft aussah, das mußte man wissen, das wurde abgefragt und gefordert." ${ }^{106}$

Die Aufgabe der Außenpolitik und ihre Bedeutung für Kiesinger wird nur vor dem Hintergrund des innenpolitischen Zieles verständlich. Und im Mittelpunkt seiner Außenpolitik stand die Beziehung zu Frankreich. Ein möglichst ungetrübtes, gutes Verhältnis zwischen Bonn und Paris sah Kiesinger als Voraussetzung für seine Strategie an, die zur Wiedervereinigung Deutschlands führen sollte. Gegen den Willen der französischen Regierung konnte die Bundesregierung nicht erfolgreich sein. Daher maß er dem ersten Staatsbesuch in Paris besondere Bedeutung bei. Daß beide Staatsmänner sich grundsätzlich in ihren Auffassungen und Plänen unterschieden, wurde unmittelbar nach dem Besuch noch nicht deutlich. In der Historiographie ist dieses erste Treffen daher frühzeitig als Zeichen der Verbesserung des deutsch-französischen Verhältnisses gewertet worden, wenn auch zunächst nur im ,atmosphärischen“ Bereich ${ }^{107}$.

\section{Nach dem Staatsbesuch: Hoffnungen für die Ostpolitik, aber keine positive Reaktion aus Moskan}

Der Bundeskanzler war bemüht, die positive Seite, seinen Willen zur Verbesserung der Beziehungen, herauszustreichen. Frankreich, so hoffte Kiesinger, werde als Vermittler in Moskau und den Hauptstädten der osteuropäischen Staaten auftreten. Diese Zusicherung hatte der französische Staatspräsident dem Bundeskanzler gegeben. Das Verhältnis zu de Gaulle habe sich nicht nur im atmosphärischen Bereich gebessert, verkündete Kiesinger daher bei der ersten großen Pressekonferenz in Bonn, wenige Tage nach

${ }^{105}$ Vgl. Rundel, Gespräch mit dem Verfasser, 6.8.1989.

${ }^{106}$ Ebenda. „Wenn man ein Hölderlin-Gedicht wußte, war man schon fein heraus!“

${ }^{107}$ Grosser, Außenpolitik, S. 231; Besson (Außenpolitik, S. 402 und 374 f.) stellt fest, daß das „Klima des Verkehrs" freundlicher geworden sei. Der im Zeichen einer gemeinsamen Ostpolitik stehende neue deutsch-französische „Frühling" habe aber einige „handfeste Mißverständnisse“ enthalten. Hildebrand (Erhard, S. 315) meint, was die Atmosphäre zwischen Paris und Bonn angehe, sei man im Vergleich zur Erhard/Schröder-Ära besser miteinander ausgekommen. „Freilich hatte ,der freundliche Realismus der Regierung Kiesinger/Brandt' kaum mehr etwas mit der herzlichen Exklusivität des deutsch-französischen Verhältnisses in der Adenauer-Zeit zu tun. " Dem Werben de Gaulles um ein politisches Zusammenwirken zwischen Bonn und Paris habe sich die neue Regierung geschickt entzogen. 
seiner Rückkehr. Dennoch waren die Reaktionen Moskaus auf die Signale aus Bonn alles andere als ermutigend. Kaum zwei Wochen nach Kiesingers Rückkehr erhielt die Bundesregierung eine Note der Sowjetunion mit dem polemischen Titel: „Erklärung über den Nazismus und Militarismus in der Bundesrepublik Deutschland“. Der Kreml wollte in Westdeutschland den Geist des Nationalsozialismus ausgemacht haben. In der Note hieß es, in vielen Städten würden Kundgebungen, Demonstrationen und Fackelzüge veranstaltet, die an die Naziaufmärsche der dreißiger Jahre erinnerten. Die Mitglieder der NPD seien „alle vom Geiste des offenen Chauvinismus, der Revanchegier, der Eroberung fremder Territorien sowie dem Bestreben durchdrungen, das Dritte Reich wiederherzustellen und es zum ,ersten Staat Europas' zu machen“. Eine Warnung am Schluß fehlte nicht: Die Sowjetunion sei bereit, „entsprechend den aus dem Potsdamer Abkommen und anderen internationalen Abkommen erwachsenden Verpflichtungen, erforderlichenfalls gemeinsam mit anderen friedliebenden Staaten, alle Maßnahmen zu treffen, die sich aus der Situation ergeben" ${ }^{108}$.

Die Schärfe des Tons der sowjetischen Note kam nicht überraschend. Seit der Diskussion im Jahr 1963 um eine mögliche multilaterale Atomstreitmacht der Nato warf die Sowjetregierung in öffentlichen Erklärungen und Noten der Bundesregierung vor, sie verfolge eine Politik des Revanchismus und des Militarismus. Denn das sogenannte MLFProjekt sah eine Beteiligung der Bundesrepublik vor. In einer Rede erklärte der Erste Sekretär des Zentralkomitees der KPdSU, Leonid Breschnew, beispielsweise im September 1965, man habe es bei der Bundesrepublik mit dem „Hauptzentrum der Reaktion und des Militarismus in Europa, mit dem Hauptverbündeten der aggressiven imperialistischen Kreise der Vereinigten Staaten zu tun“. Unter diesen Umständen gäbe es keine Möglichkeiten für eine fruchtbare Entwicklung der Beziehungen zu Westdeutschland ${ }^{109}$. Lediglich die Antwort auf die schon oben erwähnte Friedensnote der Regierung Erhard vom 25. März 1966 schlug einen versöhnlicheren Ton an. In dieser Note hatte die Bundesregierung erstmals das Angebot eines gegenseitigen Gewaltverzichts unterbreitet, den der Staatssekretär im Auswärtigen Amt, Karl Carstens, bereits auf seiner Moskauer Reise im September 1965 angeregt hatte. Carstens' Besuch stellte den ersten offiziellen Kontakt auf hoher Ebene dar, seitdem Adenauer 1955 in die sowjetische Hauptstadt gekommen war'10.

Kiesinger ließ sich von Ton und Inhalt der Sowjetnote vom Januar 1967 nicht beirren. Es ging ihm um die Verbesserung des Verhältnisses zu den Sowjets. Seine Regierungserklärung war daher als Signal an die Sowjetunion gedacht gewesen. Im außenpolitischen Teil hatte er sie an erster Stelle, noch vor allen Bündnispartnern, genannt, und Kiesinger hoffte, daß Moskau dieses Zeichen günstig aufnehmen werde. Nicht ohne Hintergedanken erwähnte der Kanzler in dieser Erklärung die Reise Adenauers von 1955, an der er als Vorsitzender des Außenpolitischen Ausschusses des Bundestages teilgenommen hatte. Damals habe er zu denjenigen gehört, die mit Nachdruck für die Aufnahme diplomatischer Beziehungen zwischen der Bundesrepublik und der Sowjetunion eingetreten seien ${ }^{111}$.

${ }^{108}$ EA 22 (1967), Folge 5, Erklärung vom 28.1.1967, S. D $111 \mathrm{f}$.

${ }^{109}$ EA 20 (1965), Folge 21, S. D 531.

$110 \mathrm{Vgl}$. ebenda, S. D 484. Ministerpräsident Kossygin sagte vor dem Obersten Sowjet am 3.8.1966:

„Was die Bundesrepublik Deutschland betrifft, so ist die Sowjetunion keineswegs bestrebt, die Bundesrepublik aus dem Kreis der Länder auszuschalten, die wir als Teilnehmer der Festigung der europäischen Sicherheit sehen möchten. "Zu Carstens' Besuch in Moskau siehe Baring, Machtwechsel, S. $225 \mathrm{f}$.

111 Vgl. VdDB, 80. Sitzung vom 13.12.1966, S. 3662, und Diehl, Kiesinger, S. 187. 
Außerdem habe er bei Gesprächen in den mit Sicherheit abgehörten Moskauer Hotelzimmern „stets laut und offen“ seine Meinung gesagt: Deutsche und Russen müßten sich aussöhnen ${ }^{112}$.

Daher wies Bundeskanzler Kiesinger zwar die Vorwürfe mit Entschiedenheit zurück, die die sowjetische Note vom Januar 1967 enthielt, beschwor aber gleichzeitig den guten Willen Moskaus. In einer Festrede anläßlich des zehnten Jahrestages der Rückgliederung des Saarlandes an Deutschland verwahrte sich der Kanzler am 30. Januar in Saarbrücken gegen die Behauptung, kaum ein Tag vergehe ohne nazistische und antisemitische Exzesse. Dieses Land sei offen für die Menschen aus aller Welt, rief Kiesinger aus. Hunderttausende, Millionen Besucher hätten die Gelegenheit, im Unterschied zu den Bürgern manch anderer Länder, die Wirklichkeit zu sehen. Alle diese Menschen rufe er als Zeugen dafür auf, daß die deutsche Wirklichkeit nicht so aussehe wie in der sowjetischen Note beschrieben. Er appelliere an die Sowjetunion, den Friedenswillen der Bundesrepublik ernst zu nehmen ${ }^{113}$. Kiesinger konnte sich nicht vorstellen, daß der Kreml den plötzlich wieder angeschlagenen, unversöhnlichen Ton beibehalten werde. Er halte die Führer der Sowjetunion für zu klug, als daß sie in diesem Augenblick eine solche Politik versuchen würden, meinte er drei Tage später ${ }^{114}$.

Aber Kiesinger täuschte sich. Die wohlwollende, werbende Haltung der Bundesregierung wurde von der anderen Seite nicht erwidert. Die Sowjetunion verhielt sich auch weiterhin diplomatisch keineswegs freundlich gegenüber der Bundesrepublik. Im Gegenzug für die ersten Gewaltverzichtsentwürfe, die das Auswärtige Amt erarbeitet hatte, übergab der sowjetische Botschafter Semjon K. Zarapkin Staatssekretär Klaus Schütz am 7. Februar 1967 eine weitere Note, in der erneut eine Drohung enthalten war: Die Staatsmänner und Politiker der BRD begingen einen "groben Fehler", wenn sie nicht auf die Warnungen hörten, die von der Sorge um den Frieden in Europa diktiert seien, hieß es in der kurzen Erklärung ${ }^{115}$. Das bedeutete: Bonn solle zuerst die Forderungen Moskaus erfüllen, bevor über anderes gesprochen werden konnte. Aber welche?

Seit der Initiative Nikita Chruschtschows für ein internationales Abkommen vom Dezember 1963, dessen Unterzeichner sich verpflichten sollten, auf Anwendung von Gewalt bei territorialen Konflikten zu verzichten, hatte Moskau einen Katalog von politischen Forderungen aufgestellt ${ }^{116}$. Auf diese Weise hofften Chruschtschow und auch seine Nachfolger, die territorialen Eroberungen des Zweiten Weltkriegs abzusichern. Im Februar 1967 verlangte die Sowjetunion daher erstens die Anerkennung der DDR, zweitens die Hinnahme der bestehenden Grenzen in Europa, drittens die Aufgabe des Alleinvertretungsanspruches und schließlich eine Ungültigkeitserklärung des Münchner Abkommens von 1938 von Anfang an (ex tunc) ${ }^{117}$. Falls die Bundesrepublik ihre Beziehungen zur Sowjetunion verbessern wolle, solle sie zuerst diese Bedingungen erfüllen.

Aber nur zwei Tage nach der Übergabe dieser Forderungsliste, am 9. Februar 1967, wurde deutlich, worauf es der sowjetischen Regierung neben den erwähnten Bedingungen in erster Linie ankam: auf die Unterzeichnung des Atomsperrvertrages durch die Bundesregierung. Während einer Pressekonferenz sagte Ministerpräsident Alexej Kos-

\footnotetext{
112 Der Spiegel, 6.2.1967, S. 15.

113 Vgl. Bulletin, 2.2.1967.

114 Vgl. Bulletin, Kiesinger im DLF am 3.2.1967, 8.2.1967.

115 DzD, 1966-1967, S. 484.

116 Vgl. EA 19 (1964), Folge 2, Schreiben an Erhard vom 31.12.1963, S. D 23-32.

117 Vgl. EA 22 (1967), Folge 6, Note der sowjetischen Regierung vom 7.2.1967, S. D $119 \mathrm{f}$.
} 
sygin in London zum Thema: „Was die BRD betrifft, so muß ich sagen, daß sie sich dem Kernwaffensperrvertrag anschließen muß, ob sie will oder nicht." "118 Das waren verletzend offene Worte. Auch der von der Bundesregierung anschließend über den Botschafter Moskaus angeforderte offizielle Wortlaut versuchte nicht, die Deutlichkeit der Aussage Kossygins zu verschleiern. Der Bonner Pressesprecher Ahlers gab am 13. Februar den von Moskau an die Bundesregierung übermittelten Text öffentlich bekannt: „Was die Bundesrepublik anlangt, so muß ich sagen, daß, unabhängig davon, ob sie dazu gewillt ist oder nicht gewillt ist, sie sich dem Atomstoppabkommen wird anschließen müssen."

Diese Aussage löste eine heftige Diskussion in der Bundesrepublik über Ziel und Zweck des Nichtverbreitungsvertrages aus, die das Fundament der Koalition erschütterte und in deren Folge sich die Große Koalition unter ihrem Kanzler zu bewähren hatte.

\section{Außenpolitik gegen Adenauęr - Neuer Streit mit den Gaullisten über den Nichtverbreitungsvertrag im Februar 1967}

Die Einigung zwischen den USA und der Sowjetunion überraschte die Deutschen. Der Vertrag über die Nichtweitergabe von Atomwaffen ${ }^{119}$ war zwar seit einigen Jahren zwischen den Supermächten im Gespräch gewesen, doch ein Abkommen schien nicht in Sichtweite zu sein. Beispielsweise stritten sich Amerikaner und Sowjets am Anfang des Jahres 1966 darüber, für welche Gebiete die Nichtweitergabe geregelt werden sollte. Zunächst wollten die Amerikaner unter dem Begriff „Weitergabe“ ausschließlich die „nationale Verfügungsgewalt" fassen. Atomwaffen sollten nicht in die Hände von Staaten gelangen, die bisher keine atomare Bewaffnung besaßen. Das war den Sowjets nicht genug. Sie lehnten diese Interpretation mit Blick auf die Westdeutschen ab. Da die Bundesregierung eine Beteiligung an einer multilateralen, westeuropäischen Atomstreitmacht anstrebte, wollte der Kreml das Weitergabeverbot auch auf solche Bündnisse oder Gemeinschaften ausweiten. Die Bundesrepublik dürfe niemals Zugang zu Kernwaffen besitzen, weder auf direktem noch auf indirektem Weg, erklärte der sowjetische Delegierte ${ }^{120}$.

Im März 1966 entschloß sich die US-Regierung zu einer neuen Offerte, die der sowjetischen Forderung nahekam. Jetzt wollte man den Begriff „nationale Verfügung“ so verstanden wissen, daß grundsätzlich kein Kernwaffenstaat die Verfügungsgewalt über Nuklearwaffen an größere Gemeinschaften wie die EG übertragen dürfe. Aber es blieb auch bei dieser Formulierung eine kleine Hintertür offen. Sie hätte es der Bundesrepublik erlaubt, indirekt am westlichen Atomwaffenpotential teilzuhaben. Falls in einem Verteidigungsbündnis der europäischen Union eine der beiden Atommächte, Frankreich oder Großbritannien, ihr atomares Arsenal vollständig einbringe, dann - so die Überlegung - würde das theoretisch nicht die Anzahl der atomar bewaffneten Staaten erhöhen. Eine solche Fusion wäre daher kein Verstoß gegen den NV-Vertrag ${ }^{121}$. Aber gerade aus diesem Grund wollte der Kreml auch dieser Interpretation nicht zustimmen. Schließlich gaben die Amerikaner im Oktober 1966 ihre Bemühungen auf, es den Deutschen in dieser

\footnotetext{
${ }_{118}$ DzD, S. 505 f.

${ }^{19}$ Die Bezeichnung „NV-Vertrag“ steht für „Nichtverbreitungsvertrag“. Im Text werden auch die Begriffe Nichtweitergabevertrag, Kernwaffen- oder Atomsperrvertrag verwendet.

$120 \mathrm{Vgl}$. Birrenbach, Sondermissionen, S. 215.

121 Vgl. ebenda, S. 217.
} 
Hinsicht recht zu machen und eine Klausel auszuhandeln, die eine europäische atomare Streitmacht nicht von vornherein ausschloß. Das Zeichen für die größere Kompromißbereitschaft der USA gab am 7. Oktober 1966 der amerikanische Präsident Johnson in New York. In einer Rede erklärte er, die Vereinigten Staaten suchten die Aussöhnung mit der Sowjetunion. Das Ziel sei der Übergang von „der engen Konzeption der Koexistenz zu der größeren Vision des friedlichen Engagements“122. Die USA wollten einen Kontinent aufbauen helfen, in dem sich die Allianzen nicht mehr feindselig gegenüberstünden, sondern die Bündnisse gemeinsam die Sicherheit aller europäischer Staaten gewährleisten würden.

Johnson kündigte zudem einige Erleichterungen im Handel zwischen den osteuropäischen Staaten und den USA an. Auch versicherte er, daß seine Regierung die Integrität der existierenden Grenzen respektiere. Diese Äußerung bezog sich auf die OderNeiße-Linie. Ohne den deutschen Bündnispartner verletzen zu wollen, habe er Polen und Russen damit wissen lassen, daß die Vereinigten Staaten niemals mit Gewalt darauf dringen würden, allgemein akzeptierte Grenzen zu verändern ${ }^{123}$. Erstmals bekannte sich damit ein US-Präsident zu dieser deutschen Ostgrenze und versicherte, daß die atlantischen Nationen sich gegen die Anwendung von Gewalt zur Änderung bestehender Grenzen überhaupt wandten. Schließlich erklärte Johnson am Ende der Liste freiwilliger Zugeständnisse, die USA wollten sich verstärkt um ein Abkommen bemühen, das die Gefahr der Weiterverbreitung von Atomwaffen banne ${ }^{124}$.

Unmittelbar darauf kam es bei den Genfer Verhandlungen über den Nichtverbreitungsvertrag zu einer Annäherung der Vertreter beider Supermächte und einem ersten, gemeinsamen Vertragsentwurf ${ }^{125}$. Dieser Entwurf, den Außenminister Brandt im Dezember 1966 bei der Nato-Tagung in Paris von seinem amerikanischen Kollegen, Dean Rusk, erhielt, schloß jetzt auch für den Fall der europäischen Union eine Weitergabe aus. Der entscheidende Passus lautete: „Jeder Kernwaffenstaat, der Vertragspartei ist, verpflichtet sich, Kernwaffen und sonstige Kernsprengkörper oder die Verfügungsgewalt darüber an niemanden unmittelbar oder mittelbar weiterzugeben und einen Nichtkernwaffenstaat weder zu unterstützen noch zu ermutigen noch zu veranlassen, Kernwaffen oder sonstige Kernsprengkörper herzustellen oder sonstwie zu erwerben oder die Verfügungsgewalt darüber zu erlangen." 126

Das war noch nicht der ganze Entwurf, den Brandt einsehen durfte. Es fehlte Artikel III, von dem der Bundesregierung auch im Februar 1967 noch keine offizielle Fassung vorlag. Der Inhalt war aber bereits bekannt und kursierte unter den Experten des

${ }^{122}$ EA 21 (1966), Folge 20, Rede vor der Konferenz amerikanischer Leitartikler, S. D 519. Sie stammte aus der Feder seines Beraters Zbigniew Brzezinski, der seit Beginn der sechziger Jahre eine „Brücke zwischen Ost und West" in Europa forderte.

${ }^{123}$ Vgl. Johnson, The Vantage Point, S. 475.

124 Vgl. EA 21 (1966), Folge 20, S. D 512.

125 Welche Gründe die Sowjetunion davon überzeugten, auf das Angebot einzugehen, kann nur vermutet werden. Diesel (Die Verhandlungen, S. 295) meint, vielleicht habe Moskau aus Furcht vor einer chinesischen und indischen Nuklearwaffe so plötzlich zugestimmt. Möglicherweise sollte auch den USA Kooperationsbereitschaft signalisiert werden - trotz der weiterbestehenden Konflikte. Wettig (Funktionen eines Sperrvertrages, S. 18) schließt aus der sowjetischen Propaganda, $\mathrm{da} ß$ es sich um ein Mittel gehandelt habe, die Bundesrepublik aus dem atlantischen Verteidigungssystem herauszuziehen (daher die Polemik gegen die Präsenz amerikanischer Waffen in der Bundesrepublik) und zugleich die Entfaltung eines nuklearen Potentials von Bonn zu verhindern.

${ }^{126}$ EA 23 (1968), Folge 14, S. D $321 \mathrm{ff}$. 
Bundestages. Immerhin genügten die ersten beiden Artikel, um das CDU-Vorstandsmitglied Kurt Birrenbach zu alarmieren. Birrenbach war zuvor als Sonderbeauftragter der Bundesregierung zur Sondierung des MLF-Projektes in den Vereinigten Staaten unterwegs gewesen. Er begriff sofort, daß es sich bei der neu angebotenen Vorlage darum handelte, die Möglichkeit einer nuklearen Bewaffnung eines Zusammenschlusses („Assoziation") von europäischen Staaten ganz auszuschließen. Birrenbach informierte in diesem Sinne Bundeskanzler und Auswärtiges Amt. Die Experten bestätigten Kiesinger, daß die Interpretation Birrenbachs richtig sei. Nach diesem Vertrag bliebe einer künftigen Union theoretisch nur noch die Sukzession, d. h. ein Staatengebilde Europa müßte die Nachfolge eines der Kernwaffenstaaten Frankreich oder England antreten. Nur für einen solchen Fall, so die Experten, könne auch der NV-Vertrag die atomare Rüstung einer europäischen Streitmacht nicht verhindern, an der die Bundesrepublik teilnehmen wolle.

Die erste öffentliche Kritik an der Vereinbarung stammte allerdings nicht von deutschen Politikern, sondern kam aus der Europäischen Gemeinschaft. Der Vertrag berührte und beeinflußte nämlich die bestehenden Abmachungen der Gemeinschaft auf direkte Weise. Drei Tage nach der Erklärung Kossygins in London, die Deutschen müßten den Vertrag unterschreiben, teilte die Kommission der europäischen Atombehörde EURATOM dem ihr übergeordneten Ministerrat mit, daß die vorgeschlagenen Bestimmungen des Kontrollartikels das Prinzip der Gleichheit unter den Mitgliedstaaten verletzten ${ }^{127}$. Die Mitglieder würden in atomwaffenbesitzende und nichtatomwaffenbesitzende unterteilt. Nur die letzteren müßten sich aber einer Kontrolle unterwerfen, was die Erforschung und Produktion der friedlichen Atomenergie in diesen Ländern behindern könne.

Diese kritische Beurteilung gab den Ausschlag für eine Diskussion in der Bundesrepublik, die gerade deshalb so brisant verlief, weil sie alten parteipolitischen Positionen entsprach. Erst jetzt meldete sich jene Fraktion hoher Unionsrepräsentanten zu Wort, die seit der Wahl Kiesingers verstummt zu sein schien: die sogenannten Gaullisten. Der CSU-Vorsitzende Strauß, prominentes Mitglied der Gruppe, gab dem Kanzler unter dem 15. Februar eine Stellungnahme, die Kiesinger nur als Kampfansage auffassen konnte. Er habe den Eindruck, hieß es in dem Schreiben, daß Bundesminister Brandt in Amerika die deutsche Unterschrift in Aussicht gestellt habe. Er kenne das Argument, daß ein Nein zu diesem Vertrag die Bundesrepublik in völlige Isolierung bringen werde. Angeblich drohe man auch mit Entzug des angereicherten Kernbrennstoffs von seiten der Vereinigten Staaten. "Wir dürfen hier weder aus Furcht vor der, Weltmeinung' noch unter dem Druck der amerikanischen Erpressung eine Unterschrift unter einen Vertrag leisten, der Deutschland endgültig zum geteilten Objekt eines Superkartells der Weltmächte abwertet, Europas Aussichten auf eine politische Einigung zerschlägt und den Bündnisgeist innerhalb der Nato noch restlos zerstört", polterte Strauß dann los. Eine deutsche Regierung, für die es noch den Begriff Nation und Geschichte gebe, könne und dürfe diesen Vertrag nicht unterzeichnen. Eine Regierung, die diesen Vertrag unterschreibe, habe das wesentlichste Recht der Souveränität „aus Schwäche oder aus Blindheit“ hinsichtlich der Tragweite preisgegeben. Er warne mit allem Nachdruck vor den außen- und innenpolitischen Folgen.

Dann folgte die Drohung: „Aus Gründen der Ehrlichkeit sage ich im voraus, daß ich auf keinen Fall hier einem unter weiß Gott welchen Bedingungen zustande gekomme-

${ }^{127}$ Vgl. EA 22 (1967), Folge 5, S. Z 56. 
nen Kabinettsbeschluß (,wir können ja doch nicht anders') mich beugen würde. Ich werde gegen das Ja zu diesem Vertrag zunächst innerhalb der gegebenen Gremien, dann aber auch in der Öffentlichkeit mit letztem Nachdruck kämpfen. Hier ist für mich und für viele andere die Grenze dessen erreicht, was man Gewissen nennt. Hier endet Opportunismus und Taktik, hier beginnt der Bereich der letzten Verantwortung. " 128 Daß es Strauß durchaus ernst war mit der Drohung, zeigt die Äußerung Adenauers vom März 1967, er sei sicher, daß der Finanzminister aus dem Kabinett „demonstrativ ausscheiden“"werde, wenn der Atomsperrvertrag ohne die für die Deutschen wesentlichen Änderungen angenommen werde $\mathrm{e}^{129}$.

Kiesinger nahm das Schreiben zur Kenntnis - eine schriftliche Antwort erfolgte nicht. Zu diesem Zeitpunkt, Mitte Februar 1967, hatte der Kanzler selbst noch keine Entscheidung getroffen, wie er sich zu dem Vertragsprojekt stellen sollte. Ernste Bedenken - neben der Frage, ob die Möglichkeit, eine künftige europäische Atomstreitmacht zu bilden, durch den Vertrag beeinträchtigt oder gar verhindert werden könne - waren bis dahin nicht formuliert worden. Am 11. Januar hatte das Kabinett sogar dem Vertrag „im Prinzip" zugestimmt ${ }^{130}$. Endgültig Stellung wollte Kiesinger erst nach reiflicher Überlegung und Diskussion der Expertenmeinungen beziehen.

\section{Offensive der Gaullisten}

Die Gefahr, die der NV-Vertrag für die Erforschung der friedlichen Nutzung der Kernenergie bedeutete, war den deutschen Politikern erst durch die sowjetische Note vom 28. Januar bewußt geworden. Der CDU-Fraktionsvorsitzende Barzel meinte, man sei durch sie erst ernsthaft auf die Idee gekommen. Denn in ihr sei die zivile Forschung und die wirtschaftliche Nutzung für die deutsche Technik und Industrie in Zweifel gestellt worden, "weil sie diskreditiert wurde als mindestens paramilitärisch“131. Die sowjetische Führung hatte in ihrer Note vor der Verbindung von deutscher Wirtschaft, deutscher Forschung und dem angeblichen militaristischen Streben der Bundesregierung nach atomarer Bewaffnung gewarnt. Die Note enthielt beispielsweise die folgende Behauptung: „Die militaristischen Kreise der BRD, die sich dadurch tarnen, daß sie von der Notwendigkeit des ,Anschlusses an den technischen Fortschritt' reden und die enge Verflechtung der Möglichkeiten, die neuesten Errungenschaften der Atom-, Raketen- und kosmischen Technik sowohl zu friedlichen als auch zu militärischen Zwecken anzuwenden, ausnutzen, führen umfangreiche Arbeiten militärischen Charakters auf diesen Gebieten durch. " ${ }^{132}$ In Verbindung mit der Londoner Erklärung des sowjetischen Ministerpräsidenten wirkte das vor allem auf Unionspolitiker wie ein Plan zur Kontrolle der Bundesrepublik durch ihren größten Feind. Strauß sprach davon, der Nichtverbreitungsvertrag sei eine „Vergewaltigung der atomaren Habenichtse“, eine Mißachtung der nationalen Souveränität, ein Diktat. „Das ist ein neues Versailles, und zwar eines von kosmischen Ausmaßen." ${ }^{133}$

\footnotetext{
${ }_{128}$ AdKASt, Kiesinger I - 226, D/IV.6, A 285, Strauß an Kiesinger vom 15.2.1967.

${ }^{129}$ Schwarz, Der Staatsmann, Adenauer, Gespräch mit Friedrich, S. 977.

${ }_{130} \mathrm{McGhee}$, Botschafter, S. 312; dem amerikanischen Botschafter war dies in Bonn mitgeteilt worden.

131 BPA, Barzel im ZDF, 23.2.1967, Anhang, S. 7.

${ }^{132} \mathrm{DzD},(1966-1967)$, S. 405.

${ }^{133}$ Ebenda.
} 
In der Kritik schwang Verbitterung über die USA mit. Jetzt schien sich zu bewahrheiten, wovor Adenauer seit Jahren gewarnt hatte: Die Supermächte verständigten sich auf Kosten der Deutschen. Die USA hatten einst den Westdeutschen zur Souveränität verholfen. Strauß, der erste Atomminister der Bundesrepublik, erinnerte sich später mit Dankbarkeit der Hilfe der Vereinigten Staaten für die private Atomforschung in Deutschland. Diese wäre ohne amerikanische Lieferungen von angereichertem Uran anfangs unmöglich gewesen ${ }^{134}$.

Der CSU-Vorsitzende war nicht die einzige Persönlichkeit aus dem Lager der Gaullisten, die sich jetzt zu Wort meldete. Auch aus Spanien kamen alarmierende Worte. Nur einen Tag, nachdem Strauß seine deutliche Warnung an Kiesinger geschickt hatte, sprach Adenauer auf seiner letzten Auslandsreise im Atteneo von Madrid von der „schicksalhaften Bedeutung", die eine deutsche Unterschrift haben werde. Wenn dieser Vertrag durchkomme und man ihm zustimme, dann lege man sich selbst den Strick um den Hals ${ }^{135}$. "Sowjetrußland will über das gesamte atomare Gebiet in Deutschland die Kontrolle erhalten, weil es damit die Kontrolle jeder Herstellung von atomarer Kraft in der Bundesrepublik erhält und damit bei der rapiden Steigerung der Verwertung von Atomkraft im wirtschaftlichen Leben auch die Kontrolle in größtem Umfang über die deutsche Wirtschaft. " ${ }^{136}$ Wenig später erläuterte Adenauer seine Haltung zum Nichtverbreitungsvertrag. In einem Interview nannte er das Werk einen „Morgenthau-Plan im Quadrat“, spielte somit auf den Plan des Amerikaners Henry Morgenthau aus dem Jahre 1944 an, Nachkriegsdeutschland in einen dezentralisierten Staat mit einer reinen Agrargesellschaft umzuwandeln ${ }^{137}$.

In die Reihen der Gegner des Vertrages gesellte sich auch das jüngste Kabinettsmitglied, Wissenschaftsminister Gerhard Stoltenberg. Er war vom Kanzler beauftragt worden, mögliche Diskriminierungen der deutschen Atomforschung durch den Vertragsentwurf festzustellen. Stoltenberg kritisierte den Grundgedanken des Abkommens ebenso wie Strauß und Adenauer. Ein System, in dem die Großmächte den nichtnuklearen Mächten so weitreichende Verpflichtungen politischer und administrativer Art auferlegen wollten, ohne selbst vergleichbare Pflichten zu übernehmen, sei bedenklich und werfe Fragen völkerrechtlicher Problematik auf. Französische Stimmen sprächen gar von einer „,nuklearen Apartheid“, betonte Stoltenberg'138.

Um ganz zu verstehen, warum der Nichtverbreitungsvertrag diese heftigen Reaktionen der Gaullisten hervorrief, ist es notwendig, sich die Herkunft dieser deutschen außenpolitischen Grundrichtung zu vergegenwärtigen.

\section{Die Entstebung der deutschen Fraktion der Gaullisten}

Der deutsche Gaullismus war eine Reaktion auf die amerikanische Entscheidung zu Beginn der sechziger Jahre, der Bundesrepublik nicht die Verfügungsgewalt über Atomwaffen zuzugestehen. Die Kernfragen der atomaren Strategie innerhalb der Nato hätten

\footnotetext{
${ }^{134} \mathrm{Vgl}$. Strauß, Erinnerungen, S. 235.

135 Poppinga, Meine Erinnerungen, S. 358.

${ }^{136}$ Adenauer, Erinnerungen 1959-1963, Rede vom 16.2.1967, S. 245.

${ }^{137}$ Der Spiegel, 27.2.1967, S. 41. Das Stichwort „Morgenthau“ wurde übrigens insbesondere deshalb aufgegriffen, weil der amerikanische Bankier am 6.2.1967 im Alter von 78 Jahren gestorben war. Aus diesem Anlaß waren Würdigungen in zahlreichen deutschen Zeitungen erschienen. 138 Ebenda.
} 
sich im Grunde nie grundlegend verändert, hat Strauß in seinen Erinnerungen behauptet. Es sei immer darum gegangen, das nukleare Risiko zwischen den Europäern und den USA auszugleichen ${ }^{139}$. Aus der Sicht der deutschen Gaullisten diente der Atomsperrvertrag einem einfachen $Z$ weck: Er war dazu erdacht, eine unabhängige, atomar aufgerüstete europäische Streitmacht zu verhindern, um die Vormacht und die Stellung der beiden Supermächte in der Welt zu festigen. Das Mißtrauen gegenüber den USA, dem wichtigsten Bündnispartner der Bundesrepublik, war die Wurzel für die Entstehung der deutschen Gaullisten, jener Gruppe von Befürwortern eines engeren Bündnisses mit Frankreich, die gleichzeitig die Abhängigkeit Bonns von Washington zu verringern strebte.

Unter dem „nuklearen Risiko“ verstand Strauß vor allem: die Gleichbehandlung der Bundesrepublik mit den anderen Atommächten des westlichen Bündnisses. Als Bundesverteidigungsminister hatte er in seiner Amtszeit von 1957 bis 1962 die Frage nach der Verfügungsgewalt über den Einsatz von Atomwaffen gestellt und auf eine Antwort von amerikanischer Seite gedrängt. Er forderte die Abschaffung jeglicher Diskriminierung und die Anerkennung Bonns als gleichberechtigten Partner im Bündnis. Er gab der Schutzmacht zu bedenken, wie denn eine gemeinsame Verteidigung aussehen solle, wenn sie in unterschiedliche Frontabschnitte gegliedert wäre. „Das berechtigte Wort von der ,Aufgabenverteilung' innerhalb der Nato“, schrieb er, „kann doch nicht so verstanden werden, daß an den Abschnitten, wo angelsächsische Truppen beziehungsweise andere nichtdeutsche Verbündete stehen, die abschreckende Wirkung durch taktische Atomwaffen gegeben ist - dort, wo deutsche Nato-Verbände stehen, aber nicht. " ${ }^{140}$ Kurz: Die deutsche Verteidigung müsse eine nukleare Verteidigung sein, die Atomwaffe müsse sich in den Händen auch deutscher Truppen befinden.

Vor diesem Hintergrund bereitete der Verteidigungsminister seine entscheidende Anregung vor. In einer Rede an der Georgetown Universität in Washington D.C. sprach er am 27. November 1961 von der historischen Bestimmung des Bündnisses, von Kooperation zur Koordination fortzuschreiten, hin zu einer Konföderation und endlich einer „Föderation partieller Art“. Aufgabe dieser Föderation solle die Festlegung einer gemeinsamen Strategie für die Nato sowie eine gemeinsame Kontrolle und Entscheidungsgewalt über Kernwaffen sein ${ }^{141}$. Strauß schwebte vor, daß der Oberbefehlshaber der Alliierten in Europa dazu ermächtigt werden sollte, über den Einsatz von Kernwaffen zu entscheiden, falls die Regierung eines Mitgliedslandes für die Verteidigung ihres Staatsgebietes darum ersuche. Der Minister forderte also nichts anderes, als die Entscheidungsbefugnis über den Einsatz von Atomwaffen von Washington nach Europa zu transferieren. Die WEU, das Organ der westeuropäischen Nato-Mitgliedstaaten, sollte vierte Atommacht werden. Auf diese Weise hoffte Strauß, die Bundesrepublik ihrer ständigen Sorge über die Frage zu befreien, ob die Vereinigten Staaten im Falle eines sowjetischen Angriffs auf Westeuropa tatsächlich in Deutschland eingreifen würden. Und der Vorschlag hatte zudem den Vorteil, daß die Bundesrepublik sich nuklear würde verteidigen können, ohne selbst im Besitz von Atomwaffen zu sein. Aber aus der Anregung wurde nichts. Die amerikanische Regierung verzögerte eine endgültige Antwort. Mit der Zeit wuchs das Mißtrauen bei Bundeskanzler Adenauer und seinem Minister. Der Rüstungswettlauf zwischen den Supermächten nährte den Zweifel, ob denn die Vereinigten Staaten überhaupt die bestehende Verteidigungsgarantie aufrechterhalten wollten.

\footnotetext{
${ }_{139}$ Vgl. Strauß, Erinnerungen, S. 361.

$1+\div$ Politisch-Soziale Korrespondenz, 15.10.1960.

${ }^{1+1}$ Mahncke, Nukleare Mitwirkung, S. 111.
} 
Die USA sahen sich zu Beginn der sechziger Jahre mit der Tatsache konfrontiert, durch sowjetische Trägersysteme erreichbar und daher selbst verwundbar geworden zu sein. Konnte die Bundesrepublik angesichts dieser Veränderung sicher sein, daß „der amerikanische Präsident im Ernstfall auf den roten Knopf drücken würde“, fragte sich Adenauer ${ }^{142}$. Wenn also Europa angegriffen würde, könnten die USA nicht einen Einsatz von Atombomben verweigern, um so ihr eigenes Territorium zu schützen? Was ein Jahrzehnt lang außer Frage gestanden hatte, verlor nun an Selbstverständlichkeit. Alarmiert sahen sich der deutsche Kanzler und sein Verteidigungsminister, als General Maxwell Taylor, ein pensionierter General, von Präsident John F. Kennedy reaktiviert wurde. 1962 berief man ihn zum Vorsitzenden der Vereinigten Stabschefs. Zwei Jahre zuvor hatte der General das Buch The Uncertain Trumpet veröffentlicht, in dem er behauptete, kein Staat, der Atomwaffen besitze, werde angesichts der drohenden Zerstörung des eigenen Landes diese Waffen zur Verteidigung seiner Bündnispartner anwenden ${ }^{143}$.

Der französische Staatspräsident bestärkte das Mißtrauen des Bundeskanzlers gegenüber den Vereinigten Staaten und machte darauf aufmerksam, daß die Bundesregierung noch immer - zu Unrecht - an dem Gedanken festhalte, daß die Nato eines Tages mit nuklearen Waffen ausgerüstet sein werde. Aber in Wirklichkeit geschehe nichts; es gäbe weder eine gemeinsame Haltung noch ein gemeinsames Handeln in der Verteidigung ${ }^{144}$. De Gaulle offerierte dagegen eine enge deutsch-französische Kooperation im militärischen Bereich, die - aus der Sicht von Strauß - eine nukleare Komponente einschloß. In seinen Erinnerungen faßte Strauß diese Perspektive folgendermaßen zusammen: Es sei damals um eine deutsch-französische Armee gegangen, „eine Armee mit gemeinsamen Atomwaffen “, mit gemeinsamer politischer und militärischer Führung. „Frankreich wäre primus inter pares, wir die Nummer zwei. “ 145

Adenauer öffnete sich dieser Sichtweise immer stärker, denn neben den strategischen Differenzen traten politische Unstimmigkeiten mit den USA hinzu. Es mißfiel dem Kanzler, daß die Amerikaner nach dem Mauerbau 1961 und der Kubakrise ein Jahr später zu sanft auf die Drohungen Moskaus gegenüber Berlin reagiert hatten. Nach wie vor suchten die Sowjets den Status West-Berlins zu verändern, die Truppen der Westmächte aus der Stadt zu drängen. Die Vereinigten Staaten hatten anscheinend gar nicht begriffen, daß jeder Anschlag auf einen Teil der freien Welt auch als ein Anschlag auf die USA angesehen werden mußte. Adenauer besann sich in dieser Lage verstärkt auf Europa, auf Frankreich und General de Gaulle. Der deutsch-französische Vertrag vom Januar 1963 wurde zum Symbol dieser Haltung, aber provozierte bei den Andersgesinnten eine Reaktion der Distanz gegenüber Paris. Denn die vom Bundestag später, am 15. Juni 1963, hinzugesetzte Präambel widersprach dem Geist des Vertrages und betonte im Gegenteil die atlantische Grundlage der Bundesrepublik. Die Präambel wurde zum Manifest der Atlantiker.

Als de Gaulle im Juli 1964 bei seinem Bonner Besuch von Erhard eine Entscheidung über sein Angebot einer engen politischen Zusammenarbeit verlangte und voll Enttäuschung und Wut über die ausgebliebene Antwort abreiste, teilte sich die Regierungspartei

142 Adenauer, Erinnerungen 1959-1963, S. 60, Gespräch mit de Gaulle vom 29.7.1960 in Rambouillet.

${ }^{143}$ Strauß (Erinnerungen, S. 364) nahm daher Taylor das bei einem Besuch des Generals beteuerte Bekenntnis zur Nato-Doktrin nicht ab.

${ }_{144}$ Vgl. Adenauer, Erinnerungen 1959-1963, Gespräch mit de Gaulle vom 15.2.1962, S. 138.

${ }^{145}$ Strauß, Erinnerungen, S. 434. 
und die öffentliche Meinung in zwei Lager. Erhard, Schröder und Verteidigungsminister von Hassel bildeten die prominente Front derjenigen, die sich gegen „eine allzu exklusive Beziehung mit Paris zu Lasten der Bindung an Amerika aussprachen", wie Hildebrand die Zielsetzung der Atlantiker definiert hat ${ }^{146}$. Ihnen gegenüber standen die Führer von CDU und CSU, Adenauer und Strauß. Auch der außenpolitische Experte der CSU Guttenberg und der geschäftsführende CDU-Vorsitzende Dufhues zählten zu den Gaullisten. Die Diskussion zog so weite Kreise, daß sich selbst einzelne gesellschaftliche Gruppierungen zum einen oder anderen Lager bekannten. Anfänglich standen die Mehrheit der Mitglieder von CDU, SPD und FDP sowie Repräsentanten aus Unternehmerschaft und Gewerkschaft den Atlantikern nahe ${ }^{147}$. Die Befürworter einer stärkeren Bindung Bonns an Paris nahmen aber an Zahl zu, je stärker der französische Staatspräsident seine Enttäuschung über die Regierung Erhard offen zeigte.

Auch die SPD hatte inzwischen ihre Hilfe für Schröder eingestellt. Zeitweilig war er als Gegenspieler Adenauers unterstützt worden. Aber die Hoffnungen der Sozialdemokraten, der Christdemokrat könnte eine Art Verbindungsmann zwischen beiden Parteien in der Außenpolitik werden, hatten sich nicht erfüllt. Außerdem betrachtete die SPD die Entspannungspolitik de Gaulles als wichtigen Ansatzpunkt für die deutsche Ostpolitik. Bei den Teilnehmern der Koalitionsverhandlungen zwischen SPD und CDU/CSU im November 1966 herrschte die übereinstimmende Meinung vor, das Verhältnis zu Paris müsse wieder in Ordnung gebracht werden. Barzel beeindruckte, daß insbesondere Brandt eindringlich für ein harmonisches Verhältnis der deutschen Bundesregierung zum französischen Staatspräsidenten plädierte ${ }^{148}$. Die SPD legte bei den Gesprächen Wert darauf, im einzelnen darzulegen, was sie Bundeskanzler Erhard und seinem Außenminister vorzuwerfen hatte. Sie wies auf zwei Versäumnisse hin, die Wehner am 28. November vor dem SPD-Parteirat noch einmal unterstrich: Zum einen habe die vormalige Regierungskoalition es unterlassen, Gegenvorschläge auszuarbeiten, als Frankreich aus der Organisation der Nato ausgetreten sei. Sie hätte sich etwa überlegen müssen, unter welchen neuen Bedingungen die in der Bundesrepublik stationierten französischen Truppen auf deutschem Boden gehalten werden konnten. Zum anderen hätten Erhard und Schröder die Gelegenheit ungenutzt verstreichen lassen, die sich für die Bundesrepublik aus der Ostpolitik de Gaulles ergeben habe. Mit Hilfe des französischen Staatspräsidenten hätte die Position der Bundesrepublik im Osten gestärkt werden können. Diese Chance sei durch die desinteressierte Haltung der Bundesregierung ausgelassen worden ${ }^{149}$.

Größer konnte die Einmütigkeit der Delegationen übrigens nicht sein. Wehner sprach auch den Mitgliedern der Unionsdelegation aus dem Herzen. Aber die Harmonie mit den SPD-Führern vom November 1966 endete für Strauß bereits im Februar 1967. Ab diesem Zeitpunkt zeichnete sich die Zustimmung der Sozialdemokraten zum Nichtweitergabevertrag ab, den man jetzt auch polemisch Atomsperrvertrag nannte.

\footnotetext{
${ }^{146}$ Hildebrand, Der provisorische Staat, S. 287.

1+7 Vgl. Griffith, Ostpolitik, S. 112. Bei der Zusammensetzung der einzelnen Gruppen betont Griffith den konfessionellen Hintergrund. Es habe sich um den Gegensatz zwischen dem katholischen Süden und dem protestantischen Norden gehandelt.

${ }_{148}$ Vgl. Barzel, Gespräch mit dem Verfasser, 10.6.1988.

${ }^{149}$ Vgl. Vorstand der SPD (Hrsg.), Bestandsaufnahme, S. 70.
} 


\section{Strau $\beta$, die SPD und die nukleare Frage}

Strauß hatte in seinem Brief an Kiesinger richtig vermutet: Trotz einiger Vorbehalte hatte Brandt in den USA tatsächlich dem Vertrag im Namen der Bundesrepublik grundsätzlich zugestimmt. Bundeskanzler Kiesinger bestätigte dies im Oktober 1967. In seinem Hintergrundgespräch antwortete Kiesinger auf die Frage, ob es wahr sei, was die Amerikaner hätten durchblicken lassen, daß die Bundesregierung den Vertrag schon „in Bausch und Bogen“ angenommen hätte: „Ich fürchte leider, daß es weitgehend stimmt. Ich fürchte, daß sich Brandt bei seinem ersten Besuch in den USA ganz erheblich festgelegt hat. " 150 Für Strauß wog diese Tatsache um so schwerer, als die Sozialdemokraten in den Koalitionsvereinbarungen sein Konzept einer europäischen Atomstreitmacht akzeptiert zu haben schienen. Der CSU-Vorsitzende vermutete einen Bruch der gemeinsam getroffenen Absprachen vom November 1966. Damals hatte die Oppositionspartei in ihrem kurzfristig verfaßten Acht-Punkte-Programm zwar gefordert, dem Nichtweitergabevertrag nicht nur zuzustimmen, sondern auch seine Zielsetzung zu unterstützen. Dennoch war die SPD-Delegation aufgrund der Hartnäckigkeit der CDU/CSU-Vertreter gezwungen gewesen, diese Forderung am Ende zu modifizieren.

$\mathrm{Zu}$ den Plänen des CSU-Vorsitzenden hatte Schmidt für die SPD am 4. November 1966 in einem Artikel des Rheinischen Merkur Stellung bezogen - jener Zeitung, die in den Jahren zuvor die gaullistische Seite unterstützt hatte. Die positive Beurteilung des Strauß-Plans darin überwog die wenigen kritischen Einwände. Schon deswegen signalisierte der Artikel die Bereitschaft der SPD zur Bildung einer Großen Koalition. Mehrmals berief sich Schmidt auf die Gemeinsamkeiten beider Politiker, und der SPD-Abgeordnete akzeptierte in seinem Artikel den Plan von Strauß für eine europäische Atomstreitmacht. Angesichts von 750 auf Westeuropa gerichteten, sowjetischen Mittelstreckenraketen wäre eine europäische nukleare Abschreckungsstreitmacht durchaus erwünscht, schrieb er. Allerdings solle man sich vor zu großen Erwartungen hüten. Eine solche Streitmacht setze voraus, daß die Deutschen die Franzosen von ihrem Anspruch auf nationale Verteidigung würden abbringen können, was äußerst unwahrscheinlich zu sein schien ${ }^{151}$.

Der CSU-Vorsitzende griff die Anregung auf. Im Beisein Wehners betonte er am 14. November 1966 vor den laufenden Kameras des Deutschen Fernsebens, dem Gedanken eines von Schmidt vorgeschlagenen deutschen Vetorechts für den Einsatz nuklearer Atomwaffen könne er sich anschließen, sofern sie von deutschem Boden aus gezündet würden oder auf deutschen Boden gerichtet seien. Ein Veto käme auch seinem ursprünglichen Ziel, einem deutschen Mitbestimmungsrecht beim Einsatz von Atomwaffen, nahe ${ }^{152}$. Wehner, der sich bis dahin in der Runde unzugänglich und mürrisch gezeigt hatte, ließ daraufhin gegenüber Strauß eine gewisse Dankbarkeit anklingen. Das sozialdemokratische Vetorecht sei eben „ordentlich von Herrn Strauß interpretiert worden“, lobte er verhalten. Erleichtert registrierte der amtierende SPD-Fraktionsführer, daß der CSUPolitiker durch seine Erklärung einen Stein aus dem Weg räumte, der die Bildung einer Großen Koalition bis dahin behindert hatte.

Grundsätzlich hatten die Parteien sich in den Koalitionsverhandlungen auf ein Tauschgeschäft verständigt. Die Union verzichtete auf die Forderung nach „physischem Mitbesitz“ atomarer Waffen, die SPD akzeptierte im Gegenzug den Plan einer nuklea-

${ }^{150}$ AdKASt, Kiesinger I - 226, D/II.1, A 008, Gespräch mit Wirsing, 5.10.1967, S. 6.

15! Vgl. Rheinischer Merkur, 4.11.1966.

152 Vgl. BPA, Wehner in der ARD, 14.11.1966, Anhang II, S. 9. 
ren europäischen Streitmacht eines zukünftigen bundesstaatlichen Westeuropas. Blieb noch der Nichtverbreitungsvertrag. In ihrem Acht-Punkte-Programm stellte die SPD fest, der Atomwaffensperrvertrag müsse unterstützt werden, da andernfalls die Verständigung und Entspannung zwischen Ost und West blockiert werde. Aber hier trennten sich schon im November 1966 die Vorstellungen der beiden Parteien.

Wenn das Ziel ein europäischer Staat mit nuklearer Verteidigung sei, müsse alles getan werden, um sich diese Möglichkeit nicht von vornherein verstellen zu lassen, argumentierte Strauß gegen den Vertrag. Die Amerikaner seien gerade im Begriff, ungewollt dieser Zielsetzung einen Riegel vorzuschieben. Denn der Nichtverbreitungsvertrag verhindere den Aufbau einer nuklearen Macht selbst bei einem westeuropäischen Zusammenschluß. Strauß hatte schon ein Jahr zuvor, im November 1965, die eigene Regierung davor gewarnt, die Forderung nach „physischem Mitbesitz“ dadurch zu retten, daß man die Unterschrift unter einen Nichtverbreitungsvertrag setze. Für Strauß wäre das ein „Kuh-Handel“ gewesen. Man könne nicht ein „Erstgeburtsrecht der deutschen Souveränität verkaufen für ein Linsengericht einer temporären physischen Lösung “153. Jetzt - ein Jahr später - befürchtete der Politiker, daß ein deutscher Beitritt zum Sperrvertrag der kommenden europäischen Macht die Chance auf atomare Bewaffnung raube.

Die anderen Unionsmitglieder teilten diese Sorge, und die Delegation der CDU/CSU wollte sich daher nicht auf eine Unterschrift von vornherein festlegen lassen. Die SPD mußte sich daher bei den Verhandlungen erneut mit einem Kompromiß zufriedengeben. Vor dem Parteirat zitierte Wehner am 28. November 1966 aus seinen Notizen das Ergebnis: Beide Seiten seien sich klar darüber gewesen, daß die Bundesrepublik „in eine schwierige Lage" gerate, wenn sie ihre Zustimmung zu der Nichtweitergabe von Atomwaffen verweigere ${ }^{154}$.

Der Brief von Strauß an Kiesinger vom Februar 1967, in dem er seine Opposition gegen den Kernwaffensperrvertrag angekündigt hatte ${ }^{155}$, richtete sich vor allem gegen die SPD-Führung. Das Schreiben steht am Beginn einer polemischen Auseinandersetzung des CSU-Vorsitzenden mit der ostpolitischen Zielsetzung der Sozialdemokraten. Sie löste den innerparteilichen Gegensatz in der Union zwischen Atlantikern und Gaullisten ab. Bisher hatte sich die Kritik von Strauß aus seiner westeuropäischen Zielsetzung ergeben. Indem Brandt das Einverständnis zum Vertrag mit dem Hinweis rechtfertigte, die Zustimmung der Bundesregierung werde die Beziehung zu Moskau verbessern, wurde sie jetzt mit der Ostpolitik verknüpft. Für den CSU-Vorsitzenden bedeutete Brandts Argument die Aufgabe souveräner Rechte zugunsten einer Geste des guten Willens gegenüber der Sowjetunion. Bei dieser Ausgangslage war der kommende, unüberbrückbare Disput zwischen SPD und CSU vorhersehbar.

\section{Brandt stimmt dem Nichtweitergabevertrag im Januar $1967 \mathrm{zu}$}

Brandt hatte von Beginn an keinen Zweifel daran gelassen, daß er den Vertrag unterschreiben wollte. Als ihm US-Außenminister Rusk bei der Nato-Konferenz im Dezember

${ }^{153}$ Zitiert nach EA 20 (1965), Folge 24, S. Z 230.

${ }^{15+}$ SPD (Hrsg.), Bestandsaufnahme, S. 71.

15s Der Inhalt geriet bald in die Öffentlichkeit. Der Spiegel (20.2.1967, S. 25) zitierte sogar einen Satz wortwörtlich und erweckte somit beim Leser den Eindruck, er sei im Besitz einer Kopie. Tatsächlich war er es nicht. Strauß hatte nicht behauptet, wie in dem Magazin zu lesen stand, daß die CSU „mit allen demokratischen Mitteln“ gegen den Vertrag zu Felde ziehen werde; vgl. AdKASt, Kiesinger I - 226, D/IV.6, A 285, Strauß an Kiesinger vom 15.2.1967. 
1966 in Paris die ersten beiden Artikel überreicht hatte, nahm er die Akten mit in den Winterurlaub nach Sizilien. Dort schrieb er nieder, worauf es ihm bei dem Vertrag ankam. Er formulierte drei Punkte: Erstens wolle er nicht, daß sein Land über nukleare Waffen verfüge. Aber zweitens dürfe Europa nicht schutzlos sein; das Risiko eines Angriffs müsse für die Sowjetunion groß genug bleiben. Drittens müsse die Bundesregierung in jenen Bereichen mitsprechen können, in denen sie betroffen sei. Dieser letzte Punkt bezog sich auf den Vorschlag Schmidts, ein Vetorecht einzuführen. Es müsse der Bundesrepublik die Möglichkeit offenstehen, sich an der Entscheidung über Ziele taktischer Atomraketen auf deutschem Territorium zu beteiligen ${ }^{156}$. Als der amerikanische Botschafter McGhee ihn am 10. Januar 1967 besuchte, sah der Außenminister offenbar gar „keinen Grund der Besorgnis“. Dieser lege lediglich Wert darauf, daß die USA den Deutschen eine offizielle Interpretation des Vertragstextes zugänglich machten, berichtete der Amerikaner ${ }^{157}$. In der deutschen Öffentlichkeit führte Brandt zwei Gründe für seine zustimmende Haltung an: Erstens betonte er den Zusammenhang zwischen der Unterschrift der Bundesrepublik und der daraus resultierenden Erleichterung für die deutsche Ostpolitik. Zweitens gestand er den beiden Supermächten im Bereich der nuklearen Waffen eine Sonderstellung gegenüber den Nichtatomstaaten zu, die er mit Einschränkungen befürwortete.

Nach der Rückkehr von seiner ersten Reise in die USA, wo er sich vom 7. bis zum 11. Februar 1967 aufgehalten hatte, griff der Außenminister den in der deutschen Diskussion am heftigsten umstrittenen Punkt der Kontrollen auf und bekannte sich zu deren Notwendigkeit: „Mir kommt es sehr auf diesen Punkt an: Kontrollen ja, aber eindeutig und jeden Zweifel ausschließend zur Sicherung gegen einen Mißbrauch des Atoms zu militärischen Zwecken. Dies ist deshalb so wichtig, weil damit den bis zum Überfluß grundlos vorgebrachten Verdächtigungen [gegen die] Bundesrepublik Deutschland der Boden entzogen wäre und wir im Sinne unserer Politik der Entspannung einen Schritt weiter wären zur Normalisierung unseres Verhältnisses mit der Sowjetunion. Hier ergibt sich durchaus ein Zusammenhang zwischen unserer Osteuropa-Politik und einem sauberen Nichtverbreitungsvertrag." Wenn die andauernde sowjetische Propaganda in diesem Punkt unterlaufen werde, sei durch den Nichtverbreitungsvertrag die Möglichkeit gegeben, den politischen Handlungsspielraum der Bundesrepublik zu vergrößern und nach Osten hin auszuweiten ${ }^{158}$.

Damit hatte Brandt erstmals eine Perspektive aufgezeigt, wie die von der Koalition angestrebten, verstärkten ostpolitischen Bemühungen in einem konkreten Fall umgesetzt werden konnten. Es sollte sich bald zeigen, daß der Kernwaffensperrvertrag die einzige Chance einer neuen Ostpolitik der Großen Koalition darstellte. Denn die Bundesregierung war noch nicht bereit, die anderen Forderungen Moskaus zu erfüllen. Hingegen reichten dem Kreml die von der Regierung Kiesinger offerierten Kompromißvorschläge nicht, um auf eine Annäherungspolitik zwischen Bonn und Moskau einzugehen. Am Ende war von allen Problemen, die das Verhältnis zwischen der Bundesrepublik und der Sowjetunion belasteten, lediglich die Zustimmung zum Nichtverbreitungsvertrag zwischen SPD

\footnotetext{
156 Vgl. Brandt, Begegnungen, S. 225.

157 Vgl. McGhee, Botschafter, S. 312 f.; dort heißt es: „Charakteristischerweise schien er [Brandt] eher an Probleme zu denken, die auf seiten der nichtatomaren Länder, besonders der Neutralen entstehen könnten. Ob wir wohl bereit wären, eine Erklärung abzugeben, daß die Atommächte sie durch ihre Nuklearwaffen nicht erpressen würden, fragte er.“

${ }^{158}$ Die Welt, 18.2.1967.
} 
und Union konsensfähig. Nur in dieser Frage schien eine Übereinkunft der beiden Koalitionsparteien möglich. Aber das war im Februar 1967 noch nicht vorherzusehen.

Es existierte für Brandt noch ein weiterer Grund für seine Bereitschaft, dem Vertrag zuzustimmen. Brandt billigte den beiden Supermächten eine gewisse Interessengemeinschaft bei der Kontrolle von Nuklearwaffen ausdrücklich zu. Am 10. Februar 1967 hatte er vor dem Adlai Stevenson Institute on International Affairs in Chicago festgestellt, wenn es richtig sei, daß die Atomwaffe das letzte Zeichen der Souveränität ist, so erkenne die Bundesregierung, daß hieraus gewisse gemeinsame Interessen der Vereinigten Staaten und der Sowjetunion erwüchsen ${ }^{159}$.

Mit dieser Behauptung unterschied sich Brandt allerdings von dem konservativen Parteiführer und Koalitionspartner Strauß auf fundamentale Weise. Er teilte die Meinung des ehemaligen Verteidigungsministers der Bundesrepublik nicht, daß man alles tun müsse, um der Republik die Möglichkeit atomarer Bewaffnung zu erhalten. Strauß beabsichtigte, wie er in seinen Erinnerungen schreibt, hinsichtlich „unserer vorhandenen militärischen Mittel und Möglichkeiten auf allen Ebenen vertreten zu sein“. Man dürfe sich nicht freiwillig aus Etagen zurückziehen, „aus denen die anderen uns raushaben wollen, nur um ihre eigene Sicherheit zu erhöhen" ${ }^{160}$.

Eine solche Sichtweise hielt Brandt für antiquiert. Die Diskussion über den Atomsperrvertrag habe gezeigt, hielt er im Rückblick fest, daß das Bonner Denken in überholten Vorstellungen verhaftet sei ${ }^{161}$. Bisher habe sich dieses Denken halten können, weil die Bundesrepublik über ihre Verhältnisse gelebt habe, beinah wie eine Siegermacht ${ }^{162}$. Die Perspektive des Außenministers sah anders aus. In einem Interview erklärte er am 18. Februar 1967: „Wir oder die meisten von uns sind in diesen Jahren davon ausgegangen, daß Deutschland keine Großmacht im militärischen Sinn mehr ist. Die Rolle Deutschlands und sein künftiges Gewicht liegt darin, ob es uns gelingt, wirtschaftlich und wissenschaftlich, technisch und qualitativ mit an der Spitze zu bleiben oder in die Spitzengruppe zu kommen. Und dafür darf ein Nichtverbreitungsvertrag kein Hindernis sein. " ${ }^{163}$

\section{Deutschlands Rolle in Brandts Denken vor dem Hintergrund seiner Biographie}

Deutschland als Nation besaß nach dem Zweiten Weltkrieg in der Vorstellung des SPDVorsitzenden vor allem eine friedensstiftende Aufgabe. Brandt war sogar bereit, das nationale Ziel der Deutschen, die Wiedervereinigung, dem höheren Streben nach Frieden unterzuordnen. „Gemessen am Frieden ist die Nation nicht mehr das höchste aller Güter", sagte er in einem Gespräch 1967. Das bedeute, daß die nationale Einheit zurückstehen müsse, wenn sie dem Aufbau einer Friedensordnung im Wege stehe. Brandt konnte und wollte sich die Zukunft der Bundesrepublik nur in der Hinwendung zu einer moralisch positiven Rolle vorstellen. Sie mußte durch ihre Mitwirkung an der Aussöhnung und Verständigung zwischen den europäischen Völkern zeigen, daß sie die richtige Lehre aus zwei verlorenen Kriegen gezogen hatte. Dabei verstand der Sozialdemokrat diese neue Rolle nicht als Buße für die Schuld der Greueltaten im Dritten Reich. Im Gegen-

\footnotetext{
${ }^{159} \mathrm{Vgl}$. Bulletin, Rede vom 10.2.1967, 14.2.1967.

160 Strauß, Erinnerungen, S. $192 \mathrm{f}$.

161 Vgl. Brandt, Begegnungen, S. 188.

${ }^{162}$ Siehe dazu auch Wehners Meinung (Die Welt, 20.2.1967): „Wir haben bisher über unsere Verhältnisse gelebt, so als ob wir eine adoptierte Siegermacht wären.“

${ }^{163}$ Die Welt, 18.2.1967.
} 
teil, Brandt war einer der ersten, der forderte, die Deutschen müßten wieder den aufrechten, normalen Gang lernen: „Wir Deutschen dürfen nicht die Geschichte vergessen. Aber wir können auch nicht ständig mit Schuldbekenntnissen herumlaufen, die junge Generation noch weniger als die ältere." 164

In diesem Punkt unterschied sich Brandt übrigens nicht von Strauß, der in seinen Memoiren behauptet, er habe sich durch das Dritte Reich „im Sinne einer persönlichen Schuld nicht betroffen" gefühlt und auch die These von der Kollektivschuld stets zurückgewiesen $^{165}$. Was Strauß, aber auch Kiesinger von Brandt trennte, waren die Einsichten aus den voneinander abweichenden Erfahrungen. Die beiden Christdemokraten hatten die Niederlage Deutschlands im Zweiten Weltkrieg als katastrophal empfunden, obwohl sie den Nationalsozialismus ablehnten. Sie erlebten den Tag der Landung alliierter Streitkräfte in der Normandie vom Reich aus - Strauß als junger Offizier in Frankreich, Kiesinger in Berlin. Für sie stellte die Invasion eine Bedrohung der eigenen Existenz dar. Sie wollten die Niederlage nicht, schon aus Furcht vor den Folgen, vor der Vergeltung des Siegers. Beide haben übrigens den 6. Juni 1944, den D-Day, in ihren Erinnerungen daher auch nicht erwähnt.

Anders Brandt. Für ihn, den Emigranten, bedeutete die sich ankündigende Niederlage Deutschlands und die Zerschlagung des Nationalsozialismus Sieg, Überleben, Freiheit! Der knapp Zwanzigjährige hatte 1933 seinen Geburtsort Lübeck verlassen müssen, weil er als Mitglied einer sozialistischen Partei, der SAPD, um sein Leben fürchtete. Sein Weg führte ihn nach Norwegen, dann nach Schweden, wo er den größten Teil des Krieges als Journalist verbrachte. Ein Glücksgefühl durchfuhr daher Brandt, als er von der Landung erfuhr. An den Tag der Invasion erinnerte er sich genau: „Als ich am 6. Juni 1944 von der Landung der Alliierten in der Normandie hörte, stiegen mir die Tränen in die Augen. “166 Für Brandt schien damit die Befreiung vom nationalsozialistischen Joch nahe zu sein. Und mit den Nazis ging auch das Reich. Er habe die These vom ungeschmälerten Fortbestand des Deutschen Reiches für Unfug gehalten, bekennt Brandt in seinen Erinnerungen. Aber die Beschränkung Deutschlands auf den Westen, auf die Bundesrepublik, hat er auch nicht hinnehmen wollen. Sein Protest gegen das reduzierte Deutschland, Adenauers Weststaat, zeigt sich in den Brandt-Memoiren des Jahres 1989, die noch vor den Novemberereignissen erschienen: „Ich, in einer Hansestadt an der Wasserkante aufgewachsen“, heißt es da, „auch kein Preuße, höchstens ein angelernter, aber auch heute noch protestierend, wenn man mich einen Westdeutschen nennt; ich sage dann, nicht in West Germany oder l'Allemagne de l'Ouest sei ich geboren, sondern in Deutschland, und falls man es genauer hören will - in Norddeutschland. " ${ }_{167}$

Das Reich existierte nicht mehr, und die Bundesrepublik mußte sich eine neue Bestimmung suchen. Davon war Brandt überzeugt. Er sei stolz darauf, daß die Bonner Republik eine Friedenspolitik verfolge, heißt es in seinen Erinnerungen. Auch aus diesen Überlegungen heraus läßt sich Brandts Eintreten für die deutsche Unterschrift unter den Nichtweitergabevertrag verstehen. Jetzt konnte die Bundesrepublik beweisen, daß es ihr in erster Linie darauf ankam, den Frieden sicherer zu machen. Öffentlich wandte er sich daher gegen die warnenden Stimmen von Strauß und Adenauer. Falls der Vertrag tatsäch-

\footnotetext{
${ }^{164}$ Harpprecht, Brandt, S. 143; siehe auch Braunmühl, Kalter Krieg, S. 55.

${ }^{165}$ Strauß, Erinnerungen, S. 240 f.

166 Brandt, Erinnerungen, S. 134.

167 Ebenda, S. 153 und 38.
} 
lich eine Neuauflage des Morgenthauplans sei, äußerte Brandt am 25. Februar 1967 gereizt, so wäre erstens die Bundesregierung klug genug, das selbst zu bemerken. In diesem Fall „würden wir zweitens über einen solchen Vertrag nicht eine Minute sprechen, geschweige denn so intensiv weltweit diskutieren" 168 .

An anderer Stelle beschuldigte er den Altbundeskanzler - ohne ihn beim Namen zu nennen-, maßlose „Scheinargumente“ vorzubringen. Man könne sich draußen nur schwer vorstellen, daß sich in der Bundesrepublik auch Leute mit respektablem Namen äußerten, ohne die Materie zu kennen, über die sie sprächen ${ }^{169}$. Was die Einwände im einzelnen betraf, die auch Brandt für „verhandlungswürdig“ betrachtete, so bemühte er sich, in Washington auf die deutschen Vorbehalte hinzuweisen ${ }^{170}$. Es war ihm allerdings vom amerikanischen Außenminister Rusk bedeutet worden, daß der Textentwurf, wie er jetzt kurz vor der Wiederaufnahme der Verhandlungen in Genf am 21. Februar 1967 vorlag, als endgültig betrachtet wurde. Vor der Auslandspresse bilanzierte Brandt am 23. Februar seine Gespräche mit den Amerikanern: Washington gehe davon aus, daß man den Text des Vertrages als weitgehend unabänderlich betrachte und den Schwerpunkt auf "befriedigende Interpretationen" verlagert habe ${ }^{171}$. Im Bundestag versicherte der Außenminister den Abgeordneten am gleichen Tag, die Regierung werde das „vitale Interesse der Bundesrepublik an einer friedlichen Nutzung der Atomenergie“ durchsetzen können. Die Vereinigten Staaten seien zu einer Interpretation des Vertrages bereit, für die bereits Konsultationen eingeleitet worden seien.

\section{Zufriedenstellende Auskünfte aus Washington: Konzessionen für die Deutschen}

Das Auswärtige Amt war nicht untätig gewesen und hatte bereits Anfang des Jahres 1967 einen Fragenkatalog zu den Vertragstexten an das State Department in Washington geschickt. Von deutscher Seite führten die erläuternden Gespräche Botschafter Karl H. Knappstein und sein Botschaftsrat Berndt von Staden. Ihnen saß der amerikanische Chefdelegierte William Forster gegenüber. Der Abrüstungsexperte zählte zusammen mit dem US-Botschafter in Moskau, Llewellyn Thompson, der als Unterhändler beim Nichtverbreitungsvertrag hinzugezogen wurde, zu den Experten des amerikanischen Außenministeriums.

Die Verhandlungen verliefen nicht einfach. Zusätzlich wurde die gespannte Atmosphäre dadurch belastet, daß die beiden Amerikaner in Botschaftskreisen als nicht deutschfreundlich galten. Sie zählten zu jenem Teil des „Ostküstenestablishments“, das in Europa lieber Paris, vor allem aber London besuchte, ohne nach Bonn zu kommen. Die Deutschen mußten sich denn auch den Vorwurf der Amerikaner gefallen lassen, ihr Land habe den Zweiten Weltkrieg entfesselt und wolle jetzt als einziger Staat die Unterzeichnung des Vertrages verweigern. Trotzdem gaben sich die Amerikaner Mühe, das Mißtrauen der Deutschen zu zerstreuen. Sie ließen sich Kritik gefallen, erklärte später von Staden. Sie betrachteten das Vertragswerk als ihr „Kind“ und taten alles, damit es sich weiter „entwickeln“ konnte ${ }^{172}$. In den ersten Wochen suchten die Deutschen zunächst die amerikanische Interpretation der Begriffe des geplanten Abkommens zu verstehen.

\footnotetext{
${ }^{168}$ Bulletin, Rede vor der Parlamentarischen Arbeitskonferenz der SPD vom 25.2.1967, 1.3.1967.

169 Neue Zürcher Zeitung, 27.2.1967.

$170 \mathrm{Vgl}$. Brandt, Atomsperrvertrag.

171 Neue Zürcher Zeitung, 25.2.1967.

172 Staden, Gespräch mit dem Verfasser, 5.11.1986.
} 
Wie würde die sowjetische Regierung die einzelnen Punkte in ihrem Sinne auslegen? Insbesondere ging es zunächst um deutsche Bedenken in der Frage, ob der Vertrag eine mögliche Atomstreitmacht innerhalb der geplanten Europäischen Union ausschließe oder nicht. Die Amerikaner gaben ihren Gesprächspartnern eine zufriedenstellende Auslegung. Ein politisch vereintes Europa werde durch den Vertrag nicht gebunden sein, versicherten sie. So hatte auch Brandt bei seinem Besuch in Washington die amerikanische Haltung verstanden ${ }^{173}$. Die US-Regierung zeigte sich davon überzeugt, daß auch Moskau sich mit dieser Interpretation einverstanden erklären würde. Allerdings hatten die Amerikaner einen kleinen Vorbehalt: Man solle die Sowjetregierung nicht dazu drängen, dies auch öffentlich zu erklären.

$\mathrm{Da}$ zwischen den beiden Supermächten über einen künftigen westeuropäischen $\mathrm{Zu}$ sammenschluß unterschiedliche Standpunkte existierten, wurde schnell in den Medien bekannt. Der Spiegel machte am 27. Februar 1967 auf folgende Abweichung aufmerksam: „Ein vereinigtes Europa kann unter Berufung auf die Rücktrittsklausel Atommacht werden, da es als neues Völkerrechts-Subjekt die Verpflichtungen seiner Vorgänger nicht übernimmt. " ${ }^{174}$ Nur die USA allein billigten den Rücktritt auch für den Fall zu, daß sich ein europäischer Bundesstaat oder Staatenbund stufenweise entwickeln würde. Bei den meisten Fragen konnten die Amerikaner den Deutschen nur ihre Interpretation darlegen, ohne die sowjetische Einschätzung zu kennen. Vielleicht vermittelten sie deswegen den Eindruck, als ob den Deutschen durch den Vertrag kaum ein Nachteil entstünde. Eine deutsche Mitsprache bei der Atomstrategie im McNamara-Komitee, die Bewaffnung der Bundeswehr mit Atomwaffen unter dem sogenannten Z wei-Schlüssel-Verschluß (ein Schlüssel befand sich im Besitz der deutschen, der andere bei amerikanischen Soldaten), sogar eine multilaterale Atommacht - all das sei erlaubt, sagten sie. Für die Bundesregierung wirkte zudem beruhigend, daß der Vertrag nicht die Nato-Verteidigung auf deutschem Boden berührte. Die Bestimmungen sollten nicht auf die Stationierung amerikanischer Atomwaffen in der Bundesrepublik angewendet werden, versicherten Forster und Thompson. Der Bundeskanzler selbst bestätigte diese amerikanische Auslegung. Die Gespräche hätten ergeben, daß bestehende Sicherheitsabmachungen im Nato-Bündnis von dem Atomsperrvertrag nicht berührt würden, erklärte Kiesinger am 21. Februar im Westdeutschen Rundfunk ${ }^{175}$.

Damit schienen deutsche Bedenken über mögliche militärische Nachteile zunächst ausgeräumt. Bundesaußenminister Brandt machte allerdings bei seinem Besuch im Februar 1967 deutlich, daß die bisherigen Erläuterungen und Erklärungen rechtlich verbindlich sein müßten. Sowohl die USA als auch die Sowjetunion müßten die Auslegung notifizieren. Der amerikanische Außenminister soll diesem Verlangen zugestimmt haben. Ohne die Notifizierung durch die sowjetische Führung werde es keinen Vertrag geben. Darüber hinaus verwies Brandt auf die Schwächen des Vertrages im Bereich der Forschung und wirtschaftlichen Nutzung der Kernenergie. Hier müßten noch Verhandlungen stattfinden. Die Bundesrepublik stehe dem Grundgedanken einer Nichtweitergabe von Kernwaffen positiv gegenüber und werde den Vertrag unterstützen, aber nur dann, wenn ihre industrielle Entwicklung dadurch nicht behindert werde ${ }^{176}$.

\footnotetext{
${ }_{173}$ Vgl. Welt am Sonntag, 12.2.1967.

${ }^{174}$ Der Spiegel, 27.2.1967, S. 27.

175 Vgl. Bulletin, Kiesinger im WDR, 22.2.1967.

${ }^{176}$ Vgl. Der Spiegel, 27.2.1967, S. 27.
} 


\section{Kiesinger zwischen SPD und Gaullisten}

Weniger entschlossen als sein Außenminister, den Vertrag ganz zu akzeptieren, zeigte sich der Bundeskanzler. Auf seiner ersten Pressekonferenz im Januar 1967 formulierte er seine Vorbehalte: „Wir haben, wie alle nichtnuklearen Mächte, ein Sicherheitsinteresse. Wir haben ein Interesse daran, nicht eines Tages Objekt von Erpressungen durch irgendeine Nuklearmacht zu werden. "Es gäbe auch wirtschaftliche Interessen, die berücksichtigt werden müßten, sagte er. Die Entwicklung von Nuklearwaffen bringe viele Nebenprodukte für die wirtschaftliche Entwicklung eines Landes hervor. Damit werde wieder das Thema der nuklearen "gap“, einer Lücke zwischen den atomaren und nichtatomaren Mächten, und die Frage einer nuklearen Zusammenarbeit aufgeworfen ${ }^{177}$.

Kiesinger teilte also die Bedenken, aber lehnte in diesen ersten Monaten eine Unterschrift nicht grundsätzlich ab. Der Kanzler war noch von der Notwendigkeit einer deutschen Zustimmung überzeugt. Er pflichtete der Ansicht seines Außenministers bei, daß man in der Ostpolitik nicht weiterkomme und der sowjetischen Propaganda in die Hände spiele, wenn man die Zustimmung versage. Die Bundesrepublik sah er allerdings einem außerordentlich starken Druck ausgesetzt. Die Londoner Äußerung des sowjetischen Ministerpräsidenten erschwerte eine positive Stellungnahme des Kanzlers. Kiesinger erklärte am 11. Februar in Oberhausen, die Bundesrepublik habe ein großes Interesse daran, daß der Besitz an atomaren Waffen beschränkt bleibe. Aber er sagte auch: „Wenn wir einen solchen Vertrag unterschreiben, dann zwingt uns niemand zu dieser Unterschrift, als unsere eigene Einsicht und unser eigenes Gewissen." 178

Natürlich war diese Bemerkung als Erwiderung auf das grobe, ungeschickte Wort des sowjetischen Politikers gemeint und zuerst an die Adresse des Kreml gerichtet. Aber schon bald wurde deutlich, daß der Kanzler beide Atommächte, also auch die USA, im Visier hatte. Ähnlich wie Brandt war Kiesinger darauf bedacht, die Vereinigten Staaten an die Pflicht zu gemahnen, selbst Abrüstungsvereinbarungen auf dem nuklearen Sektor einzuleiten. Der Atomsperrvertrag sei keine wirkliche Abrüstungsmaßnahme, kritisierte Kiesinger einige Tage später im Rundfunk. Trotz des Vertrages würden die Atommächte nicht nur ihr Potential erhalten, sie könnten es auch vergrößern. Es müßten daher Wege gefunden werden, die zu einer zunehmenden Einschränkung des Wettrüstens der Atommächte führten ${ }^{179}$.

Zunächst bemühte sich der Kanzler um eine eindeutige Stellungnahme der Bundesregierung. Am 16. Februar 1967 rief Kiesinger die Fraktionsvorsitzenden der Regierungsparteien, Barzel und Schmidt, sowie den Vorsitzenden der CSU-Landesgruppe Richard Stücklen zusammen. Etwas später kam auch Brandt hinzu. Die Runde war sich schnell darin einig, daß man nicht umhinkommen werde, den Vertrag zu unterzeichnen. Kiesinger forderte nach dieser übereinstimmenden Beurteilung durch die Fraktionschefs, man solle die Fraktionen auf diese Linie einschwören. Damit erklärten sich die Anwesenden einverstanden. Selbst der Vertreter der CSU, Stücklen, meinte angeblich, es müsse nicht sein, daß ,bei diesen Sachen die ganzen deutsch-nationalen Töne wieder hochkämen "180. Der Kanzler wollte auch Strauß einbinden, den er im Anschluß an die Koalitionsabsprache empfing. Aber dieser Versuch mißlang. Strauß, der am Tag zuvor den Droh-

177 Bulletin, Kiesinger auf einer Bundespressekonferenz, 18.1.1967.

${ }_{178}$ Bulletin, 15.2.1967.

179 Vgl. ebenda, 22.2.1967.

${ }^{180}$ Der Spiegel, 27.2.1967, S. 29. 
brief geschrieben hatte, habe ständig gedrängt, klagte Kiesinger später: „Ich solle sagen, wir würden das nie unterzeichnen." 181

Strauß wiegelte allerdings ab und erklärte sich einverstanden, die Diskussion um den Atomsperrvertrag nicht weiter anzuheizen. Der Kanzler schickte dann seinen Außenminister vor den Arbeitskreis der CDU/CSU-Fraktion, um die Gemüter zu beruhigen - was nur halb gelang. Zweifel am Vertrag blieben. Vor allem war das Mißtrauen groß, daß die Weiterentwicklung von Forschung und Wirtschaft im eigenen Land behindert werden könnte. Am 21. Februar erläuterte dann der Kanzler vor der Unionsfraktion seine Position. Die Diskussion müsse schnell verstummen, sagte er. Wenn man schließlich doch unterzeichne, gerate man in die Gefahr, als „Verzichtpolitiker“ bezeichnet zu werden ${ }^{182}$. Aber im Kabinett gab es anderntags keine eindeutige Stellungnahme. In der Fragestunde am 23. Februar formulierte Brandt vorsichtig, wie das Kabinett den Nichtweitergabevertrag beurteilte: Ihm sei kein Kabinettsmitglied bekannt, das grundsätzlich gegen das Ordnungselement der Nichtverbreitung von Atomwaffen sei.

Das war nicht viel. Wie dünn das Eis tatsächlich war, auf dem sich die Koalition bewegte, zeigte sich in den Äußerungen der beiden Fraktionsvorsitzenden vom selben Abend. Barzel erklärte zwar, daß es der Bundesregierung gelingen werde, die erwünschte Unterschriftsleistung der Bundesrepublik Deutschland zu ermöglichen. Aber er kritisierte die schwache Seite des Vertrages: die Aussparung der atomaren Mächte von allen Abrüstungsschritten. Die Friedensnote der Bundesregierung vom März 1966 sei wesentlich weiter gegangen als der jetzige Vertrag, behauptete Barzel. Man habe damals einen Vorschlag unterbreitet, „einen Vorschlag, den ich, erlauben Sie, dies zu sagen, nach wie vor für vernünftiger halte und für wirksamer als das, was jetzt in Genf erörtert wird “"183.

Aber ein scheinbarer Kompromiß im Kabinett war zunächst erreicht, ohne daß freilich eine endgültige Entscheidung getroffen worden wäre. Mit diesem Ergebnis in der Tasche hoffte Kiesinger, daß sich auch die Diskussion in der Öffentlichkeit wieder beruhigen würde. Bei aller Kritik, fand der Bundeskanzler, müsse die nüchterne Analyse überwiegen. Die scharfen Attacken von Mitgliedern der Union fand er überzogen. Am Freitag, dem 24. Februar, empfahl der Kanzler in Stuttgart der deutschen Öffentlichkeit eine „maßvolle Diskussion“ und das „rechte Augenmaß“. Die Bundesregierung sehe die Probleme des Atomsperrvertrages genau. Die bisherige Diskussion sei „zu aufgeregt“ geführt worden. Dabei erwähnte Kiesinger auch den Namen Adenauer ${ }^{184}$.

\section{Adenauers Kritik an Kiesinger}

Es dauerte nicht lange, bis der Ehrenvorsitzende der CDU auf diese Mahnung reagierte. Nur zwei Tage später schrieb Adenauer in strengem Ton an Kiesinger: „Allgemein gesagt, steht Ihnen natürlich das Recht zu, Kritik an mir auch in der Öffentlichkeit zu üben.

181 AdKASt, Kiesinger I - 226, F/3., A 322, Gespräch mit Löwe, 31.1.1978, S. 10.

${ }^{182}$ Der Spiegel, 27.2.1967, S. 30.

${ }^{183}$ BPA, Barzel im ZDF, 23.2.1967, Anhang, S. 3; EA 21 (1966), Folge 7, Note der Bundesregierung vom März 1966, S. D 175 ff. Tatsächlich hatte die März-Note einen Vorschlag enthalten, mit dem man hoffte, das Wettrüsten der atomaren Waffen einschränken zu können. Die Bundesregierung erklärte sich bereit, einem Abkommen zuzustimmen, „in dem die in Frage kommenden Staaten sich verpflichten, die Zahl der Atomwaffen in Europa nicht weiter zu erhöhen, sondern sie stufenweise zu verringern. Ein solches Abkommen müßte sich auf ganz Europa erstrecken, das Kräfteverhältnis insgesamt wahren, eine wirksame Kontrolle vorsehen und mit entscheidenden Fortschritten bei der Lösung der politischen Probleme in Mitteleuropa verbunden werden."

${ }^{184}$ Die Welt, 25.2.1967. 
Ich darf aber darauf hinweisen, daß auch mir das Recht der Kritik an Ihren Reden oder Handlungen zusteht. Ich habe das bisher nicht getan, weil ich glaube, daß es nicht gut ist, wenn Sie und ich uns gegenseitig öffentlich kritisieren. Ich würde es für richtig halten, wenn wir vor öffentlicher Kritik uns gegenseitig schriftlich oder mündlich aussprächen. Ich habe sehr ernste Sorgen wegen der flauen Haltung Ihrer Regierung und Ihrer selbst, die Sie gegenüber der US und SU in dieser lebenswichtigen Frage einnehmen. Wenn Sie und Ihre Regierung und die von dieser beeinflußten Presse, Funk und Fernsehen eine solch euphoristische Sprache haben, wird Ihre Stimme kein Gehör finden. Ich bitte Sie, mir das aufgrund meiner langjährigen Erfahrung zu glauben. Auch das, was wir unter der Kanzlerschaft Erhards erlebt haben, bestätigt diese meine Meinung.“

Gerade "Ihre Haltung" habe ihn zu seinen scharfen Reden veranlaßt, in denen er übrigens den Bundeskanzler namentlich nie erwähnt habe. Um seinen Worten Nachdruck zu verleihen, fügte Adenauer einige Zeitungsartikel bei und meinte, die an diesem Tag in der Presse gemeldete Erklärung des amerikanischen Verhandlungsführers bestätige die Richtigkeit seiner Auffassung. Welchen Einfluß die Haltung der Deutschen auf Frankreich ausübe, könne der Kanzler einer Äußerung von Agence France Press entnehmen. „General de Gaulle zieht daraus Schlüsse für unsere Abhängigkeit von den Vereinigten Staaten, die nicht günstig für uns sind“, warnte Adenauer zum Schluß ${ }^{185}$.

Die öffentliche Kritik Kiesingers an seiner politischen Meinung muß den Ehrenvorsitzenden der CDU besonders irritiert haben. Denn Adenauer hatte am selben Tag, an dem ihn Kiesinger in Stuttgart angriff, den Kanzler als Kandidaten für den Vorsitz der Partei vorgeschlagen. In dieser Frage hatte Adenauer seine Meinung revidiert. Noch Anfang Februar erklärte er, es sei am besten, wenn nicht der Bundeskanzler als Nachfolger Erhards das Amt des CDU-Vorsitzenden übernähme. Vielmehr empfehle er eine Ämtertrennung. Doch bald darauf sparte Adenauer nicht mit Lob für die neue Regierung und ihren Kanzler. Er könne "nur im Falle Kiesingers“ die Personalunion von Kanzler und Parteivorsitz empfehlen, hieß es jetzt. Kiesinger mache seine Sache gut, und die Große Koalition lasse sich gut an. Das Lob galt auch dem Koalitionspartner. Adenauer rühmte den Fleiß der sozialdemokratischen Minister ${ }^{186}$.

Aber jetzt hatte Kiesingers Bemerkung das Klima verändert. Die öffentliche Kritik Kiesingers an Adenauers Warnungen vor dem NV-Vertrag führte dazu, daß der Altbundeskanzler sofort einen scharfen Ton gegenüber dem Regierungschef anschlug. Der Brief enthielt bewußt provozierende Worte: Wenn Adenauer die Haltung Kiesingers gegenüber den USA als „flau“ bezeichnete oder vor einer „euphoristischen“ Sprache warnte, dann sollten diese Worte beleidigen, demütigen, verletzen. Immer dann, wenn Adenauer die Auseinandersetzung suchte, so hat es Baring formuliert, habe er die Distanz gesucht, dann habe sich seine Unnahbarkeit, seine Kühle und Härte gezeigt. Auseinandersetzung habe für Adenauer immer auch Demütigung für den anderen bedeutet ${ }^{187}$.

Den Streit mit dem Kanzler suchte Adenauer auch deshalb, weil die Zeitungen vom 25. und 26. Februar sein Mißtrauen zu bestätigen schienen, Washington selbst stecke hinter den Kontrollbestimmungen des Vertrages. Über den schwierigen Anfangsdialog in Genf zwischen den beiden Supermächten hatte sich nämlich inzwischen auch der Chefunterhändler Forster enttäuscht geäußert. Die Vereinigten Staaten könnten bereit sein,

${ }^{185}$ AdKASt, Kiesinger I - 226, D/IV.6, A 001, Adenauer an Kiesinger vom 27.2.1967.

186 Neue Zürcher Zeitung, 25.2.1967. Siehe auch die vertrauliche Einschätzung Adenauers bei Schwarz (Der Staatsmann, S. 977), Wehner sei heute der stärkste Mann im Kabinett. Selbst Kiesinger suche es ihm in erster Linie recht zu machen.

${ }_{187}$ Vgl. Baring, Sehr verehrter Herr Bundeskanzler!, S. 172. 
auf jegliche obligatorische Kontrolle der Ausführungsbestimmungen zu verzichten, hatte Forster vor der Presse erklärt. Und dann folgte der Satz, den Adenauer für bezeichnend hielt: „Auf bohrende Fragen amerikanischer Journalisten gestand Forster, daß die Kontrollforderung ein amerikanisches Kind ist und sich die Sowjetunion daran immer desinteressiert gezeigt habe. " ${ }^{188} \mathrm{Da}$ stand es schwarz auf weiß: Nicht dem expansiven sowjetischen Streben nach Kontrolle über Westeuropa verdankte die Bundesregierung den gefährlichen Kontrollartikel, sondern dem eigenen Bündnispartner, der eigenen Schutzmacht! Das Mißtrauen Adenauers, das sich schon Ende der fünfziger Jahre nach dem Tode von John Foster Dulles, dem früheren amerikanischen Außenminister, gebildet hatte, verstärkte sich noch. Schließlich hatte auch - worauf Adenauer Kiesinger ebenfalls hinwies - der Pariser Korrespondent im Rbeinischen Merkur dargelegt, wie die Amerikaner in der Vergangenheit verhindert hatten, daß Frankreich unkontrolliert in den Besitz von Plutonium gelangen konnte ${ }^{189}$.

Adenauer fürchtete vor allem Rückwirkungen auf das Verhältnis zu de Gaulle. Falls die Bundesregierung den Vertrag unterzeichnete, konnte der französische Staatspräsident dies nur so deuten, daß sich die militärische Abhängigkeit der Deutschen von den Amerikanern noch vergrößerte. Die Berichterstattung in den französischen Medien erweckte tatsächlich diesen Eindruck. Unter der Überschrift „In Genf und Washington: Deutsch-amerikanische Gespräche“ meldete die Agentur AFP, die Gespräche am Rande der Abrüstungskonferenz zwischen dem deutschen Beobachter in Genf, dem Diplomaten Swidbert Schnippenkoetter, und dem Chef der amerikanischen Delegation, Forster, stellten die eigentlichen Verhandlungen dar. Das Zusammentreffen der beiden sei von größter Diskretion umgeben gewesen, berichtete die Agentur. Es sei keine öffentliche Erklärung erfolgt. „Wenn es wahr ist, was eine vertrauensvolle Quelle inzwischen angedeutet habe, dann habe der Bonner Beobachter in Genf die Haltung seiner Regierung deutlich gemacht, daß die wirklichen Gespräche zwischen der Bundesrepublik Deutschland und den Vereinigten Staaten über eine mögliche Ratifizierung eines künftigen Vertrages gegenwärtig in Washington stattfänden. "190

Für Adenauers Argument, Bonns Zustimmung zum Sperrvertrag könne das Verhältnis zu Paris schnell wieder abkühlen, sprachen auch Hinweise, die Kiesinger im Februar 1967 von einem Informanten außerhalb der Diplomatie zugetragen worden waren. Kiesinger hatte zwar öffentlich betont, daß der General ihm bei seinen Gesprächen keine Empfehlung gegeben habe. Dennoch mahnten französische Stimmen die Deutschen zur Vorsicht. Der Intendant des Saarländischen Rundfunks, Mai, ein früherer Mitarbeiter Adenauers, schickte dem Kanzler am 15. Februar einen Bericht über eine Begegnung mit französischen Politikern, darunter einem früheren Minister. „Es schien mir im Hintergrund auch die Sorge wach zu sein“, schilderte Mai den Gesprächsablauf, „daß die gemeinsame Verteidigungspolitik in Europa bei seiner Unterzeichnung erhebliche Schwierigkeiten machen würde. Man wird zwar von französischer Seite Deutschland niemals den Mitbesitz nuklearer Waffen einräumen, weil man dies offenbar Moskau und den Ostblockstaaten versprochen hat. Auf der anderen Seite scheint der Weg einer nuklearen Verteidigungsgarantie durchaus möglich zu sein, wobei man allerdings offenbar auf unsere wissenschaftliche und technische Hilfe hofft. " ${ }^{191}$ Die deutsche Unterschrift unter

${ }^{188}$ Die Welt, 25./26.2.1967

189 Vgl. Rheinischer Merkur, 24.2.1967.

${ }^{190}$ Le Monde, 26./27.2.1967.

191 AdKASt, Kiesinger I - 226, D/IV.6, A 006, Mai an Kiesinger vom 15.2.1967, Blatt 2. 
den Vertrag konnte also einer Verbesserung und Vertiefung der deutsch-französischen Beziehungen im Wege stehen, sie vielleicht sogar behindern. Das war zumindest der Schluß, den Kiesinger aus dem Bericht ziehen mußte. Adenauers Mahnung, daß die Unterzeichnung durch die Bundesrepublik negative Rückwirkungen bei de Gaulle haben könnte, schien daher berechtigt.

Der Brief Adenauers verfehlte seine Wirkung auf Kiesinger nicht. Der Kanzler fühlte sich in die Defensive gedrängt. Diesmal äußerte sich das auf eine spektakuläre Art und Weise.

\section{"Atomares Komplizentum" - Kiesinger behauptet sich gegenüber den Gaullisten}

Bundeskanzler Kiesinger war am Montagmorgen, dem 27. Februar 1967, wie in den Anfangsmonaten gewöhnlich aus Tübingen mit dem Zug in Bonn eingetroffen. Er begab sich sofort in das Bundeskanzleramt. Für den späten Vormittag war eine Rede vor dem Verein der Union-Presse vorgesehen, einer Vereinigung von Journalisten, die für die CDU/CSU schrieben oder ihr zumindest nahestanden. Das war für den zukünftigen Parteivorsitzenden ein ideales Forum: Hier konnte er offen sprechen. Kiesinger machte sich keine Sorgen um seinen Vortrag. Er wollte das Aktuelle ansprechen, die Aufnahme der Beziehungen zu Rumänien, den Appell an Moskau, den an Ost-Berlin und zum Abschluß einige Worte zum Atomsperrvertrag. Doch es kam anders.

Im Palais Schaumburg eingetroffen, sah er die Post durch. Ein Brief von Adenauer war dabei - vom gleichen Tage, nur wenige Stunden zuvor diktiert und getippt. Der Kanzler öffnete, las, und seine Stimmung verdüsterte sich. Es war jener - bereits oben wiedergegebene - Brief, in dem der Altbundeskanzler seine Politik gegenüber den USA tadelte. Der Ton des Schreibens traf ihn unvorbereitet. Die privaten Beziehungen zu Adenauer hatten sich seit der Abgabe der Regierungserklärung Mitte Dezember 1966 gut entwickelt. Auf Wunsch des CDU-Ehrenvorsitzenden hatte das Parteipräsidium zum Geburtstag Adenauers am 5. Januar keinen Gratulationsempfang gegeben, sondern nur ein Abendessen im kleinen Kreis ausgerichtet. Kiesinger hatte es übernommen, die Leistung des verdienten Bundeskanzlers zu würdigen. Am nächsten Tag schrieb ihm Adenauer freundlich und dankte, er möchte noch einmal wiederholen, „was ich im Kreise unserer Parteifreunde schon sagte, daß ich Ihnen für die Lösung der großen, für das Schicksal unseres Landes so bedeutungsvollen innen- und außenpolitischen Aufgaben Glück und Segen wünsche“192. Kiesinger besaß den Segen Adenauers. So schien es.

Inzwischen waren fünf Wochen vergangen, und beide Unionspolitiker hatten sich seit dieser Zeit nicht mehr getroffen. Auch wegen der wohlwollenden Worte, mit denen Adenauer öffentlich die Große Koalition bedachte, mußte Kiesinger annehmen, daß sich an dem guten Einvernehmen nichts geändert hatte. Um so mehr war er von der Schärfe des Tons überrascht, den Adenauer jetzt anschlug. Flaue Haltung? Dieses Urteil fand Kiesinger schlicht falsch. Die USA hatte er seit Beginn seiner Amtszeit eher stiefmütterlich behandelt. Er war nicht überstürzt nach Washington gereist, wie es Adenauer 1961 und Erhard nach seiner Wahl 1963 getan hatten. Und er hatte sich deutlich von seinen beiden Vorgängern abgehoben, als er von den „amerikanischen Interessen in Europa“ sprach, um zu verdeutlichen, daß sich die Interessen der Bundesrepublik nicht automatisch mit denen der USA deckten. Die Worte „flaue Haltung“ empfand er als verletzend. Und was sollte schon mit „euphoristischer“ Sprache gemeint sein?

${ }^{192}$ AdKASt, Kiesinger I - 226, D/IV.6, Adenauer an Kiesinger am 6.1.1967. 
Vor der Union-Presse äußerte er sich wenige Stunden später in der Beethoven-Halle über Fragen der Außen- und Innenpolitik. Mit Sorge betrachte er das Verhältnis zu den westlichen Verbündeten, insbesondere zu den Vereinigten Staaten, leitete Kiesinger zum Thema über. So könne es nicht weitergehen, rief er aus: „Wir reden ja überhaupt nur noch über Streitfragen miteinander. Wir reden ja gar nicht mehr über gemeinsame Politik. Was wir einmal aufgebaut haben und was angefüllt war mit einem unbändigen Willen zur Freiheit der Welt, das droht zum leeren Gehäuse, zum bloßen Apparat zu werden: Nato, Bündnisgeist der Nato. “193

Was hier wie die Klage über den existierenden Zustand der Nato klang, war in Wahrheit als Vorwurf an die Adresse der USA gedacht. Kiesinger wollte offensichtlich zeigen, daß die Behauptung Adenauers einer "flauen“ Haltung gegenüber Washington nicht zutraf. Und gleich anschließend wandte sich Kiesinger mit der folgenden Bemerkung direkt an Adenauer: „General de Gaulle wirft uns Deutschen vor, wir seien den Amerikanern gegenüber zu gehorsam; alle, auch Adenauer.“ 194

Das war ein Satz, dessen Inhalt freilich niemand im Saal verstehen konnte. Kiesinger bereitete diese kleine Spitze gegen den CDU-Ehrenvorsitzenden eine gewisse Genugtuung. Machte es sich Adenauer nicht zu leicht, wenn er die Probleme mit Frankreich jetzt allein der Großen Koalition anzulasten schien? Schließlich war es Adenauer selbst gewesen, der die enge Bindung zu den USA mit dem damaligen Außenminister Dulles eingegangen war. Jetzt traute Kiesinger Adenauer sogar zu, bewußt einen Bruch mit den USA herbeiführen zu wollen ${ }^{195}$. Für Kiesinger drohte der Altbundeskanzler den Boden der deutschen Realität zu verlassen.

Zum Teil stimmte Kiesinger dem Gründer der westdeutschen Republik in seiner Rede allerdings zu: Es sei seine Aufgabe als Kanzler, festzustellen, inwieweit die amerikanischen Interessen mit den deutschen und denen der anderen Europäer noch übereinstimmten. Auf dem Höhepunkt des Kalten Krieges seien die Interessen weithin identisch gewesen. Seitdem habe sich allerdings "diese merkwürdige, fast paradoxe Situation herausgebildet, die offenbar von keiner Diplomatie so richtig in den Griff genommen worden ist. Das Bündnis besteht weiter. Der Antagonismus besteht weiter. Aber darüber hat sich so eine Form des atomaren Komplizentums oder der gemeinsamen atomaren Verantwortlichkeit gebildet, die diese Antagonisten immer näher und näher zusammenzwingt. ${ }^{~}{ }^{196} \mathrm{Im}$ Falle des Atomsperrvertrages habe keine gründliche Beratung zwischen den Verbündeten stattgefunden, mahnte Kiesinger. In Zukunft werde er auf einer umfassenden und gründlichen Beratung der politischen Zusammenhänge bestehen, kündigte er an.

Tatsächlich hatte sich der Kanzler darüber geärgert, auf welche Weise der amerikanische Botschafter, McGhee, ihn über die einzelnen Punkte des Atomsperrvertrages informiert hatte. McGhee habe buchstäblich aus seiner Brusttasche kleine Zettel mit einzelnen Formulierungen hervorgeholt, berichtete der Persönliche Referent des Kanzlers, Neusel, später. Diese unprofessionelle Vorbereitung des amerikanischen Botschafters empörte Kiesinger ${ }^{197}$. Sie schien ihm kein Einzelfall zu sein. Schon einmal, am 8. Oktober 1963, hatte er die amerikanische Regierung rügen müssen, weil die Bundesregierung über das Teststoppabkommen nicht hinreichend unterrichtet worden war. Damals traf

\footnotetext{
193 Oberndörfer (Hrsg.), Große Koalition, S. 36.

194 Ebenda.

${ }^{195}$ Schwarz (Staatsmann, S. 976) berichtet, Kiesinger habe dies Ahlers gegenüber bemerkt.

196 Oberndörfer (Hrsg.), Große Koalition, S. 36.

197 Vgl. Neusel, Gespräch mit dem Verfasser, 30.9.1989.
} 
er als Bundesratspräsident im Weißen Haus mit Präsident Kennedy zusammen - nur wenige Wochen vor dessen Tod. Kennedy wies seinen Sicherheitsberater an, auf verbesserte Konsultationen zu achten ${ }^{198}$. Aber es hatte sich offensichtlich nicht viel geändert, wie Kiesinger jetzt, vier Jahre später, feststellen mußte.

Den direkten Anlaß für Kiesingers Vorwurf, es bestehe eine Art „atomares Komplizentum" zwischen den Supermächten, lieferte allerdings der Brief von Adenauer. Das verriet Kiesingers Antwortschreiben, obwohl es in scheinbar gelassenem Ton verfaßt wurde. Aber schon die Tatsache, daß Kiesinger die Anrede „Sehr verehrter“ wegließ, deutete darauf, daß er gleich zu Beginn eine Distanz aufbauen wollte. Kiesinger hatte ernste, unerfreuliche Dinge mitzuteilen:

„Ich bin mit Ihnen darin einig“, hieß es, „daß wir uns nicht öffentlich kritisieren oder jedenfalls vor einer solchen öffentlichen Kritik uns gegenseitig aussprechen sollten. Ich habe in meinen bisherigen Stellungnahmen Ihre eigenen Äußerungen, die für jeden intelligenten Leser eine deutliche Kritik an der Politik meiner Regierung darstellen, kaum berührt. Sie schreiben mir, Sie hätten sehr ernste Sorgen wegen der, flauen Haltung' meiner Regierung und meiner selbst gegenüber der US und der SU in der Frage des Atomsperrvertrages. Ich muß dieser Auffassung auf das Entschiedenste widersprechen; wer eine maßvolle Sprache spricht, treibt deswegen noch lange keine, flaue` Politik. Was ich in Oberhausen sagte, gilt für mich nach wie vor: Die Entscheidung darüber, ob wir den Atomsperrvertrag unterschreiben oder nicht, wird ausschließlich durch unsere eigene Einsicht und durch unser eigenes Gewissen bestimmt. Wenn Sie meine Äußerungen genau gelesen haben, werden Sie übrigens kaum einen Anlaß finden festzustellen, ich hätte ,euphoristisch' gesprochen. Im übrigen halte ich mich über alles, was mit diesem Vertrag zusammenhängt, und auch über die Meinungen in den verschiedenen Hauptstädten dazu auf das Genaueste unterrichtet. “ Dann schloß Kiesinger mit Worten, die noch immer seinen Zorn verrieten: „Seien Sie überzeugt, daß meine Sorgen gegenüber diesem Vertrag nicht geringer sind als die Ihrigen. Und nicht geringer ist auch meine Entschlossenheit, die lebenswichtigen deutschen Interessen gegenüber diesem Vertrag zu wahren. Es wäre, auch um des Zusammenhalts unserer Partei willen, gut, wenn wir uns bald über dieses schwierige Problem unterhalten würden. “ 199

Kiesinger unterzeichnete mit „hochachtungsvollen Grüßen“, ließ das „Ihnen sehr ergebener" früherer Briefe weg. Er wollte keinen Zweifel daran lassen, wer in der Großen Koalition die Richtlinien deutscher Außenpolitik entschied. Wie sehr ihn die Vorwürfe, eine „flaue“ Haltung zu haben und eine „euphoristische“ Sprache zu verwenden, dennoch getroffen und geärgert hatten, zeigte die Wortwahl: Da er seine Äußerungen „maßvoll“ nannte, konnte die Kritik daran nur von der Maßlosigkeit des CDU-Ehrenvorsitzenden zeugen. Kiesinger wollte also auch verletzen, wollte mit gleicher Münze heimzahlen. Trotz dieser scheinbar versteckten Spitzen war der Kanzler darum bemüht, die Gemeinsamkeiten zu betonen: Seine Sorgen gegenüber dem Vertrag seien nicht geringer als diejenigen Adenauers. Auch er sei entschlossen, die lebenswichtigen deutschen Interessen zu wahren. Der letzte Satz, ein Angebot eines persönlichen Gespräches, gab dem Brief eine versöhnliche Wendung. Am guten Einvernehmen mit dem „Alten“ war dem Kanzler nicht nur aus Respekt vor dem Politiker und Staatsmann gelegen. Kiesin-

${ }^{198}$ Vgl. Lilienfeld, Besuch bei Kennedy, S. 292.

199 AdKASt, Kiesinger I - 226, D/IV.6, Kiesinger an Adenauer vom 28.2.1967. Der Spiegel (24.4.1967, S. 31) berichtet, Kiesinger habe den letzten Briefwechsel mit Adenauer einen „heftigen Briefwechsel“ genannt. 
ger hatte mit ansehen müssen, wie die Kritik Adenauers dazu beitrug, die Position Erhards langsam, aber nachhaltig zu schwächen. Diese Gefahr drohte auch ihm. Daher war er darauf bedacht, daß das Verhältnis zwischen beiden nicht dauerhaft belastet würde.

Aus diesem Grund suchte er bei Adenauer den Eindruck zu erwecken, als ob beide am Ende doch dieselbe Politik verfolgten. Das galt für seine Frankreichpolitik ebenso wie die Haltung gegenüber dem Sperrvertrag. Den entscheidenden Beitrag dazu hatte er bereits in der Pressekonferenz vom Vortag geleistet, indem er die Regierung der Vereinigten Staaten mit dem Vorwurf des „atomaren Komplizentums“ bedachte. Hier zeigte sich eine Eigenart von Kiesinger: Ganz offensichtlich hatte Adenauers Kritik diese scharfe Sprache ausgelöst. Eigentlich zwang das Naturell Kiesingers ihn eher dazu, abzuwiegeln, herunterzuspielen, Polemik beiseite zu lassen und um Ausgleich bemüht zu sein. Aber wenn er kritisiert oder gedrängt wurde, konnte er impulsiv reagieren und handeln. Das fiel besonders nach Gesprächen mit Staatsmännern oder anderen bedeutenden Persönlichkeiten auf, denen Kiesinger scheinbar unbefangen gegenübertrat, sich jedoch sichtlich von ihnen beeindrucken, ja beeinflussen ließ. Das war etwa bei Adenauer, General de Gaulle und auch bei Wehner der Fall. Kaum vier Wochen waren vergangen, als Kiesinger auf seiner ersten großen Pressekonferenz, unmittelbar unter dem Eindruck der Gespräche mit de Gaulle, erklärt hatte, Amerika vertrete in Europa amerikanische Interessen, aber es gebe daneben auch europäische Interessen ${ }^{200}$. Kein Bundeskanzler hatte das vorher zu sagen gewagt. Beide Male schien Kiesinger mit seinem öffentlichen Auftreten sich selbst bestätigen zu müssen. Diese ungewöhnlich scharfen und provozierenden Äußerungen entstanden aus dem Augenblick, waren nicht wie sonst sorgfältig durchdacht.

\section{Adenauers letzter Appell}

Aber Adenauer genügten Kiesingers öffentliche und private Beteuerungen nicht. Drei Wochen nach der Mahnung, nicht zu weich gegenüber den USA aufzutreten, schrieb er am 22. März 1967 erneut. Er berichtete Kiesinger vom Besuch des französischen Staatspräsidenten im Sommer 1966. Damals habe er in einem persönlichen Gespräch in seinem Bonner Büro de Gaulle prophezeit, daß im Herbst eine Änderung der Regierung eintreten werde. Dann werde auch Schröder nicht mehr Außenminister sein. Die Grundhaltung des neuen Kabinetts werde den „Freundschaftsvertrag mit Leben erfüllen“. De Gaulles Aufgabe werde es sein, die Politische Union Westeuropas herbeizuführen. „Frankreich müsse darangehen, wir gingen mit. Er hat meinen Ausführungen nicht ausdrücklich zugestimmt, aber erkennen lassen, daß sie ihn beeindruckten." ${ }^{201}$

Und das war noch nicht alles. Am 3. April besuchte der Kanzler Adenauer zum letzten $\mathrm{Mal}^{202}$. Im Mittelpunkt der Unterhaltung sei es um das deutsch-französische Verhältnis gegangen. „Er sprach mit einer Dringlichkeit, als wolle er noch vom Krankenbett aus in der letzten ihm vergönnten Frist eine günstige Wendung erzwingen“, schrieb Kiesinger später ${ }^{203}$. Die Chancen eines Richtungswechsels der deutschen Politik schienen Adenauer durch eine Rede des amerikanischen Vizepräsidenten Hubert Humphrey

200 Vgl. Bulletin, 18.1.1967.

201 AdKASt, Kiesinger I - 226, D/IV.6, Adenauer an Kiesinger vom 22.3.1967.

$202 \mathrm{Vgl}$. Kiesinger, So war es, sowie Kiesinger, Gespräch mit Baring, 16.6.1977. Dort heißt es, man habe dem Altbundeskanzler das nahe Ende schon ansehen können. Zusammengefallen habe er auf einem Stuhl gesessen. Sein Hals bedeckte ein Tuch, das eine offene Wunde verbergen sollte.

${ }^{203}$ Ebenda. 
gestiegen. Wenige Tage zuvor hatte der Amerikaner ein starkes und unabhängiges Europa gefordert und eine gleichberechtigte Partnerschaft mit dem atlantischen Bündnis anvisiert. Adenauer habe sich von den Vorschlägen Humphreys neue Impulse für das Bündnis ebenso wie für die Einigung Europas erhofft, erzählt Kiesinger. Die deutsche Ostpolitik müsse stärker im Zusammenhang mit dem Verhältnis zu Frankreich gesehen werden. Nur in einem Zusammengehen mit Frankreich könnten die Spannungen in Europa verringert und dann auch das große deutsche Anliegen gelöst werden. Auf de Gaulle sei in der Wiedervereinigungsfrage Verlaß. Er habe vor allem in Moskau unbeirrt in unserem Sinne Stellung genommen.

Kiesinger verabschiedete sich von Adenauer. Einen Tag später erhielt er überraschend einen weiteren Brief des Altkanzlers mit einer Botschaft de Gaulles: „Als Sie gestern bei mir waren, hatte ich noch keine Antwort. Ich wollte erst, wenn ich sie in meinem Besitz hätte, sie Ihnen mitteilen. Heute mittag kam sie; ich finde sie sehr gut und aussichtsreich. Ich empfehle Ihnen, wenn Sie erlauben, die weitere Entwicklung in Ihre Hand zu nehmen. Ich danke Ihnen für den gestrigen Besuch und unsere Aussprache, über die ich sehr froh und glücklich bin. ${ }^{204}$ Nicht nur die Aufforderung, Kiesinger solle die Entwicklung in die Hand nehmen, auch die zittrige Handschrift, mit der der Altbundeskanzler die außergewöhnlich lange und herzliche Grußformel schrieb, zeigte, daß Adenauer langsam seine feste Haltung verlor, sein Leben Stück für Stück aufgeben mußte. Noch deutlicher wird dies im Gratulationsbrief vom folgenden Tag, dem letzten Schreiben Adenauers an Kiesinger. Der sonst so saubere Eindruck der Briefe Adenauers wurde dadurch gestört, daß er „wie immer" mit dicker Feder durchgestrichen hatte. Seinen Namen schrieb er nicht mehr aus, nur ein großes, am Ende abgebrochenes A blieb übrig ${ }^{205}$. Kiesinger verstand, daß der Altbundeskanzler noch soviel wie möglich in kurzer Zeit erreichen wollte. Und Adenauer tat nichts anderes, als ihm sein Vermächtnis anzubieten! Kiesinger beurteilte die außenpolitische Lage jedoch anders. Im Verhältnis beider Staaten hatte sich auch durch das Telegramm de Gaulles nichts verändert. Den entscheidenden Satz des nur vier Sätze umfassenden Antworttelegramms an Adenauer hatte de Gaulle so formuliert: „Wie Sie bin auch ich davon überzeugt, daß für unser Europa der Weg zur Einheit über den Fortschritt in die Unabhängigkeit führt. “206

Dem Kanzler war die Diskrepanz zwischen der Aussage de Gaulles und der Interpretation Adenauers nicht entgangen. Das Schlüsselwort für die Meinungsverschiedenheit zwischen Paris und Bonn lautete: Unabhängigkeit. Offenbar hatte Adenauer diesen deutlichen Hinweis im Brief des Staatspräsidenten nicht bemerken wollen. Es schien für die Beziehung Adenauers zu de Gaulle charakteristisch zu sein, daß Adenauer noch an die politische Gemeinsamkeit glaubte, selbst als offenbar geworden war, daß sich ihre Politik konzeptionell unterschied. Das galt für das Ziel einer bundesstaatlichen europäischen Union mit supranationalen Elementen, die Adenauer anstrebte, oder einen Staatenbund, wie ihn de Gaulle wollte. Über die Jahre sah es immer mehr danach aus, als ob die beiden führenden Staatsmänner aneinander vorbeiredeten und sich trotzdem

${ }^{204}$ AdKASt, Kiesinger I - 226, D/IV.6, Adenauer an Kiesinger vom 4.4.1967; vgl. Kiesinger, So war es, 17.11.1974.

${ }^{205}$ AdKASt, Kiesinger I - 226, D/IV.6, Adenauer an Kiesinger vom 5.4.1967. Kiesinger (So war es, 17.11.1974) verschweigt diesen Brief - vermutlich aus Pietät. In seinem Artikel heißt es, der Brief vom 4. April sei "das letzte Wort" gewesen, „das ich von Konrad Adenauer empfing“.

${ }^{206}$ AdKASt, Kiesinger I - 226, D/IV.6, Adenauer an Kiesinger am 4.4.1967, Abschrift eines Telegramms de Gaulles vom 4.4.1967; vgl. Kiesinger, So war es, I, 17.11.1974. 
versicherten, daß sie beide das gleiche Ziel verfolgten. So war es auch hier. Zumindest schien Kiesinger von dem Mißverständnis beider Politiker überzeugt zu sein. Der letzte Tausch persönlicher Botschaften, meinte er später, habe klar gezeigt, daß Adenauer de Gaulle nicht verstanden habe. Es bliebe nur die Frage offen, ob der Altbundeskanzler vielleicht schon so krank gewesen sei, daß er die Wirklichkeit nicht mehr wahrgenommen habe. Doch diesen Erklärungsversuch akzeptierte selbst Kiesinger nicht. Er habe Adenauers Methode gekannt: Dieser habe einfach zugegriffen, wo er geglaubt habe, „hier kanns weitergehen". Wichtig sei für Adenauer lediglich gewesen, daß es in einer Richtung Fortschritte gab ${ }^{207}$.

Aber Kiesinger verschleierte mit dieser Deutung, die allein den überhöhten Forderungen de Gaulles die Schuld am Stillstand des deutsch-französischen Verhältnisses anlastete, daß seine eigene Frankreichpolitik ein enges Bündnis nach gaullistischen Vorstellungen nicht zuließ. Er wollte auf keinen Fall die Abhängigkeit von Washington gegen eine Abhängigkeit von Paris eintauschen. Insofern machte sich Adenauer falsche Hoffnungen, wenn er Kiesinger das Vermächtnis in die Hand legte, mit de Gaulle die politische Union auf den Weg zu bringen.

Als Adenauer zwei Wochen darauf in Rhöndorf starb, endete auch jene Debatte zwischen Atlantikern und Gaullisten, die die außenpolitische Diskussion der Bundesrepublik seit Beginn der Großen Koalition bestimmt hatte. Mit Adenauer verlor sie ihren prominentesten Vertreter. Kiesinger aber verlor zugleich seinen schärfsten und gefährlichsten Kritiker. Künftig wurde der Streit um den Atomsperrvertrag nur noch im $\mathrm{Zu}$ sammenhang mit der Ostpolitik und den konzeptionellen Vorstellungen der Sozialdemokraten geführt. Kiesinger entschied sich jetzt gegen die Annahme des Vertrages. Diese Haltung, und nicht die Fortentwicklung der deutsch-französischen Beziehungen, war das eigentliche Erbe Adenauers, das er antrat. Zunächst drängte sich aber das Deutschlandproblem in die Außenpolitik der Großen Koalition.

${ }^{207}$ AdKASt, Kiesinger I - 226, F/3., A 322, Gespräch mit Löwe, 31.1.1978, S. 18. Auch der Pressesprecher von Hase (Rhöndorfer-Gespräch, 26.10.1989) bestätigt die Geschichte. Adenauer habe ihn ein letztes Mal angerufen, als Vizepräsident Humphrey seine Rede in Bonn vortrug. Diesen Faden müsse man unbedingt aufnehmen, habe der auf dem Totenbett liegende Adenauer an ihn appelliert. 